\title{
Hodgkin's disease : clinical and biological determinants of prognosis
}

Citation for published version (APA):

Erdkamp, F. L. G. (1993). Hodgkin's disease : clinical and biological determinants of prognosis. [Doctoral Thesis, Maastricht University]. Datawyse / Universitaire Pers Maastricht.

https://doi.org/10.26481/dis.19930402fe

Document status and date:

Published: 01/01/1993

DOI:

10.26481/dis.19930402fe

Document Version:

Publisher's PDF, also known as Version of record

\section{Please check the document version of this publication:}

- A submitted manuscript is the version of the article upon submission and before peer-review. There can be important differences between the submitted version and the official published version of record.

People interested in the research are advised to contact the author for the final version of the publication, or visit the DOI to the publisher's website.

- The final author version and the galley proof are versions of the publication after peer review.

- The final published version features the final layout of the paper including the volume, issue and page numbers.

Link to publication

\footnotetext{
General rights rights.

- You may freely distribute the URL identifying the publication in the public portal. please follow below link for the End User Agreement:

www.umlib.nl/taverne-license

Take down policy

If you believe that this document breaches copyright please contact us at:

repository@maastrichtuniversity.nl

providing details and we will investigate your claim.
}

Copyright and moral rights for the publications made accessible in the public portal are retained by the authors and/or other copyright owners and it is a condition of accessing publications that users recognise and abide by the legal requirements associated with these

- Users may download and print one copy of any publication from the public portal for the purpose of private study or research.

- You may not further distribute the material or use it for any profit-making activity or commercial gain

If the publication is distributed under the terms of Article $25 \mathrm{fa}$ of the Dutch Copyright Act, indicated by the "Taverne" license above, 


\section{HODGKIN'S DISEASE}


Boekproduktie: Datawyse I Universitaire Pers Maastricht

CIP DATA KONINKLIJKE BIBLIOTHEEK DEN HAAG

Erdkamp. Franciscus Louisa Gerardus

Hodgkin's disease : clinical and biological determinants of prognosis / Franciscus Louisa Gerardus Erdkamp. Maastricht : Universitaire Pers Maastricht

Thesis Maastricht. - With summary in Dutch.

ISBN 90-5278-068-4

NUGI $742 / 743$

Subject headings: Hodgkin's disease / DNA aneuploidy

Het in dit proefschrift gepresenteerde onderzoek werd mede mogelijk gemaakt door het Integraal Kankercentrum Zuid, het Ank van Vlissingen Fonds en het. Catharina Fonds. Verder dient de ondersteuning door Bristol-Myers Squibb BV, Boehringer Mannheim BV, Sandoz BV en ScheringPlough BV, Roche BV en Amgen BV, DG Lederle BV. Farmitalia Carlo Erba, ICl-Farma en Smithkline Beecham Farma BV vermeld te worden. 


\section{HODGKIN'S DISEASE}

\section{Clinical and biological determinants of prognosis}

\section{PROEFSCHRIFT}

ter verkrijging van de graad van doctor aan de Rijksuniversiteit Limburg te Maastricht, op gezag van

de Rector Magnificus, Prof.Mr. M.J. Cohen,

volgens het besluit van het College van Dekanen, in het openbaar te verdedigen op vrijdag, 2 april 1993 om 14.00 uur

$$
\text { door }
$$

\section{Franciscus Louisa Gerardus Erdkamp}




\section{Promotor}

Prof. dr. G.H. Blijham

Co-promotores

Dr. W.P.M. Breed

Dr. H.C. Schouten

Beoordelingscommissie

Prof. dr. J.W. Arends (voorzitter)

Prof. dr. P.J.C. van Breda Vriesman

Prof. dr. J.M.A. van Engelshoven

Prof. dr. J.P.M. Geraedts

Dr. R. Somers (A. van Leeuwenhoekhuis, Amsterdam) 
ter nagedachtenis aan mijn vader voor mijn meisjes en mijn zoon 



\section{Contents}

\section{Chapter 1}

Hodgkin's disease: An introduction and aims of the study

\section{Chapter 2}

Hodgkin's disease: A regional retrospective study

\section{Chapter 3}

Hodgkin's disease in the elderly: A retrospective registrybased analysis

\section{Chapter 4}

The prognostic value of mediastinal enlargement in the treatment of patients with early stage Hodgkin's disease:

A population-based study

\section{Chapter 5}

The reliability and value of determining mediastinal involvement and width in Hodgkin's disease

\section{Chapter 6}

DNA aneuploidy in Hodgkin's disease: A multiparameter flow cytometric analysis

\section{Chapter 7}

DNA aneuploidy and cell proliferation in relation to histology and prognosis in patients with Hodgkin's disease

\section{Chapter 8}

Comparison of image and flow cytometry determined DNA content of paraffin-embedded Hodgkin's disease tissue 
Chapter 9

Summary and future outlook

Chapter 10

Samenvalting

Dankwoord

Curriculum vitae 
CHAPTER 1

\section{Hodgkin's disease}

An introduction and aims of the study 


\section{Introduction}

Over the past 30 years remarkable progress has been made in the treatment for Hodgkin's disease. Our knowledge about its cellular biology, however, is still limited. The origin of the malignant cell remains a continuing challenge to researchers all over the world. The diagnosis of Hodgkin's disease is still based almost entirely upon the morphologic detection of Reed-Sternberg cells or one of its morphologic variants in an appropriate background.

\subsection{Historical aspects}

In 1832 Thomas Hodgkin published a report of seven cases with primary tumors of the lymphoid gland and spleen (1). The pathognomonic multinucleated giant cells were first accurately described by Sternberg in 1898 (2) and Reed in 1902 (3). From then on the diagnosis of Hodgkin's disease was based on the recognition of these bizarre giant cells surrounded by a "benign" appearing background cellularity consisting of lymphocytes, histiocytes, eosinophils and plasma cells. In 1966, Lukes et al (4) proposed a histologic classification, which was modified into four major histologic subtypes during the so-called "Rye Conference" (5). Subsequently, the histological classification appeared to be of limited prognostic value (6-8). Because up to $75 \%$ of all cases have the nodular sclerotic (NS) subtype Bennett et al, on behalf of the British National Lymphoma Investigation (BNLI) group, subclassified the NS subtype according to the cellularity of the nodules and the degree of sclerosis in the subtypes NSI and NSII (9).

\section{Treatment}

The Ann Arbor classification, defining four stages of the spread of Hodgkin's disease (10) has become the basis of treatment decisions and has enabled the comparison of treatment schedules from different centers. In general, Hodgkin's disease frequently involves supradiaphragmatic lymph nodes and the spleen. Initial spread is limited to contiguous lymphatic nodes. In later stages, blood borne spread to other, even non-lymphocytic organs is more pronounced $(11,12)$. In practical therapeutic terms two groups of patients have to be distinguished: those patients with localized disease who benefit from local (radio) therapy alone and those patients with disseminated disease who require systemic (chemo) therapy. 


\subsection{Radiotherapy}

The first observation that lymph nodes of patients with Hodgkin's disease are sensitive to irradiation was made in 1902 by Pusey (13), but due to technical deficiencies it took many years for a widespread application. Gilbert (14) and Peters (15) were the first who observed that localized forms of Hodgkin's disease frequently relapse in lymph nodes adjacent to the previously involved nodes. Therefore, they proposed extended-field irradiation of not only involved nodes but also adjacent regions. The introduction of mega-voltage apparature and in the later years linear-accelerators have enabled proper wide-field irradiation to a dose adequate to ensure tumor eradication with acceptable early and long-term toxicity $(16,17)$. In the last two decades radiotherapy as single modality has proven to be an adequate treatment modality, particularly in patients with early stage non-bulky disease. Long-term survival rates of $80 \%$ to $90 \%$ with freedom from relapse rates of about $75 \%$ can be achieved with the various radiotherapy treatment techniques and schedules in localized disease (18-26). However, still $25 \%$ can not be cured with radiotherapy alone. Since relapses after radiotherapy for early stage Hodgkin's disease occur rarely in previously adequately irradiated areas $(17,27)$, it seems obvious to deliver chemotherapy upfront in patients who have likely systemic disease. Prospective randomized trials, like the EORTC $\mathrm{H} 7$, are ongoing, using prognostic factors to identify subgroups of patients with a less favourable outcome for whom radiotherapy alone is probably not appropriate.

\subsection{Chemotherapy}

In 1964 DeVita introduced chemotherapy for clinical purpose (28). Several combinations (schedules) of non-cross resistant drugs are capable of inducing complete remissions in $75 \%$ to $90 \%$ of patients presenting with disseminated Hodgkin's disease (29-43). Relapses occur in about $30 \%$ of these patients and half of them can be cured by the nowadays available salvage regimens leading to overall survival rates varying from $60 \%$ to $75 \%(31-33)$. It has to be noted, however, that none of the chemotherapeutic regimens has convincingly be proven to be superior in terms of curability than the original MOPP (mechlorethamine, vincristine, procarbazine, prednisolone) schedule. Current trials are investigating whether alternating non-cross resistant combinations of MOPP and ABVD (doxorubicin, bleomycin, vinblastine, dacarbazine) are capable of inducing higher complete remission rates and improving long-term outcome. 
Following the Goldie and Coltman hypothesis (44) much attention has been given to dose intensity and several investigators have already demonstrated the importance of delivering the intended dose on time-schedule $(34,38,45)$.

Recurrences following chemotherapy alone tend to occur in originally involved lymph node areas, particularly if they were bulky $(46,47)$. It has been suggested that additional radiotherapy on these sites can eradicate potentially remaining disease. Reviewing the reports on chemotherapeutic and combined modality trials, Longo concluded that patients with bulky mediastinal disease are the only subset of patients who seem to benefit from combined modality treatment (48). Whether this statement, however, is justified for early stage Hodgkin's disease is controversial, because although relapse rates up to $50 \%$ are reported for patients with massive mediastinal involvement data on survival benefit are scarce $(49,50)$.

\subsection{Salvage therapy}

Salvage therapy for treatment failures depends on the initial treatment given and the time to relapse. No clearly superior chemotherapeutic salvage regimen is available and 5-year survival rates of about $60 \%$ are obtained using MOPP, $A B V D$ or a combination of regimens (51-53). Patients relapsing after long-term initial remission induced by chemotherapy can be effectively treated with the same regimen and half of these patients are cured after achieving a second complete remission $(51,53,54)$. In contrast, patients who fail to respond to a first line chemotherapeutic regimen or relapse within a year after initial (chemo) therapy have a poor prognosis $(52,55,56)$. Intensification of treatment for this group of patients seems justified. Results of high-dose chemotherapy programs with or without radiotherapy followed by autologous or allogeneic bone marrow transplantation are encouraging with today about half of these patients achieving a complete remission with prolonged disease free survival of $30 \%$ to $40 \%$ (57-64). However, longer follow up is necessary.

\subsection{Summary}

Hodgkin's disease is a curable disease in the majority of cases. However, a distinct subgroup of patients is dying from this disease and another group suffers from treatment-related long-term toxicities (cardiac, pulmonary and thyroid diseases) or develops secondary malignancies (65-68). Particularly the 
combination of radiotherapy and chemotherapy seems responsible for a part of these complications $(69,70)$. Therefore, treatment schedules have to strike a balance between improving cure and avoiding clinical relevant late toxic effects and secondary tumors. For this purpose it is important to find risk factors that can identify subgroups of patients with particularly favourable or unfavourable outcome. With these prognostic factors, "tailored therapy" can be given. Such factors have to be tested in prospective randomized trials.

\section{Prognostic Factors}

A prognostic indicator is a variable that is important for determining the outcome of a given disease. Prognostic factors may be used to define risk groups forming the basis for treatment decisions. Furthermore, they may help us to understand the mechanisms of a disease and provide directions for further studies. An overview of the prognostic risk factors has recently been published (71). Two of them will be discussed more in detail.

\subsection{Age}

In Hodgkin's disease older age is an established risk factor and several observations on this subject have been made. Older patients are less likely to achieve complete remissions and poorer survival rates are observed (72-88). Some studies have demonstrated that aged patients were more likely to have advanced clinical stage, B symptoms and poor prognosis histologic subtypes at presentation $(80,83)$. Others have observed in Hodgkin's disease a more pronounced age-related deterioration of T-cell function compared to normal subjects (8991). Older patients with Hodgkin's disease often have underlying medical problems, which has been associated with the decrease in treatment response $(75,78,81,86)$. There seems, however, a widespread misconception that the elderly are always poorly tolerant of chemo- or radiotherapy, with the inevitable result that some older patients with cancer are undertreated. In current practice the elderly are often not included in clinical trials and receive sometimes either inadequate treatment or even none at all.

Therefore, whether this unfavourable outcome for oider patients simpiy reflects Hodgkin's disease behaving more aggressively in elderly patients, the fact that older patients more frequently suffer from concomitant diseases compared to younger ones or is treatment related remains to be solved. 


\subsection{Volume of disease}

The Ann Arbor classification is based on the anatomic extent of the disease and the presence or absence of systemic symptoms (10). Its prognostic significance has been demonstrated in many studies $(12,82,85,87,92,93)$. However, the extent of the disease may vary widely within a particular stage. Also the size/volume of the involved lymph nodes or organs is not taken into consideration in the Ann Arbor classification (88). EORTC data have shown that the number of involved sites appears to be an important independent prognostic indicator. Studying tumor mass, a special interest has been focused on mediastinal enlargement measured in a two-dimensional way $(18,88,49,50,94-105)$. Interestingly bulky disease in regions other than the mediastinum is not frequently observed. Therefore, the prognostic value of bulky disease at other sites is not well documented, but the available reports do not indicate extra-mediastinal bulk being an independent prognostic factor $(87,96,106)$.

The importance of the combination of the number and volume of involved sites has been studied extensively by Specht et al. They found that quantification of the total tumor burden is by far the most important risk factor. From their multivariate analysis it is apparent that stage, number of involved regions, mediastinal size, systemic symptoms and ESR appear to be closely related to the total tumor burden (106).

\subsection{Summary}

Many risk factors are identified in one or more large series of patients. However, most of them seem to give only additional information in certain subgroups of patients. Generally, the outcome of the treatment of a malignant tumor is determined by the size of tumor mass and the sensitivity to therapy. In case of Hodgkin's disease. Specht et al have shown that total tumor burden is the single most important prognostic factor. There remains a need to better select poor prognosis patients, since they can potentially benefit from more aggressive treatment including marrow-ablative therapy with bone marrow rescue. Also, more insight into the biology of these poor prognosis cases may lead to new treatment strategies, directed at the malignant cell population once it is properly defined. 


\section{Nuclear DNA Content and Cell Cycle Analysis}

\subsection{Introduction}

In non-Hodgkin's lymphoma, karyotyping and DNA flow cytometry are now often used as a valuable adjunct to the morphological assessment of these patients. In contrast, in Hodgkin's disease considerably less progress has been made along these lines. Several factors might be responsible for the paucicity of cytogenetic and flow cytometric data in Hodgkin's disease, such as the low proliferative index of Hodgkin's tumors, the (presumed) small number of neoplastic cells in involved tissues and the poor quality of metaphase cells. Cytogenetic studies revealed, in contrast to the non-Hodgkin's lymphomas, a relatively high incidence of numerical abnormalities (12,107-109). Although several chromosomes or breakpoints were overrepresented no special patterns could be recognized. Studies of DNA content in Hodgkin's disease as detected by DNA flow cytometry have generaily yielded negative or disappointing results (110-114). In one study, an anti-nucleolar polyclonal antibody was applied to select for nuclei, that presumably are of the RS/H type (115); this study contained only 15 patients who all showed DNA aneuploidy. The cytogenetics, DNA flow cytometric and immunotyping data have all raised an important question as to the delineation of the malignant population in Hodgkin's disease. Schouten et al found cytogenetic abnormalities in a proportion of cells, that exceeded the frequency of the malignant cell type and reported the absence of normal cells in two patients suggesting that all dividing cells were part of the malignant clone (108). Anastasi and co-workers detected concomitant and similar DNA aneuploidy in both RS nuclei as well as in morphologically not clearly neoplastic nuclei (115). Griesser et al, finally, looked for $\mathrm{T}$ and B cell receptor gene rearrangements in 112 cases of Hodgkin's disease and found the clonally rearranged cell population not to be confined to the RS cell population (116). So, although there is little doubt, that $\mathrm{RS} / \mathrm{H}$ cells belong to the malignant population in Hodgkin's disease, it remains to be determined whether the other cells present are also part of the neoplastic cell population and even may constitute the tumor stem cells in this disease. 


\subsubsection{General aspects}

Most currently available flow cytometers enable simultaneous measurements of several fluorescent signals with different wave-lengths as well as forward and side light scatter (parameters for size and structure, respectively). Briefly, the cells or nuclei in suspension are introduced to the center of a liquid jet stream, which is intercepted by a laserbeam that is turned to the appropriate wavelength to excite a dye. Each particle is individually characterized by its volume and by the intensity and color of fluorescence emitted. The measurement of total nuclear DNA content is one of the applications of flow cytometry. For this purpose, staining for DNA occurs with a fluorescent dye that binds specifically and stoichiometrically to the DNA i.e. the amount of dye bound is proportional to the amount of DNA. Results from tens of thousands of cells or nuclei analyzed can be displayed by one-parameter DNA histograms giving an impression of the number of nuclei being dipioid or aneuploid (hypo and hyper). A visual correlation of other parameters acquired simultaneously from analysis of a single sample can be represented as two-dimensional dot plots.

The interpretation of DNA histograms is usually straight forward. The diagnosis of DNA aneuploidy should only be reported when at least two separate G0/G1 peaks are demonstrated (117). Sometimes problems arise because of the presence of broadened coefficients of variation (CV) and varying amounts of debris particularly if deparaffinized material is used. Generally, the higher the $\mathrm{CV}$ the more important becomes the shape of the curve, because a histogram with a broad CV can hide a second cell population (118). If a curve, however, is perfectly symmetrical, the possibility of a single cell population is high. On the other hand if a histogram is skewed, overlapping cell population must be considered. Debris may obscure minor diploid or aneuploid populations that constitute less than $5 \%$ of the total nuclei number (118).

\subsubsection{DNA content and cell cycle}

The normal diploid cells contain 23 pairs of chromosomes, this is called DNA diploidy (117). In flow cytometry DNA aneuploidy is defined as a deviation in nuclear DNA content and is expressed as the DNA index. A DNA index of 1.00 represents a normal diploid population. Apart from measuring the DNA content, DNA flow cytometry also provides information regarding the distribution of nuclei in the various phases of cell cycle. The cell cycle can be roughly divided in three phases, characterized by differences in DNA content: the G0/G1 phase (2N DNA content), the G2/M phase (4N DNA content) and the 
S-phase (synthetic phase). The percentage of nuclei in S-phase (SPF) is indicative for the proliferative activity of a tumor. However, although the modern mathematical software programs are capable of subtracting debris and overlapping populations of nuclei, it has to be kept in mind that in particular in the case of complex DNA histograms, the SPF is only an estimate of S-phase nuclei.

\subsubsection{Clinical significance of flow cytometric data}

Since the introduction of flow cytometry, DNA and cell cycle analyses have been performed on tissues of nearly all types of malignancies and have been related to well established prognostic characteristics and prognosis (119-121). Particularly after the introduction by Hedley et al (122) of a method for obtaining single cell suspensions from paraffin-embedded material satisfactory for DNA measurement using flow cytometry, a large number of retrospective studies have been reported. Although reports on the prognostic value of DNA aneuploidy are sometimes conflicting, for most of the solid tumors diploidy is associated with a better prognosis compared to aneuploid tumors $(119,120$, 123). In non-Hodgkin's lymphoma, however, particularly cases with a higher frequency of DNA aneuploid cells have not shown this apparent relation between ploidy status and prognosis (124-127). Limited data are available for Hodgkin's disease and only two studies correlated their data with clinical characteristics and outcome $(111,113)$. High proliferative activity i.c. SPF has proven to be a negative predictor for relapse free and overall survival in all kinds of malignancies (123-130). From studies on non-Hodgkin's lymphoma it is obvious that a higher SPF is associated with a higher histologic grade $(124,125,131)$.

\subsection{Image cytometry}

For quantification of DNA content, flow and image cytometry can be used. The advantage of DNA image analysis is that the measured nuclei can be visualized at the time of measurement. Some authors suggest that with a limited number of nuclei reliable data can be obtained (132-136). When flow cytometry is used on deparaffinized tissue, internal controls are absent, and diploid peaks may show large CV's. In some of these broad diploid peaks DNA aneuploidy may be present when the same population is measured with image cytometry (137). 


\subsubsection{General aspects}

The CAS (Cell Analysis Systems) is an interactive video image cytometer consisting of a modified optical microscope and two full color display monitors: a graphic and system control menu monitor and an image display for morphologic selection. After DNA staining by the Feulgen method and morphologic selection of specific nuclei the sum of the optical density of each nucleus is used to calculate the amount of DNA present. By this method a reliable estimation of DNA content has been demonstrated for several tumors including one study on non-Hodgkin lymphoma (132). So far, no data on Hodgkin's disease have been reported. Because of the advantage of finding a correlation between a particular nuclear size and aneuploidy, this type of study might be very important in Hodgkin's disease, being a disease with a variety of cell types involved and the origin of the neoplastic cell still obscure.

\section{Alms of the Study}

The presented data on treatment and prognosis of patients with Hodgkin's disease are mainly derived from large center studies and clinical trials. Limited information is available on patients staged and treated in non-university hospitals. To bypass the possible bias introduced by studies from referral centers, we have performed a retrospective analysis of patients with Hodgkin's disease, all diagnosed and treated in ten community hospitals in the southeastern part of the Netherlands (chapter 2). Among the risk indicators, well described in Hodgkin's disease two were analyzed in more detail. First, we examined which factors contributed to the age-related prognostic effect in this disease (chapter 3). Second, we analyzed the prognostic impact of (bulky) mediastinal disease determined in several ways (chapter 4). In addition, we looked in more detail whether interobserver variability was present between radiologists and we. investigated various cut-off points of mediastinal size as to their respective ability to identify high- and low-risk patients (chapter 5). Due to the need for better discriminative risk factors and because of the high incidence of numerical abnormalities found by classical cytogenetic studies we investigated paraffinembedded material from Hodgkin's disease patients for the frequency of DNA aneuploidy applying a polyclonal goat anti-nucleolar antibody to enrich for the neoplastic population (chapter 6). In chapter 7 the clinical implications of DNA content (aneuploidy) and S-phase fraction in patients with Hodgkin's disease are described. Due to the lack of morphologic information using flow cytometry, we explored an alternative approach using DNA image cytometry. The aims of the latter study were to assess whether DNA content could be 
accurately determined on cytocentrifuge preparations and if so to correlate the findings with the flow cytometric results from the same deparaffinized lymph nodes. Also we tried to identify the morphology of the aneuploid nuclei, which may help to identify the neoplastic nuclei (chapter 8). 


\section{References}

1. Hodgkin T. On some morbid appearances of the absorbent glands and spleen. Trans Med Chir Soc Lond 1832; 17:68-114.

2. Sternberg $\mathrm{C}$. Uber eine eigenarte unter dem bilde der pseudoleukamie verlaufende tuberculose des lymphatischen apparates. Z Heilk 1898; 19:21-90.

3. Reed DM. On the pathological changes in Hodgkin's disease, with special reference to its relation to tuberculosis. Johns Hopkins Hosp Rep 1902; 10:133-196.

4. Lukes RJ, Butler JJ, Hicks EB. Natural history of Hodgkin's disease as related to its pathologic picture. Cancer 1966; 19:317-344.

5. Lukes RJ, Gompel LF, Hall TC, Rappaport H, Rubin P: Report of the Nomenclature Committee. Rye classification. Cancer Res 1966; 26:1311.

6. Fuller LM, Madoc-Jones H, Gamble JF, et al. New assessment of the prognostic significance of histopathology in Hodgkin's disease for laparotomy-negative stage I and stage II patients. Cancer 1977; 39:2174-2182.

7. DeVita VT, Simon RM, Hubbard SM, et al. Curability of advanced Hodgkin's disease with chemotherapy. Ann Intern Med 1980; 92:587-595.

8. Kaplan HS. Hodgkin's disease: unfolding concepts concerning its nature, management and prognosis. Cancer 1980: 45:2439-2474.

9. Bennett MH, Tu A, Vaughan Hudson G. Analysis of grade I Hodgkin's disease. Report no.2, part.2. Clin Radiol 1981; 32:491-498.

10. Carbone PP, Kaplan HS, Masshoff K, Smithers DW, Tubiana M. Report of the committee of Hodgkin's disease staging. Ann Arbor Classification. Cancer 1971; 31:18601861 .

11. Rosenberg SA, Kaplan HS. Evidence for an orderly progression in the spread of Holgk in's disease. Cancer Res 1966; 26:1225-1231.

12. Kaplan HS. Hodgkin's disease. 2nd ed. Cambridge, MA: Harvard University Press, 1980.

13. Pusey WA. Cases of sarcoma and of Hodgkin's disease treated by exposures to X-rays. JAMA 1902; 28:166-169.

14. Gilbert R. Radiotherapy in Hodgkin's disease (malignant granulomatosis): anatomical and clinical foundations; goveming principles; results. Am J Roentgenol 1939; 41:998241.

15. Peters MV. A study of survivals in Hodgkin's disease treated radiologically. Am J Roentgenol 1950: 63:299-311.

16. Hoppe RT. Radiation therapy in the management of Hodgkin's disease. Semin Oncol 1990; 17:704-715.

17. Kaplan HS. Long term results of palliative and radical radiotherapy of Hodgkin's disease. Cancer Res 1966; 26:1250-1252.

18. Hoppe RT, Coleman NC. Cox RS, Rosenberg SA, Kaplan HS. The management of stage I-II Hodgkin's disease with irradiation alone or combined modality therapy: The Stanford experience. Blood 1982; 59:455-465.

19. Leslie NT, Mauch PM. Hellman S. Stage IA to IIB supradiaphragmatic Hodgkin's disease. Cancer 1985: 55:2072-2078. 
20. Tubiana M, Henry-Amar M, Carde P, et al. Toward comprehensive management tailored to prognostic factors of patients with clinical stages I and II in Hodgkin's disease. The EORTC Lymphoma group controlled clinical trials: 1964-1987. Blood 1989; 73:47-56.

21. Cimino G, Biti GP, Anselmo AP, et al. MOPP chemotherapy versus extended-field radiotherapy in the management of pathological stages I-IlA. Hodgkin's disease. J Clin Oncol 1989; 7:732-737.

22. Longo DL, Glatstein E, Duffey PL, et al. Radiation therapy versus combination chemotherapy in the treatment of early-stage Hodgkin's disease: Seven-year results of a prospective randomized trial. J Clin Oncol 1991; 9:906-917.

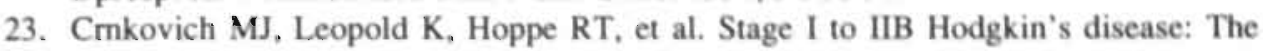
combined experience at Stanford university and the joint center for radiation therapy. $J$ Clin Oncol 1987; 5:1041-1049.

24. Lee CKK, Aeppli DM, Bloomfield CD, Levitt SH. Int J Radiat Oncol Biol Phys 1987; 13:983-991.

25. Wasserman TH, Trenkner DA, Fineberg B, Kucik. N. Cure of early-stage Hodgkin's disease with subtotal nodal irradiation. Cancer 1991; 68:1208-1215.

26. Willett CG, Linggood RM, Meyer J, et al. Results of treatment of stage IA and IIA Hodgkin's disease. Cancer 1987; 59:1107-1111.

27. Fletcher GH, Shukovsky L. The interplay of radiocurability and tolerance in the irradiation of human cancers. I Radiol Electrol 1975; 56:383-400.

28. DeVita VT, Serpick AA, Carbone PP. Combination chemotherapy in the treatment of advanced Hodgkin's disease. Ann Intern Med 1970; 73:881-895.

29. Bonadonna G, Zucalli R, Monfardini S, et al. Combination chemotherapy of Hodgkin's disease with adriamycine, bleomycin, vinblastine and imidazole carboximide versus MOPP. Cancer 1975; 36:252-259.

30. McElwain TJ, Toy J, Smith E, et al. A combination of chloorambucil, vinblastine, procarbazine and prednisolone for treatment of Hodgkin's disease. $\mathrm{Br}$ J Cancer 1977; $36: 276-280$.

31. Sutcliffe SB, Wrigley RF, Peto J, et al. MVPP chemotherapy regimen for advanced Hodgkin's disease. Br Med J 1978; i:679-683.

32. DeVita VT, Simon RM, Hubbard SM, et al. Curability of advanced Hodgkin's disease with chemotherapy. Longterm follow-up of MOPP-treated patients at the National Cancer Institute. Ain Intern Med 1980; 92:587-595.

33. Santorro A, Bonadonna G, Bonfante $F$, et al. Alternating drug combinations in the treatment of advanced Hodgkin's disease. N Engl I Med 1982; 306:770-775.

34. Klimo P, Connors . MOPP/ABV hybrid program: combination chemotherapy based on early introduction of seven effective drugs for advanced Hodgkin's disease. J Clin Oncol 1985; 3:1174-1182.

35. Longo DL, Young RC, Wesley M, et al. Twenty years MOPP therapy for Hodgkin's disease. J Clin Oncol 1986; 4:1295-1306.

36. Wagstaff $\mathrm{J}$, Steward $\mathbf{W}$, Jones. $\mathrm{M}$, et al. Factors affecting remission and survival in patients with advanced Hodgkin's disease treated with MVPP. Hematol Oncol 1986; $4: 135-147$. 
37. Hancock BW. Randomized study of MOPP (mustine, oncovin, procarbazine, prednisone) against LOPP (leukeran substituted for mustine) in advanced Hodgkin's disease. British National Lymphoma Investigation. Radiother Oncol 1986; 7:215-221.

38. Bonadonna G, Valagussa $\mathrm{P}$, Santoro A, et al. Alternating non-cross-resistant combination chemotherapy or MOPP' in stage IV Hodgkin's disease. Ann Intern Med 1986; 104:739-746.

39. Connors JM, Klimo P. MOPP/ABV hybrid chemotherapy for advanced Hodgkin's disease. Sem Hematol 1987: 24:35-40 (suppl 1).

40. Klimo P, Connors JM. Arr update on the Vancouverexperience in the management of advanced Hodgkin's disease treated with the MOPP/ABV hybrid program. Sem Hematol 1988; 25:34-40 (suppl 2).

41. Vosse J, Armitage J, Weisenburger D, et al. ChlVPP an effective and well-tolerated alternative to MOPP therapy for Hodgkin's disease. Am J Clin Oncol 1988; 11:423426.

42. McKendrick JJ, Mead GM, Sweetenham J, et al. ChlVPP chemotherapy in advanced Hodgkin's disease. Eur J Cancer Clin Oncol 1989; 25:557-561.

43. Druker BJ, Rosenihal DS, Canellos GP. Chloorambucil, vinblastine, procarbazine and prednisone. An effective but less toxic regimen than MOPP for advanced-stage Hodgkin's disease. Cancer 1989; 63:1060-1064.

44. Goldie JH, Coldman AJ. A mathematical model for relating the drug sensitivity of tumours to their spontaneous mutation rate. Cancer Treat Rep 1979; 63:1727-1733.

45. Carde P. MacKintosh FR, Rosenberg SA. A dose and time response analysis of the treatment of Hodgkin's disease with MOPP chemotherapy. J Clin Oncol 1983; 1:146153.

46. Frei E, Luce JK, Gamble, et al. Combination chemotherapy in advanced Hodgkin's disease. Induction and maintenance of remission. Ann Intem Med 1973; 79:376-382.

47. Young RC, Canellos GP, Chabner BA, et al. Patterns of relapse in advanced Hodgkin's disease treated with combination chemotherapy. Cancer 1978; 42:1001-1007.

48. Longo DL. The use of chemotherapy in the treatment of Hodgkin's disease. Sem Oncol 1990; 6:716-735.

49. Lee CKK, Bloomfield CD. Goldman AI, Levitt SH. Prognostic significance of mediastinal involvement in Hodgkin"s disease treated with curative radiotherapy. Cancer 1980: 46:2403-2409.

50. Anderson $H$, Jenkins JPR, Brigg DJ, et al. The prognostic significance of mediastinal bulk in patients with stage I-IVB Hodgkin's disease: A report from the Manchester lymphoma group. Clin Radiol 1985; 36:449-454.

51. Vinciguerra V. Propert KJ. Coleman M, et al. Alternating cycles of combination chemotherapy for patients with recurrent Hodgkin's disease following radiotherapy. A prospectively randomized study by the cancer and leukemia group B. J Clin Oncol 1986 ; $4: 838-846$.

52. Lohri A, Bamett M, Randall N, et al. Outcome of treatment of first relapse of Hodgkin's disease after primary chemotherapy: Identification of risk factors from the British Columbia experience 1970 to 1988. Blood 1991; 77:2292-2298.

53. Santorro A, Viviani, Villarreal CJ, et al. Salvage chemotherapy in Hodgkin's disease irradiation failures: superiority of doxorubicin-containing regimens over MOPP. Cancer Treat Rep 1986; 70:343-348. 
54. Portlock CS, Rosenberg SA, Glarstein E, et al. Impact of salvage treatment on initial relapses in patients with Hodgkin's disease, stage I-III. Blood 1978; 51:825-833.

55. Harker WG, Kushlan P, Rosenberg SA. Combination chemotherapy for advanced Hodgkin's disease after failure of MOPP: ABVD and B-CAVe, Ann Intern Med 1984; 101:440-446.

56. Fisher I, DeVita VT, Hubbard SP, et al, Prolonged disease-free survival in Hodgkin's disease with MOPP reinduction after first relapse. Ann Intern Med 1979; 90:761-763.

57. Applebaum FR, Sullivan KM, Thomas ED, et al. Allogeneic marrow transplantation in the treatment of MOPP-resistant Hodgkin's disease. J Clin Oncol 1986; 3:1490-1494.

58. Carella AM, Congiu AM, Gaozza E, et al. High-dose chemotherapy and autologous bone marrow transplantation in 50 advanced resistant Hodgkin's disease patients: An Italian study group report. J Clin Oncol 1988; 6:1411-1416.

59. Gribben JG, Linch DC, Singer SRJ, et al. Succesful treatment of refractory Hodgkin's disease by high-dose chemotherapy and autologous bone marrow transplantation. Blood 1989; 73:340-344.

60. Zulian GB, Selby P, Milan S, et al. High dose melphalan, BCNU and etoposide with autologous bone marrow transplantation for Hodgkin's disease. Br J Cancer 1989; 59:631-635.

61. Phillips GL, Wolff SN, Herzig RH, et al. Treatment of progressive Hodgkin's disease with intensive chemoradiotherapy and autologous bone marrow transplantation. Blood 1989; 73:2086-2092.

62. Jones. RJ, Piantadosi S, Mann RB, et al. High-dose cytotoxic therapy and bone marrow transplantation for relapsed Hodgkin's disease. J Clin Oncol 1989; 8:527-537.

63. Phillips GL, Reece DE, Barnett MJ, et al. Allogeneic marrow transplantation for refractory Hodgkin's disease. J Clin Oncol 1989; 7:1039-1045.

64. Reece DE, Bamett MJ, Connors JM, et al. Intensive chemotherapy with cyclofosfamide, carmustine and etoposide followed by autologous bone marrow transplantation for relapsed Hodgkin's disease. J Clin Oncol 1991; 9:1871-1879.

65. Bookman MA, Longo DL. Cocomitant illness in patients treated for Hodgkin's disease. Cancer Treat Rev 1986; 13:77-111.

66. Henry-Amar $\mathrm{M}$, Hayat $\mathrm{M}$, Meerwaldt $\mathrm{JH}$, et al. Cause of death after therapy for early stage Hodgkin's disease entered on EORTC protocols. Int J Radiat Oncol Biol Phys 1990; 19:1155-1157.

67. Kaldor JM, Day NE, Clarke EA, et al. Leukemia following Hodgkin's disease. N Engl J Med 1990; 322:7-13.

68. Hancock SL, Cox RS, McDougall IR. Thyroid diseases after treatment of Hodgkin's disease. N Engl J Med 1991; 325:599-605.

69. Mauch PM, Canellos JP, Rosenthal DS, Hellman S. Reduction of fatal complications from combined modality therapy in Hodgkin's disease. J Clin Oncol 1985; 3:501-505.

70. Andrieu J-M, Ifrah N, Payen C, Fermanian J, Coscas Y, Flandrin G. Increased risk of secondary acute nonlymphocytic leukemia after extended field radiation therapy combined with MOPP chemotherapy for Hodgkin's disease. J Clin Oncol 1990; 8:1 1481154.

71. Specht L. Prognostic factors in Hodgkin's disease. Cancer Treat Rev 1990; 18:21-53.

72. Specht L, Nissen NI. Hodgkin's disease and age. Eur J Haemato! 1989; 43:127-135. 
73. Fuller LM, Gamble JF, Velazquez WS, et al. Evaluation of the significance of prognostic factors in stage III Hodgkin's disease treated with MOPP and radiotherapy. Cancer 1980; 45:1352-1364.

74. Eghbali H, Hoerni-Simon G, Mascarel I de, Durand M, Chauvergne J, Hoerni B. Hodgkin's disease in the elderly. Cancer 1984; 53:2191-2193.

75. Burgers JMV, El Sharouni SY, Leeuwen FE van, Somers R, Hart AAM. Ziekte van Hodgkin: invloed van leeftijd op de prognose. Ned Tijdsch Geneeskd 1988; 132:13541357.

76. Wedelin C, Björkholm M, Biberfeld P, Holm G, Johansson B, Mellstedt H. Prognostic factors in Hodgkin's disease with special reference to age. Cancer 1984; 53:1202-1208.

77. Vaughan Hudson B, MacLennan KA, Easterling MJ, Jelliffe AM, Haybittle L, Vaughan Hudson G. The prognostic significance of age in Hodgkin's disease: Examination of 1500 patients (BNLI report no. 23). Clin Radiol 1983; 34:503-506.

78. Peterson BA, Pajak TF, Cooper MR et al. Effect of age on therapeutic response and survival in advanced Hodgkin's disease. Cancer Treat Rep 1982; 66:889-898.

79. Tirelli U. Management of malignant lymphoma in the elderly. An EORTC retrospective evaluation. Acta Oncol 1989; 28:199-201.

80. Walker A, Schoenfeld ER, Lowman T, Mettlin CJ, MacMillan J, Grufferman S. Survival of the older patient compared with the younger patient with Hodgkin's disease. Cancer 1990; 65: 1635-1640.

81. Austin-Scymour MM, Hoppe RT, Cox RS, Rosenberg SA, Kaplan HS. Hodgkin's disease in patients over sixty years old. Ann Int Med 1984; 100:13-18.

82. Gobbi PG, Federico M, Di Prisco UA et al. Hodgkin's disease prognosis: A directly predictive equation. Lancet 1988; i:675-679.

83. Enblad G, Glimelius B, Sundström C. Treatment outcome in Hodgkin's disease in patients above the age of 60 : A population-based study. Ann Oncol 1991; 2:297-302.

84. Bosi $\mathrm{A}$, Ponticelli $\mathrm{P}$, Casini $\mathrm{C}$ et al. Clinical data and therapeutic approach in elderly patients with Hodgkin's disease. Haematologica 1989; 74:463-473.

85. Somers R, Henry-Amar M, Meerwaldt JH, Carde P. Treatment strategy on Hodgkin's disease. Proceedings of the Paris international workshop and symposium held on june 28-30, 1989. London-Paris: John Libbey Eurotext, 1990.

86. Lokich JJ. Pinkus GS, Moloney WC. Hodgkin's disease in the elderly. Oncology 1974; 29:484-500.

87. Sutcliffe SB, Gospodarowicz MK, Bersagel DE, et al. Prognostic groups for management for localized Hodgkin's disease. J Clin Oncol 1985; 3:393-401.

88. Tubiana M, Henry-A.mar M, van der Werf-Messing B, et al. A multivariate analysis of prognostic factors in early stage Hodgkin's disease. Int J Radiation Oncology Biol Phys 1985: 11:23-30.

89. Van Rijswijk REN, de Meyer AJ, Sybesma JPHB, Kater L. Five-year survival in Hodgkin's disease. The prognostic value of immune status at diagnosis. Cancer 1986; 57:1489-1496.

90. Björk.holm M, Wedelin C, Holm G, Ogenstad S, Johansson B, Mellstedt H. Immune status of untreated patients with. Hodgkin's disease and prognosis. Cancer Treat Rep 1982; 66:701-709. 
91. Wedelin C, Björkholm M, Holm G, Ogenstad S, Johansson B, Mellstedt H. Lymphocyte function in untreated Hodgkin's disease: An important predictor of prognosis. $\mathrm{Br}$ J Cancer 1982; 45:70-79.

92. Björkholm M, Holm G, Mellstedt H, Johansson B, Askergren J, Söderberg G. Prognostic factors in Hodgkin's disease. I. Analysis of histopathology, stage distribution and results of therapy. Scand J Haematol 1977; 19:487-495.

93. Nordentoft AM, Pederson-Bjergaard J, Brincker H, et al. Hodgkin's disease in Denmark. Scand J Haematol 1980; 24:321-334.

94. Mauch P, Goodman R, Hellman S. The significance of mediastinal involvement in early stage Hodgkin's disease. Cancer 1978; 42:1039-1045.

95. Mauch P, Gorshein D, Cunningham J, Hellman S. Influence of mediastinal adenopathy on site and frequency of relapse in patients with Hodgkin's disease. Cancer Treat Rep 1982; 66:809-817.

96. Liew KH, Easton D, Horwich A, Barrett A, Peckham J, Bulky mediastinal Hodgkin's disease management and prognosis. Hematol Oncol 1984; 2:45-59.

97. Gomez GA, Panahon AM, Stuzman L, et al. Large mediastinal mass in Hodgkin's disease. Results of two treatment modalities. Am J Oncol 1984; 6:65-73.

98. Thar TL, Million RR, Hausner RJ, McKetty MH. Hodgkin's disease, stages I and II, relationship of recurrence to size of disease, radiation dose and number of sites involved. Cancer 1979; 43:1!01-1105.

99. Fuller LM, Madoc-Jones H, Hagemeister FB, et al. Further follow-up of results of treatment in 90 laparotomy-negative stage I and II Hodgkin's disease patients: significance of mediastinal and non-mediastinal presentations. Int J Radiat Oncol Biol Phys $1980 ; 6: 799-808$.

100. North LB, Fuller LM, Hagemeister FB, Rodgers RW, Butler JJ, Shullenberger CC. Importance of initial mediastinal adenopathy in Hodgkin's disease. Am J Roentg 1982; 138:229-235.

101. Cosset JM, Henry-Amar M, Carde P, Clarke D, Le Bourgeois P, Tubiana M. The prognostic significance of large mediastinal masses in the treatment of Hodgkin's disease. The experience of the institute Gustave-Roussy. Hematol Oncol 1984: 2:33-43.

102. Rostock RA, Siegelman SS, Lenhard RE, Wharam MD, Order SE. Thoracic CT scanning for mediastinal Hodgkin's disease: Restilts and therapeutic implications. Int J Radiat Oncol Biol Phys 1983; 9:1451-145?.

103. Ryoo MC, Kagan AR. Wollin M, et al. Observations on the treatment of mediastinal masses in Hodgkin's disease emphasizing site of failure. Am J Clin Oncol 1987; 10:185-193.

104. Verger E, Easton D, Brada M, Duchesne G, Horwich A. Radiotherapy results in laparotomy-staged Hodgkin's disease. Clin Radiol 1988; 39:428-431.

105. Bonadonna G, Valagussa P, Santoro A. Prognosis of bulky Hodgkin's disease treated with chemotherapy alone or combined with radiotherapy. Cancer Surv 1985; 4:439. 458.

106. Specht L, Nordentoft AM, Cold S, Toffner Claussen N, Nissen NI. Tumor burden as the most important prognostic factor in early stage Hodgkin's disease. Relations to other prognostic factors and implications for choice of treatment. Cancer 1988; 61:1719. 1727.

107. Rowley JD. Chromosomes in Hodgkin's disease. Cancer treat Rep 1982; 66:639-643. 
108. Schouten HC, Sanger WG, Duggan M, Weisenburger DD, MacLennan KA, Amnitage JO. Chromosomal abnormalities in Hodgkin's disease. Blood 1989; 73:2149-2154.

109. Tilly H, Bastard C, Delastre T, et al. Cytogenetic studies in untreated patients with Hodgkin's disease. Blood 1991; 77:1298-1304.

110. Diamond LW, Nathwani. BN, Rappaport H. Flow cytometry in the diagnosis and classification of malignant lymphoma and leukemia. Cancer 1982; 50:1122-1135.

111. Joensuu H, Klemi PJ, Korekeila E. Prognostic value of DNA ploidy and proliferative activity in Hodgkin's disease. Am J Clin Pathol 1988; 90:670-673.

112. Joensuu H, Klemi PJ, Eerola E. Diagnostic value of DNA flow cytometry combined with fine needle aspiration biopsy in lymphomas. J Pathol 1988; 154:237-245.

113. Morgan KG, Quirke P, O'Brien CJ, Bird CC. Hodgkin's disease: a flow cytometric study. J Clin Pathol 1988; 41:365-369.

114. Lehtinen T, Lehtinen M, Aine R, et al. Quantity of nuclear DNA in malignancies and benign lymphadenopathies associated with Epstein-Barr virus. J Clin Pathol 1989; 42:699-704.

115. Anastasi J, Bauer KD, Variakojis D. DNA aneuploidy in Hodgkin's disease. Am J Pathol 1987; 128:573-582.

116. Griesser H, Mak TW. Imunnotyping in Hodgkin's disease. Hematol Oncol 1988; 6:239-245.

117. Hiddeman $\mathrm{W}$, Schumann J, Andreeff $\mathrm{M}$, et al. Convention of nomenclature for DNA cytometry. Cytometry 1984; 5:445-446.

118. Wersto RP, Liblit RL, Koss LG. Flow cytometric DNA analysis of human solid tumors: a review of the interpretation of DNA histograms. Progr Pathol 1991; 22:1085-1098.

119. Friedlander ML, Hedley DW, Taylor IW. Clinical and biological significance of aneuploidy in human tumours. J Clin Pathol 1984; 37:961-974.

120. Merkel DE, Dressler LG, McGuire WL. Flow cytometry, cellular DNA content, and prognosis in human malignancy. J Clin Oncol 1987; 5:1690-1703.

121. Coon JS, Landay AL, Weinstein RS. Biology of disease. Lab Invest 1987; 57:453-479.

122. Hedley DW, Friedlander ML, Taylor IW, Rugg CA, Musgrove EA. Method for analysis of cellular DNA content of paraffin-embedded pathological material using flow cytometry. J Histochem Cytochem 1983; 31:1333-1335.

123. Clark GM, Dressler LG, Owens MA, et al. Prediction of relapse or survival in patients with node-negative breast cancer by DNA flow cytometry. N Eng J Med 1989; 320:627-633.

124. Cowan RA, Harris M, Jones M, et al. DNA content in high and intermediate grade non-Hodgkin's lymphoma - prognostic significance and clinicopathological correlations. Br J Cancer 1989; 60:904-910.

125. Rehn S. Glimelius B, Strang P, et al. Prognostic significance of flow cytometry studies in B-cell non-Hodgkin's lymphoma. Hematol Oncol 1990; 8:1-12.

126. Christensson B, Lindemalm C, Johansson B, et al. Fiow cytometric DNA analysis: a prognostic tool in non-Hodgkin's lymphoma. Leukemia Res 1989; 13:307-314.

127. Bauer KD. Merkel DE, Winter JN, et al. Prognostic implications of ploidy and proliferative activity in diffuse large cell lymphomas. Cancer Res $1986 ; 46: 3173-3178$.

128. Dressler LG, Seamer LC, Owens MA, et al. DNA flow cytometry and prognostic factors in 1331 frozen breast cancer specimens. Cancer 1988; 61:420-427. 
129. Schutte B, Reynders MMJ, Wiggers T, et al. Retrospective analysis of the prognostic significance of DNA content and proliferative activity in large bowel carcinoma. Cancer Res 1987: 47:5494-5496.

130. Kallioniemi O-P, Punnoner R, Matilla J, Lehtinen M, Koivula T. Prognostic significance of DNA index, multiploidy, and S-phase fraction in ovarian cancer. Cancer 1988; 61:334-339.

131. Jaikanen S, Joensuu H, Klemi P. Prognostic value of lymphocyte homing receptor and S-phase fraction in non-Hodgkin's lymphoma. Blood 1990: 75:1549-1556.

132. Felman P, French M, Souchier C, Magaud J-P, Gentilhomme O, Bryon P-A. Comparison between image and flow DNA cytometry in non-Hodgkin's lymphomas. Path Res. Pract 1989; 185:709-714.

133. Cope C, Rowe D, Delbridge L, Philips J, Friedlander M. Comparison of image analysis and flow cytometric determination of cellular DNA content. J Clin Pathol 1991; 44:147-151.

134. Tay!or SR, Titus-Ernstoff L, Stitely S. Central values and variation of measured nuclear DNA content in imprints of normal tissues determined by image analysis. Cytometry 1989; 10:382-387.

135. Cohen C, Tickman RJ, DeRose PB, Whitaker BP. DNA ploidy studies of benign and malignant tumours: Comparison of flow cytometry and image analysis techniques using two types of cytological specimen. Cytopathology $1991 ; 2: 247-259$.

136. Falkmer UG, Hagmar T, Auer G. Efficacy of combined image and flow cytometric assessments in human breast cancer: $\mathrm{A}$ methodological study based on a routine histopathological material of 2024 excised tumour specimens. Anal Cell Pathol 1990; 2:297-312.

137. McFadden PW, Clowry LJ, Daehnert K, Hause LL, Koethe SM. Image analysis confirmation of DNA aneuploidy in flow cytometric DNA distributions having a wide coefficient of variation of the G0/G1 peak. Am J Clin Pathol 1990; 93:637-642. 


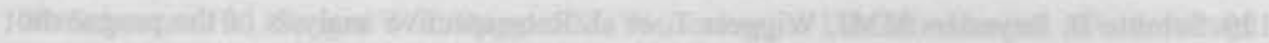

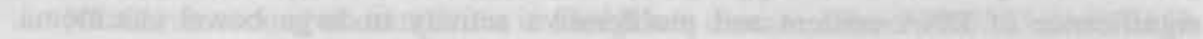

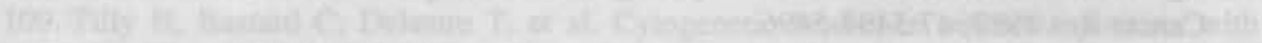

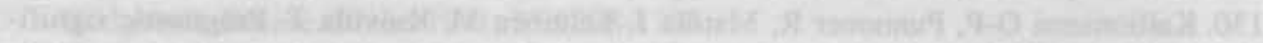

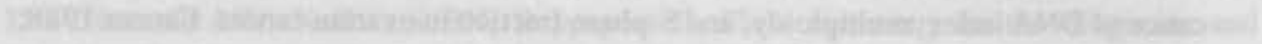

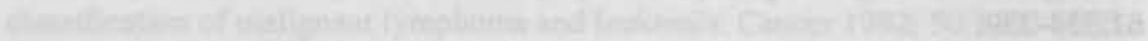

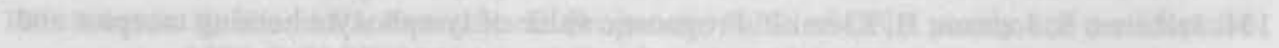

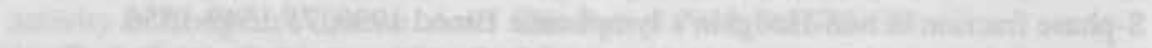

Whar

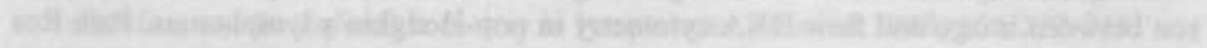

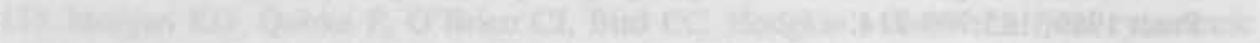

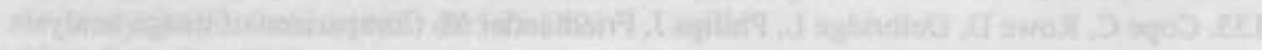

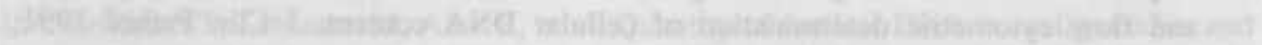

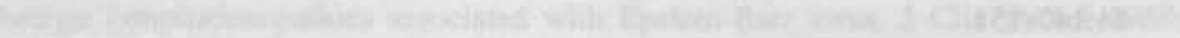

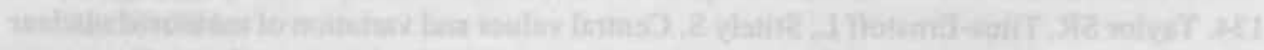

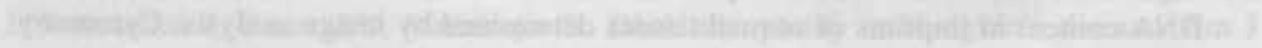

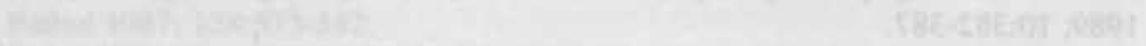

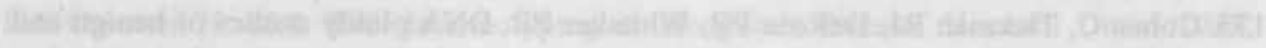

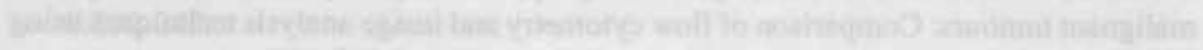

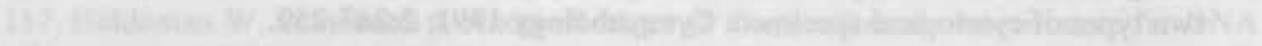

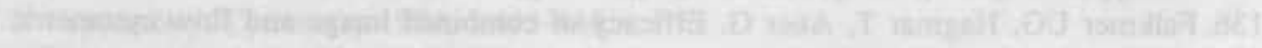

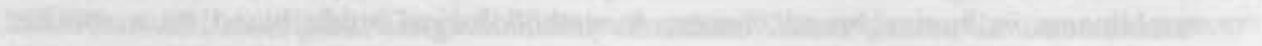

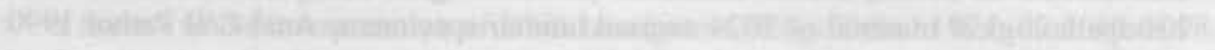

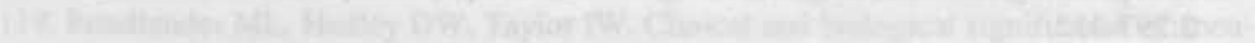

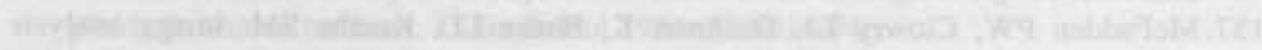

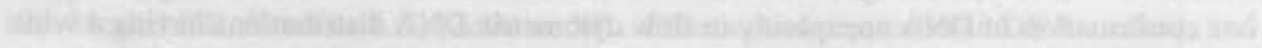

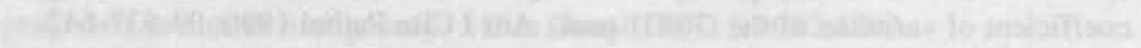

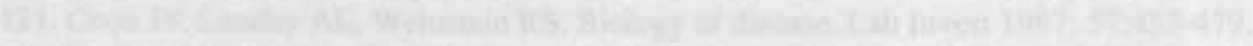

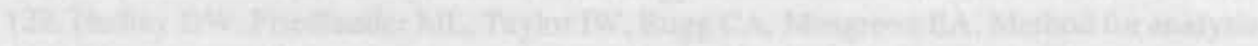

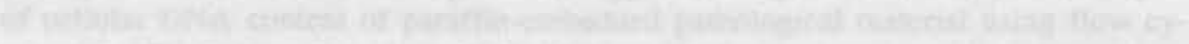

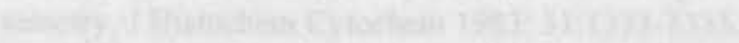

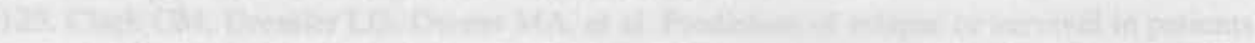

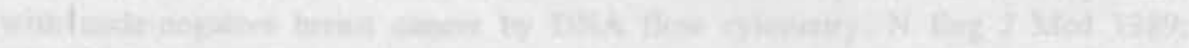

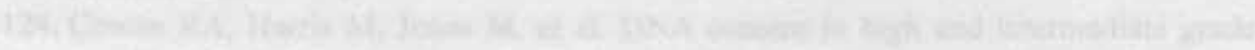
145

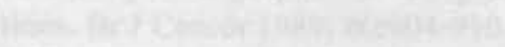

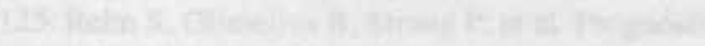

that

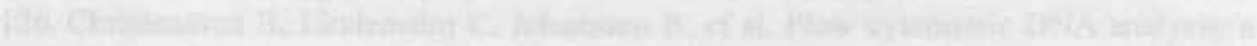

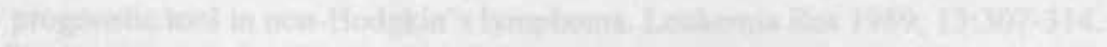

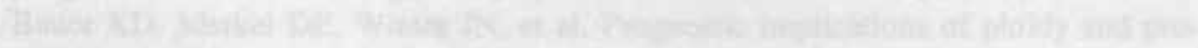

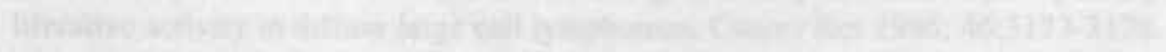

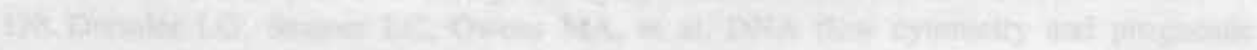

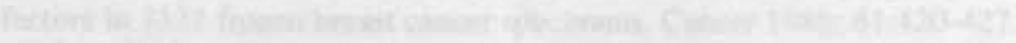




\section{CHAPTER 2}

\section{Hodgkin's disease}

\section{A regional retrospective study}

Frans L. Erdkamp. Theo J. Wijthuizen, Frans E. van Dam

Translation of the original paper published in: Ned Tijdschr Geneeskd 1988; 132:1801-1806. 


\section{Abstract}

In the period 1972-1983, 182 patients with Hodgkin's disease were diagnosed and treated in ten community hospitals in the southeastern part of The Netherlands. Staging procedures and treatment were not uniform. 114 patients underwent a diagnostic laparotomy ( 100 also splenectomy), leading to upstaging in $25 \%(28 / 114)$. Overall 5 - and 10-year survival rates were $72.5 \%$ and $55 \%$, and the 5- and 10-year relapse-free survival rates $65 \%$ and $53 \%$, respectively. 63 patients died, of whom 44 from direct complications of Hodgkin's disease. Up to 1985, 11 patients developed a second malignancy. Age, clinical stage and histology were important factors for overall survival. Our study population and treatment results are compatible with other studies. From the results of this study we may conclude that Hodgkin's disease can be treated in community hospitals if some conditions are fulfilled.

\section{Introduction}

In the southeastem part of The Netherlands a registry-based analysis was done, including all patients with Hodgkin's disease diagnosed and treated between 1972-1983 in ten community hospitals of Eindhoven, Deurne, Geldrop, Helmond, Roermond, Veghel, Venlo and Venray. These hospitals participated in the registry of the SOOZ-cancer registration, from 1982 incorporated in the Comprehensive Cancer Center South (IKZ).

Former studies have already demonstrated the good prognosis and curability of this disease (1-4). These data were generally obtained from prospective or retrospective studies from major cancer centers, who staged and treated patients according to fixed protocols. Recently, it was suggested that the possibility of errors in diagnosis, staging, treatment and detection of complications perhaps could be minimized by treating Hodgkin's disease patients only at centers and by teams with substantial experience in this field (5).

In the present study we investigated whether our clinical data and the results of a non-standardized staging system and treatment schedules were comparable with those from specialized centers, working with fixed management programs $(1-4,6)$. 


\section{Patients and Methods}

Between 1972 and 1983, 208 patients had Hodgkin's disease diagnosed in 10 community hospitals in the southeastern part of The Netherlands. Clinical data of these patients were obtained from a central registration system, maintained by the Comprehensive Cancer Center South (SOOZ/IKZ). Of this population, 12 patients were excluded because the diagnosis of Hodgkin's disease appeared to be made before 1972. From 6 patients insufficient data were available. After reviewing the histological material in 8 cases the diagnosis was changed to non-Hodgkin's lymphoma. The data of the remaining 182 patients were studied from the date of histologic diagnosis until last follow-up or death. Mean observation time was 5 years (minimum, 3 years; maximum, 14 years). In all of the patients the pathology was reviewed and classified according to the Rye classification (16). In addition the nodular sclerotic (NS) subtype was subdivided in grade NSI and NSII as previously described (2,9-12). All patients were clinically staged according to the Ann Arbor classification (17). Staging procedures such as bone marrow examination, lymphangiography, and laparotomy were performed as clinically indicated; in the later years of the accrual period computed tomography scanning often was applied. Patients with stages IA and IIA were usually treated with either mantle or inverted Y-field irradiation to a dose of $40 \mathrm{~Gy}$, whereas patients with stages IB, IIB and IIIA usually were treated with subtotal or total lymphoid irradiation with or without chemotherapy. Most patients with stages IIIB and IV received combined modality treatment, usually mechlorethamine, vincristine, procarbazine, and prednisone (MOPP) followed by "iceberg" irradiation to a dose of 20 Gy (table 1.). The statistical analyses were performed with the BMDP package. Pearson's chi-square test was used to analyze tables. The survival curves for all causes of death were plotted according to the Kaplan-Meier method. Survival curves were

Table 1. Treatment applied in relation to the diflerent clinical stages in 177 patients with Hodgkin's disease.

\begin{tabular}{|c|c|c|c|c|c|c|c|c|c|}
\hline \multirow[t]{3}{*}{ treatment } & \multicolumn{8}{|c|}{ clinical stage } & \multirow[t]{3}{*}{ total } \\
\hline & \multicolumn{2}{|c|}{ I } & \multicolumn{2}{|c|}{ III } & \multicolumn{2}{|c|}{ III } & \multicolumn{2}{|c|}{ IV } & \\
\hline & A & $\mathbf{B}$ & A & E & A & $\mathbf{B}$ & A & $\mathbf{B}$ & \\
\hline chemotherapy & 2 & 4 & 1 & 5 & 11 & 6 & 4 & 8 & 41 \\
\hline radiotherapy & 22 & 1 & 32 & 6 & 7 & 1 & 2 & 2 & 73 \\
\hline combined & 6 & 3 & 19 & 8 & 12 & 11 & 3 & 1 & 63 \\
\hline total & 30 & 8 & 52 & 19 & 30 & 18 & 9 & 11 & 177 \\
\hline
\end{tabular}


compared with the generalized Wilcoxon (Breslow) and generalized Savage (Mantel-Cox) methods $(13,14)$.
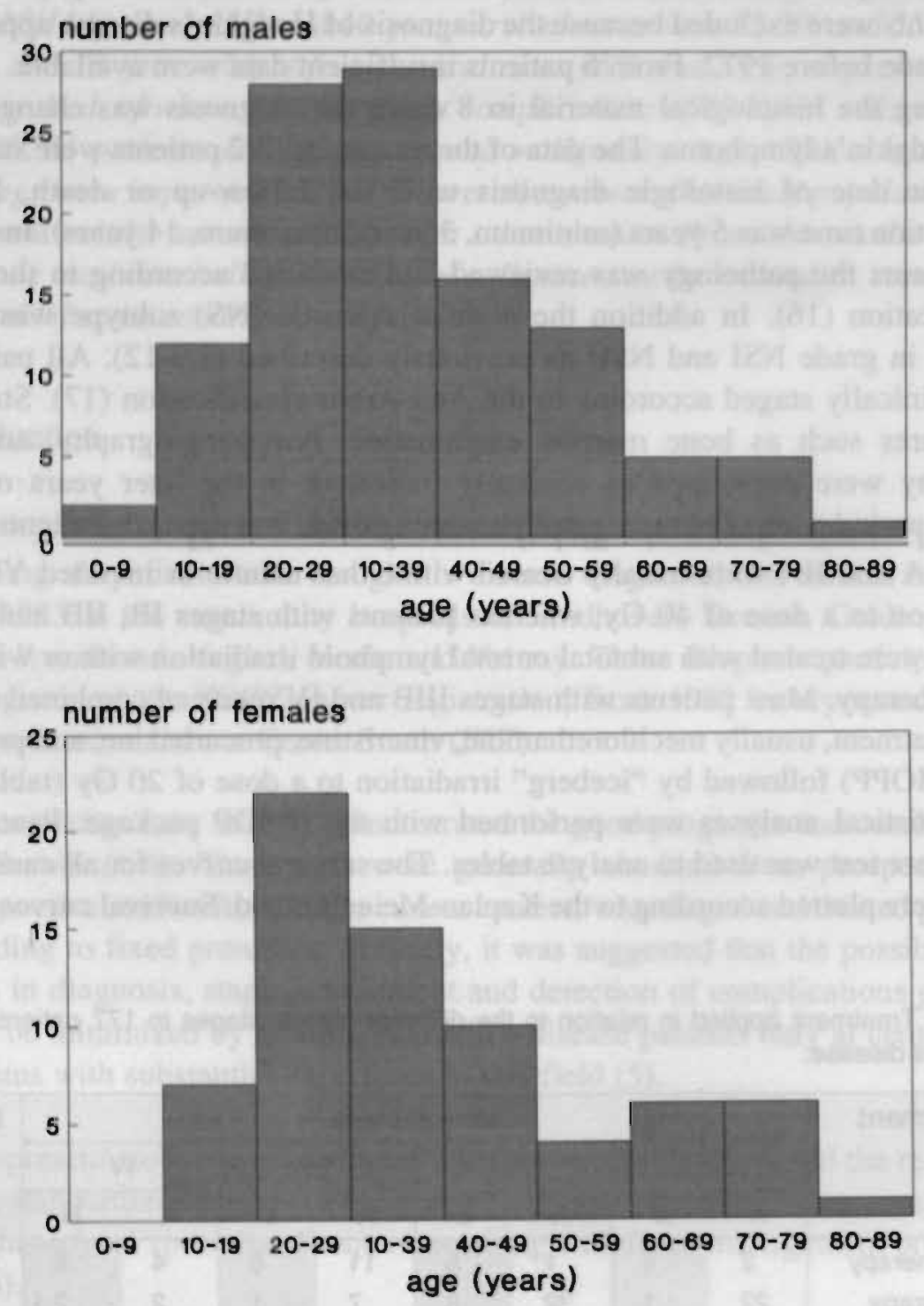

Figure 1. The age distribution of 111 males and 71 females with Hodgkin's disease. 


\section{Results}

The 182 patients constituted an unselected registry of patients with Hodgkin's disease in a 12-year period. With a population of 800.000 this corresponds to an incidence of 1.9 cases per 100.000 inhabitants per year. There were $111(61 \%)$ males and $71(39 \%)$ females in this study. Figure 1 gives the age-adjusted distribution, the mean age was 38 years. Survival was significantly reduced for elderly patients, particularly the group of patients 60 -years or older (figure 2 , $\mathrm{P}<0.001$ ). Table 2 shows the distribution of the clinical stages (CS) in relation to the histological classification. There were $109(63 \%)$ patients with clinical stage I or II, $65(37 \%)$ in stage III or IV. Relatively more patients presenting with systemic (B) symptoms had advanced disease (CS III and IV) compared to patients initially having more localized disease (CS I and II). Patients with early stage Hodgkin's disease (CS I and II) had a significantly better overall survival compared to patients with clinical stage III and IV (figure 3, $\mathrm{P}<0.015$ ). From table 2, it is apparent that the lymphocytic predominant (LP) histologic subtype was found more frequently in the early clinical stages, on the contrary the lymphocytic depleted (LD) form in the more advanced stages. There was a significant correlation between the histologic subclassification and overall survival: survival figures were significantly better for the LP and NSI subtype than for the NSII, mixed cellularity and LD histologic types $(\mathrm{P}<0.001)$. Staging

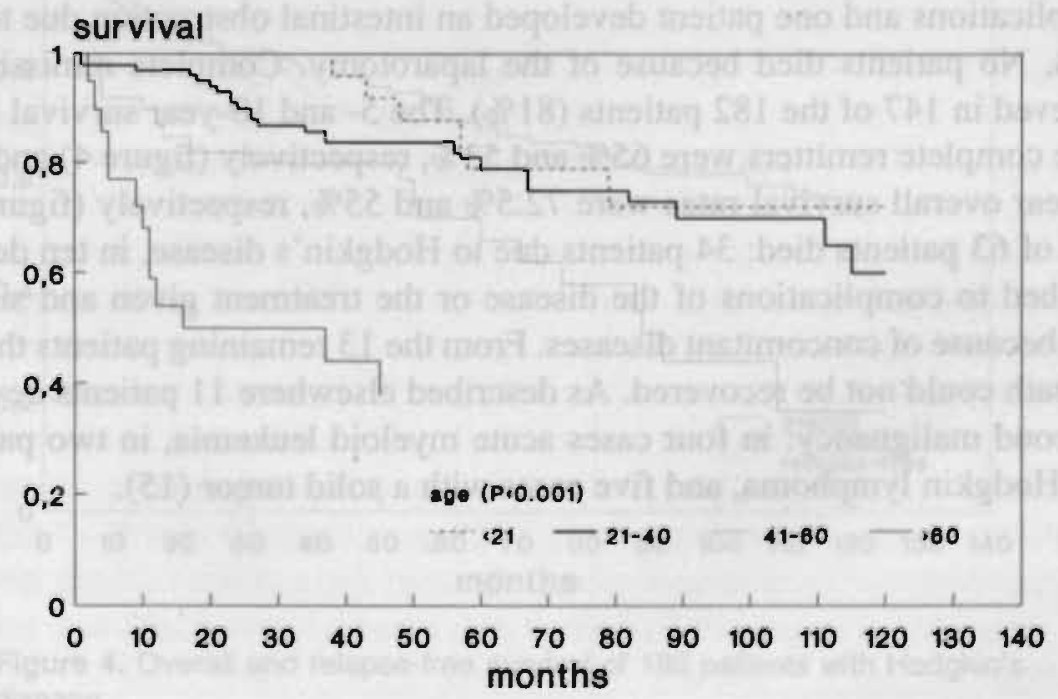

Figure 2. Overall survival of 182 patients with Hodgkin's disease divided according to age categories. 
Table 2. Clinical stage in relation to histology in 174 patients with Hodgkin's disease.

\begin{tabular}{|c|c|c|c|c|c|c|}
\hline \multicolumn{2}{|c|}{ clinical stage } & \multicolumn{4}{|c|}{ histology } & \multirow{2}{*}{ total } \\
\hline & & LP & INS & MC & LD & \\
\hline \multirow[t]{2}{*}{1} & A & 7 & 12 & 11 & 1 & 31 \\
\hline & $B$ & 1 & 4 & 2 & 0 & 7 \\
\hline \multirow[t]{2}{*}{ II } & A & 7 & 37 & 8 & 0 & 52 \\
\hline & B & 1 & 15 & 1 & 2 & 19 \\
\hline \multirow[t]{2}{*}{ III } & A & 4 & 16 & 7 & 2 & 29 \\
\hline & B & 0 & 9 & 8 & 1 & 18 \\
\hline \multirow[t]{2}{*}{ IV } & A & 1 & 5 & 14t5x & 0 & 7 \\
\hline & B & 1 & 3 & 6 & 1 & 11 \\
\hline total & & 22 & 101 & 44 & 7 & 174 \\
\hline
\end{tabular}

LP: Iymphocylic predominant, NS: nodular sclerotic, MC: mixed cellularity, LD: lymphocytic depleted.

laparotomy and splenectomy was preformed on 114 and 100 patients, respectively. Abdominal disease was detected in 54 cases and the spleen was involved in 34 patients. In 28 of the 114 cases laparotomy resulting in upstaging. In 114 laparotomies seven cases suffered from complications: three postoperative infections without sepsis, one intra-abdominal bleeding, three thrombo-embolic complications and one patient developed an intestinal obstruction due to adhesions. No patients died because of the laparotomy. Complete remission was achieved in 147 of the 182 patients $(81 \%)$. The 5 - and 10 -year survival rates of these complete remitters were $65 \%$ and $53 \%$, respectively (figure 4 ) and 5 - and 10-year overall survival rates were $72.5 \%$ and $55 \%$, respectively (figure 4 ). A tota! of 63 patients died: 34 patients due to Hodgkin's disease, in ten dead was ascribed to complications of the disease or the treatment given and six cases died because of concomitant diseases. From the 13 remaining patients the cause of death could not be recovered. As described elsewhere 11 patients developed a second malignancy: in four cases acute myeloid leukemia, in two patients a non-Hodgkin lymphoma, and five cases with a solid tumor (15). 


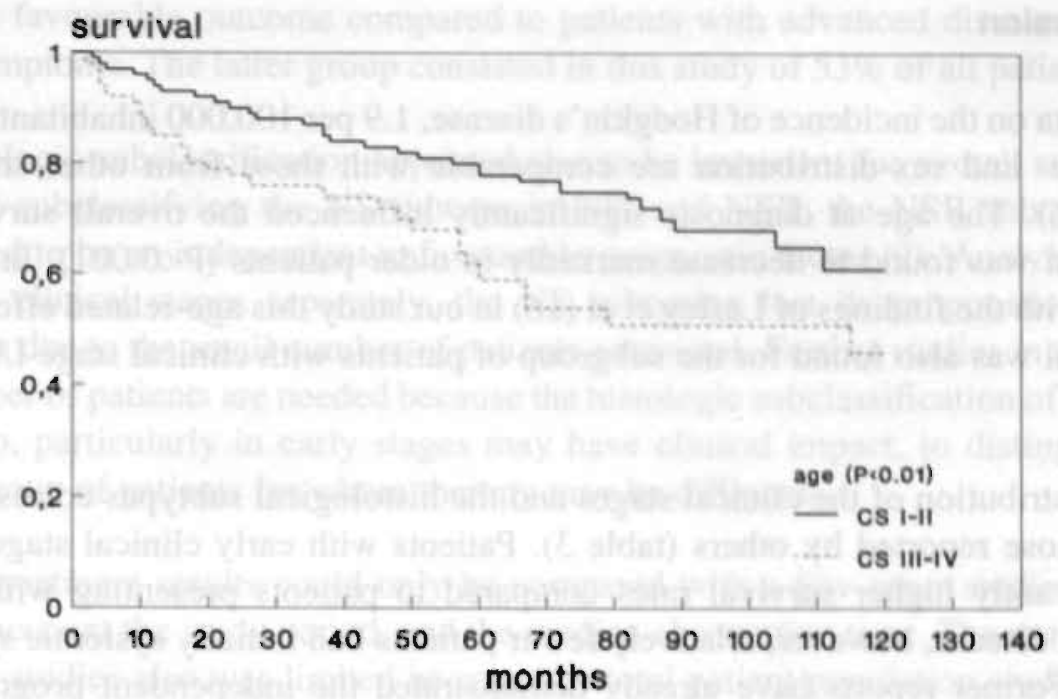

Figure 3. Overall survival of 182 patients with Hodgkin's disease according to clinical stage.

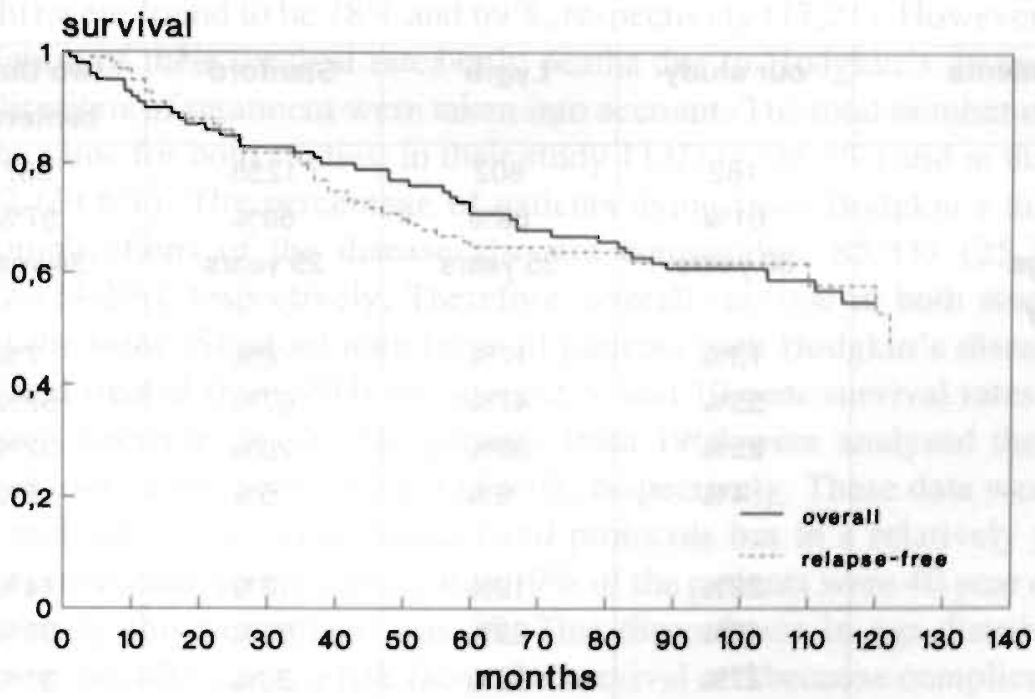

Figure 4. Overall and relapse-free survival of 182 patients with Hodgkin's disease. 


\section{Discussion}

Our data on the incidence of Hodgkin's disease, 1.9 per 100.000 inhabitants and the age- and sex-distribution are comparable with those from other studies $(1,2,4,6)$. The age at diagnosis significantly influenced the overall survival: survival was found to decrease markedly in older patients $(\mathrm{P}<0.001)$. In contrast, with the findings of Lesley et al (16) in our study this age-related effect on survival was also found for the subgroup of patients with clinical stage IA and IIA.

The distribution of the clinical stages and the histological subtypes correspond with those reported by others (table 3 ). Patients with early clinical stage had significantly higher survival rates compared to patients presenting with advanced disease, however, relatively fewer patients had initially systemic symptoms. Former reports have already demonstrated the independent prognostic impact of B-symptoms on survival $(18,19)$. Patients initially having more localized disease and presenting without systemic symptoms seem to have a

Table 3. Patient characteristics of 182 patients with Hodgkin's disease compared to other centers.

\begin{tabular}{|l|c|c|c|c|}
\hline \multicolumn{1}{|c|}{ patients } & our study & "Lygra"1 & "Stanford" & $\begin{array}{c}\text { two Dutch } \\
\text { centers }\end{array}$ \\
\hline $\begin{array}{l}\text { number } \\
\text { male } \\
\text { mean age } \\
\text { histology }\end{array}$ & 182 & 802 & 1255 & 337 \\
LP & $61 \%$ & $62 \%$ & $60 \%$ & $57 \%$ \\
NS & 38 years & 35 years & 29 years & 34 years \\
MC & $13 \%$ & $17 \%$ & $8 \%$ & $7 \%$ \\
LD & $55 \%$ & $47 \%$ & $67 \%$ & $52 \%$ \\
CS & $25 \%$ & $30 \%$ & $20 \%$ & $32 \%$ \\
I & $4 \%$ & $6 \%$ & $5 \%$ & $9 \%$ \\
II & & & & \\
III & $22 \%$ & $19 \%$ & $10 \%$ & $14 \%$ \\
IV & $40 \%$ & $28 \%$ & $55 \%$ & $39 \%$ \\
B symptoms & $27 \%$ & $32 \%$ & $30 \%$ & $31 \%$ \\
\hline
\end{tabular}

LP: Iymphocytic predominant, NS: nodular sclerotic, MC: mixed cellularity, LD: lymphocytic depleted, CS: clinical stage. 
more favourable outcome compared to patients with advanced disease and/or B-symptoms. The latter group consisted in this study of $53 \%$ of all patients.

Histologic subclassification appeared also to be important for overall survival. After subclassifying the NS subtype in NSI and NSII, the NSII subtype appeared to be an independent unfavourable prognostic factor (9). Analyzing the early clinical stages separately, the NS subtyping lost its prognostic value, partly due to the small number of patients examined. Further studies in a larger number of patients are needed because the histologic subclassification of the NS group, particularly in early stages may have clinical impact, to distinguish a subgroup of patients for whom therapy may be different.

Our treatment results could only be compared with a few other studies taken into account the study period, and the median observation time. The number of other studies also was limited because the total patient population studied had to be included for the survival analysis. In our multicenter, non-standardized treated population of patients, the 5 - and 10 -year survival rates were $72.5 \%$ and $55 \%$, respectively. These results are comparable with those of a similar Danish study: 5 - and 8 -year survival rates of $72 \%$ and $66 \%$, respectively (1). Those data from a comparable Dutch study of two university hospitals (Nijmegen and Utrecht) were found to be $78 \%$ and $69 \%$, respectively $(17,21)$. However, for the calculation of their survival rates only deaths due to Hodgkin's disease or the complications of treatment were taken into account. The total number of deaths was the same for both studies; in their study $113 / 337(33.5 \%)$ and in this report $63 / 182(34.6 \%)$. The percentage of patients dying from Hodgkin's disease or the complications of the disease also are comparable: $85 / 337(25.2 \%)$ and $44 / 182(24.2 \%)$, respectively. Therefore, overall survival in both studies was almost the same. Stanford data from all patients with Hodgkin's disease diagnosed and treated from 1960 on, showed 5- and 10-year survival rates of $79 \%$ and $62 \%$, respectively. If only patients from 1968 were analyzed the overall survival looks even better: $83 \%$ and $69 \%$, respectively. These data were, however obtained in one center using fixed protocols but in a relatively younger patient population. In their trials only $19 \%$ of the patients were 40 year or older, in our study this percentage was 35 . This discordance in age-distribution is important because age is a risk factor for survival and because complications of treatment and concomitant diseases are more likely to occur at older age.

The relapse-free survival is in contrast to the overall slirvival a more reliable measurement to assess the quality of a given therapy. The 5-and 10-year relapse-free survival rates in this study were $65 \%$ and $53 \%$, in the Stanford 
studies $69 \%$ and $67 \%(4)$ and the Lygra group reported a 8 -year rate of 55\% (1).

Survival percentages divided according to clinical stage showed slight differences for the different studies (table 4). Bennett et al, analyzing more than 2000 patients, reported a 5-year survivai rate of $87 \%$ for patients with clinical stage IA and IIA with a corresponding 5-year relapse-free survival rate of $65 \%$ (2). In this study these percentages were 80 and 72.5 , respectively. The EORTC trials of the seventies showed 5-year survival rates varying from $85 \%$ to $90 \%$ for patients with clinical stage 1 and II. The 5-year survival rate, found by Friedenburg et al in their non-university study, for patients with clinical stage III and IV was $50 \%$. A result comparable with the Danish (1) and our study.

Table 4. The 5-years overall survival according to clinical stage. A comparison with different studies.

\begin{tabular}{|l|c|c|c|c|}
\hline clinlcal stage & our study & "Lygra" & "Stanford"4 & $\begin{array}{c}\text { two Dutch } \\
\text { centers }\end{array}$ \\
& (1972-1983) & (1971-1979) & (1968-1978) & (1970-1984)" \\
\hline I & $80 \%$ & $86 \%$ & $93 \%$ & $93 \%$ \\
II & $78 \%$ & $79 \%$ & $90 \%$ & $83 \%$ \\
III & $65 \%$ & $57 \%$ & $79 \%$ & $74 \%$ \\
IV & $48 \%$ & $49 \%$ & $61 \%$ & $60 \%$ \\
\hline
\end{tabular}

" In this study only those patients who died from Hodgkin's disease or complications of treatment were taken into account. On the contrary in the other three studies survival curves were drawn from the total number of deaths.

In conclusion our patient population, but particularly our treatment results are comparable with data reported by others $(1,2,4,6)$. However, we do not want to make a plea for the treatment of this relatively uncommon tumor by physicians in smaller local hospitals. First, the results in this study are achieved because in this region patients with Hodgkin's disease were treated by physicians with special interest and knowledge in the field of hemato-oncology. Second, from 1979 on the treatment schedule for every new patient was discussed by internists, radiation-oncologists and pathologists and from then on more and more patients were treated according to well established treatment programs or by (clinical) EORTC trials. By this approach Rosenberg's statement (5) to treat all patients with Hodgkin's disease principally in major cancer research centers is not supported here. Other analyses also have shown that the quality of the data reported and the treatment results of non-universiry hospitals are not yield to those of university hospitals $(22,23)$. Despite the good concordance of our results to those reported by others, only with clinical trials accruing large 
numbers of patients, making the participation of major centers and large community hospitals necessary, we will be able to distinguish high-risk patients for which more effective but less toxic treatment schemes have to be developed. Participation of community hospitals to these international investigations may lead to specialized treatment of patients near home: the patient does not need to go to the expert in a major treatment center, but the expertise will come to the patient. 


\section{References}

1. Nordenhoft AM, Petersen-Bjergaard J, Brincker H, et al. Hodgkin's disease in Denmark. A national clinical study by the Danish Hodgkin study group. Lygra. Scand J Haematol 1980; 24:321-334.

2. Haybittle JL, Easterling MJ, Bennett MH, et al. Review of British national lymphoma investigation studies of Hodgkin's disease and development of prognostic index. Lancet 1985; i:967-972.

3. Somers R, Burgers JMV, Hartgrink-Groeneveld CA, et al. EORTC-onderzoekingen bij de ziekte van Hodgkin. Ned Tijdschr Geneeskd 1982; 126:616-622.

4. Kaplan HS. Hodgkin's disease, 2nd ed. Cambridge, MA: Harvard University Press, 1980.

5. Rosenberg SA. Hodgkin's disease: no stage beyond cure. Hosp Pract (Off) 1986; 21:91-108.

6. Friedenburg WR, Dirks P, Beltaos E, et al. Improved survival in the treatment of advanced Hodgkin's disease at a nonuniversity institution (1970-1979). Cancer 1986; 57:12-17.

7. Carbone PP, Kaplan HS, Masshoff K, Smithers DW, Tubiana M. Report of the committee of Hodgkin's disease staging. Ann Arbor Classification. Cancer 1971; 31:18601861.

8. Lukes RJ, Gompel LF, Hall TC, Rappaport H, Rubin P. Report of the Nomenclature Committee. Rye classification. Cancer Res 1966; 26:1311.

9. Jairam R, Vrints LW, Breed WPM, Wijlhuizen ThJ, Wijnen JThM. Histological subclassification of the nodular sclerotic type of Hodgkin's disease. Neth J Med 1988; 33:160-167.

10. Bennell MH, MacLennan KA, Easterling MJ, et al. The prognostic significance of cellular subtypes in nodular sclerosing Hodgkin's disease. An analysis of 271 non-laparotomised cases (BNLI-report No 22). Clin Radiol 1983; 34:497-501.

11. Bennett MH, MacLennan KA, Easterling MJ, et al. Analysis of histological subtypes in Hodgkin's disease in relation to prognosis and survival. In: Qualino D. Hayhoe FGJ, eds. The cylobiology of leukemias and lymfomas. Serono Symposia publications (New York: Raven Press) 1985; 20:15-32.

12. Gärtner HV, Wehrmann M, Inniger R, Steinke B. Nodular sclerosing Hodgkin's disease: prognostic relevance of morphological parameters. First International Symposium on Hodgkin's Lymphoma. Cologne, Oct 2-3, 1987; abstract 27. Berlin: Springer.

13. Bishop YMM, Fienberg SE, Holland PW. Discrete multivariate analysis: theory and practice. Cambridge, MA: MIT press, 1975.

14. Gross AJ, Clark VA. Survival distribution reliability application in the biomedicall sciences. New York: Wiley and Sons, 175.

15. Wijlhuizen ThJ, Breed WPM. Secundaire maligniteiten na behandeling van de ziekte van Hodgkin. Ned Tijdschr Geneeskd 1987; 131:1342-1346.

16. Leslie TN, March PM, Hellman S. Stage IA to IIB supradiaphragmatic Hodgkin's disease. Cancer 1985; 55:2072-2078.

17. Rijswijk REN van. Hodgkin's disease, clinical and immunological investigations. Utrecht: 1988. Thesis. 
18. Tubiana M, Henry-Amar M, Werf-Messing B van der, et al. A multivariate analysis of prognostic factors in early stage Hodgkin's disease. Int J Radiat Oncol Biol Phys 1985; 11:23-30.

19. Gobbi PG, Cavalli C, Gendarmi A, et al. Reevalation of prognostic significance of symptoms in Hodgkin's disease. Cancer 1985; 56:2874-2880.

20. Tubiana M, Henry-Amar M, Burgers MV, Werff-Messing B van der, Hayat M. Prognostic significance of erythrocyte sedimentation rate in clinical stages I-II of Hodgkin's disease. J Clin Oncol 1984; 2:194-200.

21. Rijswijk REN van, Verbeek J, Haanen C, Daal WAJ van, Peperzeel HA van. Resultaten van de behandeling van de ziekte van Hodgkin; 15 jaar ervaring van de universiteitsklinieken van Nijmegen en Utrecht. Ned Tijdschr Geneeskd 1987; 131:1866-1870.

22. Koretz M, Jackson PM, Jorti FM, Carter SK. A comparison of the quality of participation of community affiliates of universities in the Northern Califomia Oncology Group (NCOG). J Clin Oncol 1984; 1:640-644.

23. Begg CB, Carbone PP, Elson PJ, Zelen M. Participation of community hospitals in clinical trials. N Engl J Med 1982; 306:1076-1080. 



\section{CHAPTER 3}

\section{Hodgkin's disease in the elderly}

A registry-based analysis

Frans L. Erdkamp, Wim P. Breed, Leo J. Bosch, Jac Th. Wijnen, Geert H. Blijham

Cancer: 1992; 70:830-834. 


\section{Abstract}

In a retrospective study of a nonselected population of patients with Hodgkin's disease, the authors evaluated which factors contributed to the age-related prognostic effect in this disease. The survival curves of 182 patients, were compared, and survival time was found to decrease markedly after the age of 50 years. Differences in disease characteristics between older and younger patients were small and not statistically significant. Significantly fewer older patients received adequate treatment ( $34 \%$ versus $2 \%$ ) and they were less likely to achieve a complete remission (61\% versus $90 \%)$. However, the relapse-free survival time of the patients with complete disease remission was not significantly different from that of younger patients, $50 \%$ of all patients being free of disease after 10 years. Intercurrent disease did not appear to be responsible for the decreased survival times in the elderly (32\% versus 26\%). The authors conclude that the inability to give adequate treatment seems to be the major determinant of the poorer overall survival time of older patients with Hodgkin's disease.

\section{Introduction}

Studies of prognostic factors in Hodgkin's disease generally have revealed an inverse relationship between age and survival (1-14). Walker et al., in a study of 6345 patients from a cancer registry, found that patients older than 50 years of age had higher rates of advanced stage, systemic symptoms and histologic types associated with poor prognosis at presentation; older patients were also less likely to be adequately staged and treated. However, even after correction for these factors, patients older than 50 years of age showed a poorer 5-year survival rate (9). In contrast, in single- institution investigations from large cancer centers, such as Stanford and M.D. Anderson, no differences in survival were found for older and younger patients with disease that was adequately staged and treated. The referral pattern of older patients from community hospitals to such institutions may have introduced some selection bias, which is difficult to control $(2,10)$. As a result, controversies regarding the role of age as a factor predicting prognosis and influencing the treatment of patients with Hodgkin's disease remain. In an earlier study of patients with Hodgkin's disease diagnosed and treated in 10 community hospitals in the southeastern part of the Netherlands, age appeared to be a determinant of survival (15). In the 
current study, we examined this relationship in more detail to delineate the factors contributing to this age-related effect in a nonselected, registry-based population of patients with this disease.

\section{Patients and Methods}

Between 1972 and 1983, 208 patients in 10 community hospitals in the southeastern part of The Netherlands had Hodgkin's disease diagnosed. Clinical data of these patients were obtained from a central registration system, maintained by the Comprehensive Cancer Center South (SOOZ/IKZ). Of this population, 12 patients were excluded because the diagnosis of Hodgkin's disease appeared to be made before 1972. Insufficient data were available for six patients. Review of the histologic material of eight patients led to a change in diagnosis of non-Hodgkin's lymphoma. The data of the remaining 182 patients were studied from the date of histologic diagnosis until last follow-up or death of the patient. Mean observation time was 5 years (minimum, 3 years; maximum, 14 years). In all of the patients the pathology was reviewed and classified according to the Rye classification (16). All patients were clinically staged according to the Ann Arbor classification (17). Staging procedures, such as bone marrow examination, lymphangiography, and laparotomy, were performed as clinically indicated; in the later years of the accrual period, computed tomography scanning often was used. Patients with stages IA and IIA usually received mantle or inverted $Y$-field exposure to radiation to a dose of $40 \mathrm{~Gy}$, whereas patients with stages IB, IIB, and IIIA usually received subtotal or total lymphoid exposure to radiation with or without chemotherapy. Most patients with stage IIIB and IV disease received combined modality treatment, usually mechlorethamine, vincristine, procarbazine, and prednisone (MOPP) followed by "iceberg" exposure to radiation to a dose of $20 \mathrm{~Gy}$. Treatment was considered to be incomplete if involved field radiation therapy was given when more extensive radiation therapy was needed or when chemotherapy of less than three full-dose cycles on schedule was administered. The statistical analyses were performed with the BMDP Statistical Software package (Los Angelis, CA, USA) package. Pearson chi-square test was used to analyze tables. The survival curves for all causes of death were plotted according to the Kaplan-Meier method. Survival curves were compared with the generalized Wilcoxon (Breslow) and generalized Savage (Mantel-Cox) methods $(18,19)$. 


\section{Results}

We evaluated the relation between prognosis and age by comparing survival curves of cohorts of patients in age-classes of 10 years. Survival curves for patients younger than the age of 50 did not differ appreciably; however, the age class of 50-60 years showed a significantly reduced survival time, as was true with the patients older than 60 years (figure 1). The probability of dying within the first 10 years after diagnosis seems to increase from approximately $40 \%$ for patients younger than 50 years to approximately $60 \%$ for patients 50 years of age or older.

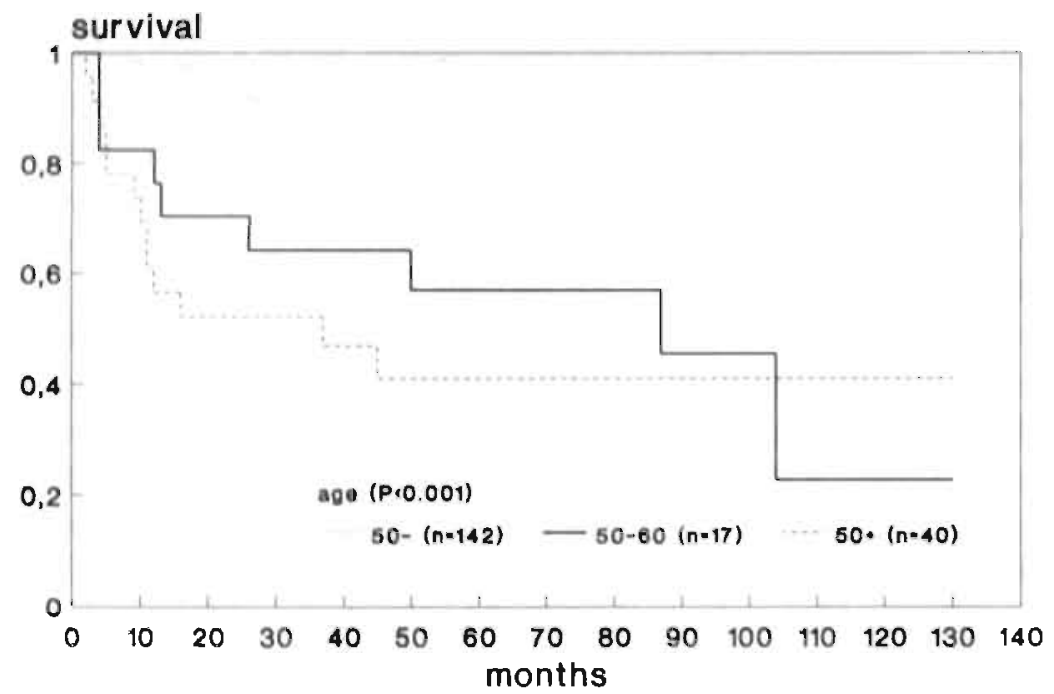

Flgure 1. Survival of 182 patients with Hodgkin's disease in relation to different age-classes.

Patient characteristics that may explain prognostic differences were analyzed (table 1). Patients younger than and older than 50 years of age were similar with regard to sex, the presence of systemic symptoms, mediastinal involvement and histology. Patients older than 50 years of age were more or less equally distributed throughout the four clinical stages, younger patients more often had stage IIl disease ( $\mathrm{P}<0.01)$. Clinical stages were clustered in early (CSI-IIIA) and advanced (IIIB-IV) categories, and no significant differences were found. Thirty-one percent of the younger patients had four or more involved sites, in contrast with $12 \%$ of the older patients. However, this difference may be 
Table 1. Patient characteristics in relation to age in 182 patients with Hodgkin's disease.

\begin{tabular}{|l|c|c|c|}
\hline & $<\mathbf{5 0}$ years & $\geq \mathbf{5 0}$ years & P value \\
\hline number of patients & 142 & 40 & $\mathrm{~ns}$ \\
men (\%) & $62 \%$ & $58 \%$ & $\mathrm{~ns}$ \\
systemic symptoms (\%) & $30 \%$ & $38 \%$ & $\mathrm{~ns}$ \\
histologic types (\%) & & & \\
LP & $13 \%$ & $11 \%$ & \\
NS & $61 \%$ & $48 \%$ & \\
MC & $24 \%$ & $30 \%$ & $\mathrm{P}<0.01$ \\
LD & $2 \%$ & $11 \%$ & \\
clinical stage (\%) & & & \\
I & $19 \%$ & $32 \%$ & $\mathrm{~ns}$ \\
II & $45 \%$ & $20 \%$ & $\mathrm{Ps}$ \\
III & $27 \%$ & $28 \%$ & \\
IV & $9 \%$ & $20 \%$ & \\
clinical stage I-IIIA (\%) & $79 \%$ & $70 \%$ & \\
mediastinal involvement (\%) & $44 \%$ & $31 \%$ & \\
$>3$ sites & $31 \%$ & $12 \%$ & \\
\hline ns: not significant; LP: lymphocytic predominant, NS: noclular sclerotic, MC: mixed cellu- \\
larity, LD: lymphocytic depleted.
\end{tabular}

Table 2. The number of patients who received incomplete or no treatment at all in relation to age.

\begin{tabular}{|l|c|c|c|c|}
\hline & number & no therapy & $\begin{array}{c}\text { Incomplete* } \\
\text { chemotherapy }\end{array}$ & $\begin{array}{c}\text { Incomplete* } \\
\text { radlotherapy }\end{array}$ \\
\hline$<50$ years & 142 & 0 & 3 & 0 \\
$\geq 50$ years & 40 & 2 & 7 & 6 \\
\hline * as defined in the "Patients and Methods" section. \\
\hline
\end{tabular}

influenced by staging laparotomy being performed in $71 \%$ of the younger and in $35 \%$ of the older patients. These data suggest, that patients. older than 50 years of age more often have systemic symptoms (38\% versus $30 \%$ ), unfaverable histology (MC and LD, $41 \%$ versus $26 \%$ ) and higher stage (stage III and IV, $48 \%$ versus $36 \%$ ). However, none of these differences were large enough to be statistically significant.

In the group of patients older than 50 years, 13 of 38 (34\%) received incomplete therapy, as defined in the "Patients and Methods" section compared with only $2 \%$ of younger patients (table 2). In patients older than 50 years, incomplete 
chemotherapy was attributable to considerable hematologic toxicity in 5 of 23 patients and severe neuropathy in 2 of 23 patients; one of these latter patients also develloped Cushing's disease. All patients receiving incomplete radiotherapy were oider than 60 years. Four patients were considered to have general health status to poor to tolerate more extensive therapy than involved field radiation therapy; one patient had signs of cardiac failure, and one patient had severe mental disturbance.

Complete remission rates for the young and old patients were $90 \%$ and $61 \%$, respectively (table 3 ), but if complete therapy was given to patients older than 50 years, the complete remission rate reached $80 \%$, compared with $92 \%$ for patients younger than 50 years. Complete remission rates for patients older than 50 years with incomplete therapy was $31 \%$, and the survival rate of this group was significantly lower compared with the rate of patients who received complete therapy (figure 2).

Finally, we analyzed the data regarding the course of disease in patients, who had complete remission. Relapse-free survival curves are shown in figure 3 and were not significantly different for patients younger than and older than 50 years. This suggests, that the observed difference in overall survival between these two patient groups probably is not attributable to deaths not related to Hodgkin's disease, but rather to elderly patients dying of Hodgkin's disease that has not been brought into remission. This conclusion is supported by an analysis of causes of death, that shows that $26 \%$ of younger patients died of causes other than non-Hodgkin's disease, compared with $32 \%$ of older patients (table 4 ).

Table 3. Complete remission rates in relation to age for all patients and subclassified for clinical stage.

\begin{tabular}{|l|c|c|r|}
\hline \multirow{2}{*}{} & \multicolumn{3}{|c|}{ complete remission rates (\%) } \\
\cline { 2 - 4 } & all stages & CS I-IIIA & CS IIIB-IV \\
\hline all patients & $150 / 179(84)$ & $121 / 139(87)$ & $29 / 40(73)$ \\
$<50$ years & $127 / 141(90)$ & $103 / 112(92)$ & $24 / 29(83)$ \\
$\geq 50$ years & $23 / 38(61)$ & $18 / 27(67)$ & $5 / 11(45)$ \\
\hline CS: clinical stage. & \multicolumn{4}{|c}{} \\
\hline
\end{tabular}




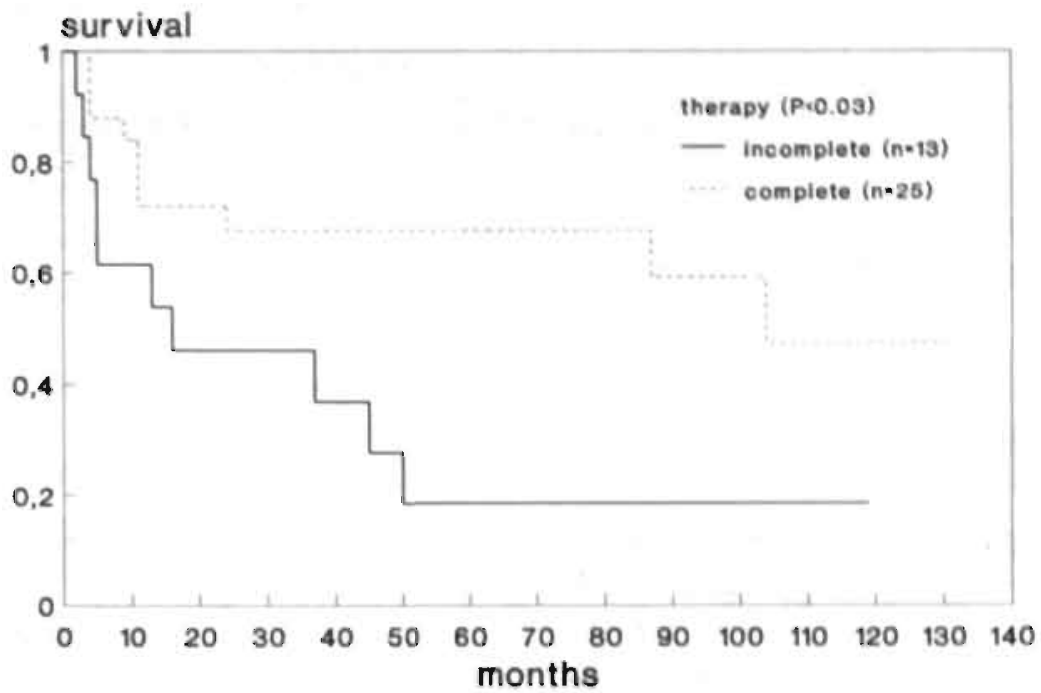

Figure 2. Survival compared with therapy for patients older than 50 years of age.

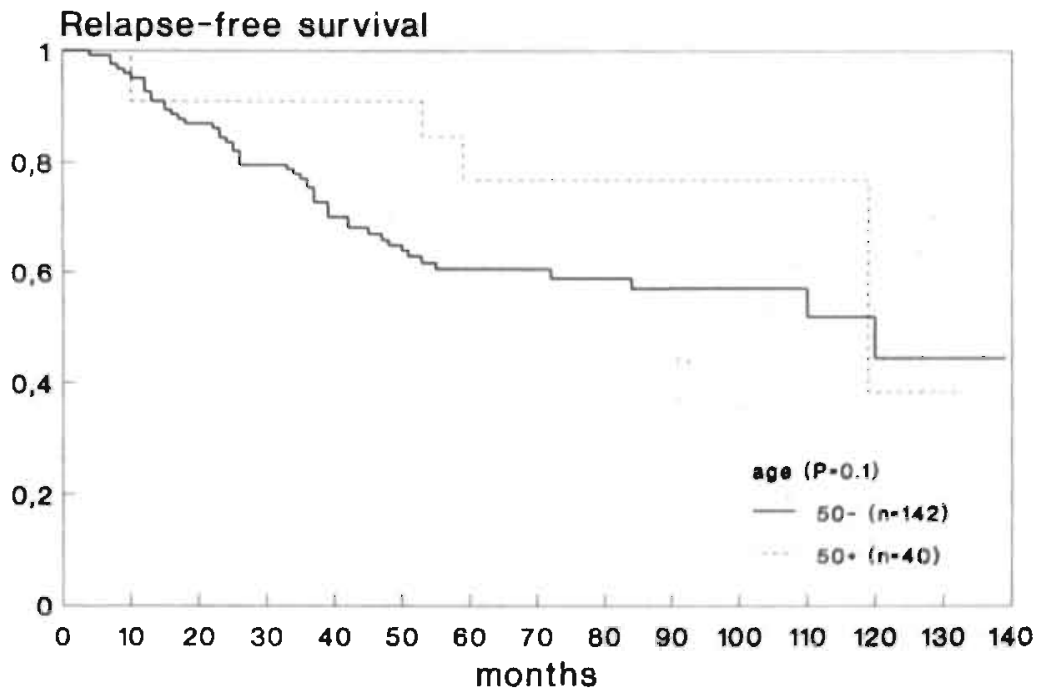

Figure 3. Relapse-free survival for patients younger and older than 50 years of age. 
Table 4. The cause of death in relation to age in 182 patients with Hodgkin's disease.

\begin{tabular}{|l|c|c|}
\hline \multirow{2}{*}{} & \multicolumn{2}{|c|}{ cause of death (\%) } \\
\cline { 2 - 3 } & Hodgkin's disease* & other causes \\
\hline$<50$ years & $28 / 38(74)$ & $10 / 38(26)$ \\
250 years & $15 / 22(68)$ & $7 / 22(32)$ \\
\hline * including treatment-related deaths.
\end{tabular}

\section{Discussion}

The 182 patients, who are the basis of this analysis, constitute an unselected and complete registry of patients with Hodgkin's disease diagnosed in a 12-year period. With a population of 800,000 this corresponds to an incidence of 1.9 cases per 100,000 inhabitants per year, a figure that is in line with data from registration projects in other Western-European countries (20). In addition, in this part of the Netherlands, which has a mixed rural-urban character, all patients, have easy access to adequate medical care and facilities, including one central radiation therapy department and facilities for administering intensive chemotherapy. Because treatment options in Hodgkin's disease have not appreciably changed since the beginning of this study, we believe that our data represent a fair estimation of the implications of age for the prognosis of patients with this disease.

The age of 50 years seems to be a turning point in this respect, with patients younger than 50 years having a $20 \%$ greater chance of experiencing 10 -year survival than patients older than 50 years. Similar differences were demonstrated by the British National Lymphoma Investigation (BNLI) group (6) and in a Swedish study (5). In our study, this difference was found to be mostly attributable to mortality from the disease, rather than from other causes; these data agree with some $(1,5,6)$ but not all $(4,10)$ studies. Thus, the question is whether Hodgkin's disease behaves differently in elderly patients than in younger ones or are there differences in approaches to diagnosis or therapy. We believe that our results in particular support the latier view for two reasons. First, the relapse-free survival curve of patients who had a complete remision is not significantly different for older or younger patients, with $50 \%$ of all patients being free of disease after 10 years. Second, the lower rate of complete remission in elderly patients can be explained by significantly fewer of those patients receiving adequate treatment. When patients older than 50 years were given radiation therapy or chemotherapy, as is done for younger patients, comparable 
remission and relapse-free survival rates were observed; this also has been found in studies by the BNLI group (6), the Dutch Cancer Center, (4) and the Finsen Institute (1). Thus, the inability to give adequate therapy appears to be the main determinant of the inferior 10-year survival rate of elderly patients. This conclusion agrees with the findings of Lipschitz et al., who reported almost without exception, similar behaviour of common cancers in older and younger patients (21).

Some disease-related differences between younger and older patients were found. As reported by Walker et al., (9) elderly patients tend to have more advanced disease, a higher frequency of systemic symptoms and histologic subtypes associated with less favorable prognosis. However, these differences were small, and it is unlikely that they can explain the survival differences between the two groups. In our study, the number of patients was too small to perform a multivariate analysis to correct for these prognostic factors; in the study of Walker et al., (9) which reviewed the data of 6345 patients, these factors could not explain the poorer 5 -year survival rate of patients older than 50 years. We found the disease characteristics to be remarkably independent from age; for patients older than 50 years, nodular sclerosis remains the main histologic subtype (48\%), mediastinal involvement is common $(31 \%)$, and early clinical stages (stage I-IIIA) remain preponderant. With further reduction in patient or physician delay in elderly patients, this latter similarity may become even more evident.

Saying that the poorer prognosis of elderly patients with Hodgkin's disease is primarily attributable to inadequate treatment does not imply, that the problem can easily be solved. Treatment for this disease can cause considerable morbidity and mortality, and these risks may outweigh possible benefits. Hematologic toxicity and intercurrent disease, possibly related to diminished organ functions, appear to occur more frequently or to be more severe in elderly patients $(4,7,10,12)$. Thus, the inability to administer full therapy may be real and may be resolved only by concentrating the treatment of these patients in centers that have adequate experience and by developing new, less-toxic treatment strategies. In particular, the application of new methods to prevent or ameliorate side effects, such as emesis, myelosuppression, neurotoxicity, and cardiotoxicity may be needed. 


\section{References}

1. Specht L, Nissen NI. Hodgkin's disease and age. Eur J Haematol 1989; 43:127-135.

2. Fuller LM, Gamble JF, Velazquez WS et al. Evaluation of the significance of prognostic factors in stage III Hodgkin's disease treated with MOPP and radiotherapy. Cancer $1980 ; 45: 1352-1364$.

3. Eghbali H, Hoemi-Simon G, Mascarel I de, Durand M, Chauvergne J, Hoerni B. Hodgkin's disease in the elderly. Cancer 1984; 53:2191-2193.

4. Burgers JMV, El Sharouni SY, Leeuwen FE van, Somers R, Hart AAM. Ziekte van Hodgkin: invloed van leeftijd op de prognose. Ned Tijdsch Geneeskd 1988; 132:13541357.

5. Wedelin C, Björkholm M, Biberfeld P, Holm G, Johansson B, Mellstedt H. Prognostic factors in Hodgkin's disease with special reference to age. Cancer 1984; 53:1202-1208.

6. Vaughan Hudson B, MacLennan KA, Easterling MJ, Jelliffe AM, Haybittle L, Vaughan Hudson $G$. The prognostic significance of age in Hodgkin's disease: Examination of 1500 patients (BNLI report no. 23). Clin Radiol 1983; 34:503-506.

7. Peterson BA, Pajak TF, Cooper MR et al. Effect of age on therapeutic response and survival in advanced Hodgkin's disease. Cancer Treat Rep 1982; 66:889-898.

8. Tirelli U. Management of malignant lymphoma in the elderly. An EORTC retrospective evaluation. Acta Oncol 1989; 28:199-201.

9. Walker A, Schoenfeld ER, Lowman T, Mettlin CJ, MacMillan J, Grufferman S. Survival of the older patient compared with the younger patient with Hodgkin's disease. Cancer 1990; 65:1635-1640.

10. Austin-Seymour MM, Hoppe RT, Cox RS, Rosenberg SA, Kaplan HS. Hodgkin's disease in patients over sixty years old. Ann Int Med 1984; 100:13-18.

11. Gobbi PG, Federico M, Di Prisco UA et al. Hodgkin's disease prognosis: A directly predictive equation. Lancet 1988; i:675-679.

12. Enblad G, Glimelius B, Sundström C. Treatment outcome in Hodgkin's disease in patients above the age of 60: A population-based study. Ann Oncol 1991; 2:297-302.

13. Bosi A, Ponticelli P, Casini $\mathrm{C}$ et al. Clinical data and therapeutic approach in elderly patienis with Hodgkin's disease. Haematologica 1989; 74:463-473.

14. Somers R, Henry-Amar M, Meerwaldt JH, Carde P. Treatment strategy on Hodgkin's disease. Proceedings of the Paris intemational workshop and symposium held on june 28-30, 1989. London-Paris: John Libbey Eurotext, 1990.

15. Erdkamp FLG, Wijthuizen ThJ, Dam FE var. De ziekte van Hodgkin; een regionaal, retrospectief onderzoek. Ned Tijdschr Geneeskd 1988; 132:1801-1806.

16. Lukes RJ, Gompel LF, Hall TC, Rappaport H, Rubin P. Report of the Nomenclature Committee. Rye classification. Cancer Res 1966; 26:1311.

17. Carbone PP, Kaplan HS, Masshoff K., Smithers DW, Tubiana M. Report of the committee of Hodgkin's disease staging. Ann Arbor Classification. Cancer 1971; 31:18601861.

18. Bishop YMM, Fienberg SE, Holland PW. Discrete multivariate analysis: Theory and practice. Cambridge, MA: MIT press, 1975.

19. Gross AJ, Clark VA. Survival distribution reliability application in the biomedical sciences. New York: Wiley and Sons, 1975. 
20. Kaplan HS. Hodgkin's disease. 2nd ed. Cambridge, MA: Harvard University Press, 1980 .

21. Lipschitz DA, Goldstein S, Reis R, Weksler ME, Bressler R, Neilan BA. Cancer in the elderly: basic science and clinical aspects. Ann Int Med 1985; 102:218-228. 

CHAPTER 4

\section{The prognostic value of mediastinal enlargement in the treatment of patients with early stage Hodgkin's disease}

A population-based study

Frans L. Erdkamp, Martin J. Houben, Wim P. Breed, Jac Th. Wijnen, Harry C. Schouten, Geert H. Blijham 


\section{Abstract}

The mediastinum is a common site of involvement in Hodgkin's disease, but conflicting results have been reported for the prognostic value of (bulky) mediastinal disease. In a retrospective population-based study of 96 patients with clinically staged I-IIIA Hodgkin's disease we investigated the prognostic impact of (bulky) mediastinal mass. In $46 \%$ of the patients mediastinal involvement was present. Complete remission rates were $95 \%$ and $94 \%$ for patients with and without mediastinal enlargement, respectively. Relapses occurred, although not statistically significant, especially more often in patients with mediastinal enlargement treated initially with radiation therapy alone. However, remission duration and survival were not adversely influenced by the presence of mediastinal disease. Analyzing, separately, the subgroup of patients with large mediastinal masses we also could not establish a significant correlation between the degree of mediastinal enlargement and remission rate, relapse-free and overall survival. In conclusion, with the limitations of a retrospective study, our data do not support the view that small versus large mediastinal disease has an impact on overall survival in patients with early stage Hodgkin's disease. Treatment decisions should therefore depend on other prognostic factors as well, particularly in the light of the observed early and late toxicities and secondary malignancies.

\section{Introduction}

A marked improvement in the overall prognosis of patients with Hodgkin's disease has been achieved during the last two decades $(1,2)$. Over the years several prognostic indicators have been identified including the size of mediastinal involvement $(1,2)$. Bulky mediastinal disease has been reported as a poor risk prognostic factor for relapse-free survival, particularly in early stage Hodgkin's disease $(3,4,5,6,7)$. In some studies in addition a negative correlation with survival could be demonstrated $(8,9)$. In the past the definition and treatment of patients with a large mediastinal mass has been variable making it difficult to formulate general recommendations $(5,8,10,11)$. Moreover the reported data are mainly derived from single institution studies and therefore they may not be representative for the unselected population of patients with Hodgkin's disease. In the early eighties several major centers have proposed intensification of therapy at initial presentation because of the inferior relapse-free survival rates in patients with bulky mediastinal disease. However, this may increase the risk of early and late toxicities as well as secondary malignancies (2). 
In order to address these problems we studied the prognostic impact of (bulky) mediastinal disease, determined in a number of ways in clinical stage I-IIIA Hodgkin's disease treated in 10 community hospitals.

\section{Patients and Methods}

Between 1972 and 1983, 182 patients with Hodgkin's disease were diagnosed in 10 community hospitals in the southeastern part of The Netherlands. From these patients a central registration system was maintained by the Comprehensive Cancer Centre South (SOOZ/IKZ). 96 patients fulfilled the entry criteria of this study being: clinical stage I-IIIA and a chest X-ray available for reviewing. All patients were studied from the date of histologic diagnosis till last follow-up or death. Median observation time was 5 years (range 3 to 14 years). In all cases the pathology was centrally reviewed and classified according to the Rye classification (12). All patients were clinically staged according to the Ann Arbor classification (13). Staging procedures such as bone marrow examination, lymphangiography and laparotomy were performed as clinically indicated; in the later years of the entry period computed tomography scanning (CT) was increasingly applied, but only from eight patients CT scans of the chest were available.

Standard postero-anterior chest radiographs from the time of diagnosis were re-examined for the presence of mediastinal involvement, the maximum mediastinal diameter with exclusion of hilar structures, chest diameter at TH5-6 and maximal chest diameter. Two methods of measuring the ratio of mediastinal mass to the thoracic transverse diameter were used. One ratio was calculated for maximal mediastinal diameter to chest diameter at TH5-6 (M1) as described by Lee et al. (9); the other method was the ratio of the maximal mediastinal mass to the chest diameter at the widest thoracic level (M2), as described by Mauch (4). For sake of uniformity and to compare our data with other studies we took generally accepted cut off points for large mediastinal mass: M1 $\geq 0.35$ or M2 $\geq 0.33(5,6)$. Patients with an abnormal mediastinum by chest radiograph but with $\mathrm{M} 1<0.35$ or $\mathrm{M} 2<0.33$ were defined as having small mediastinal mass.

Patients characteristics in relation to mediastinal pathology are shown in table 1. Radiation therapy was the single treatment modality in 50 patients, that is $30 / 52(58 \%)$ of those without and $20 / 44(45 \%)$ of those with a mediastinal mass (table 2). Patients with stages IA and IIA were treated with either mantle or inverted Y-field irradiation to a dose of $40 \mathrm{~Gy}$, while patients with stages IB and 
Table 1. Patient characteristics according to size of mediastinal mass in CS I-IIIA patients with Hodgkin's disease.

\begin{tabular}{|c|c|c|c|c|}
\hline \multirow{2}{*}{ 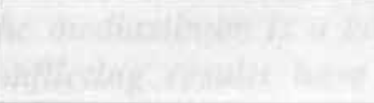 } & \multicolumn{4}{|c|}{ mediastinal mass } \\
\hline & absent & small & large* & all \\
\hline patients (n) & 52 & 29 & 15 & 96 \\
\hline mean age $(y)$ & 36 & 30 & 37 & 34 \\
\hline male & $31(60 \%)$ & $15(52 \%)$ & $7(47 \%)$ & $53(55 \%)$ \\
\hline \multicolumn{5}{|l|}{ histology } \\
\hline $\mathrm{LP}+\mathrm{NS}$ & $32(62 \%)$ & $25(86 \%)$ & $12(80 \%)$ & $69(72 \%)$ \\
\hline$M C+L D$ & $20(38 \%)$ & $4(14 \%)$ & $3(20 \%)$ & $27(28 \%)$ \\
\hline clinical stage I-II & $40(77 \%)$ & $25(86 \%)$ & $11(73 \%)$ & $76(79 \%)$ \\
\hline systemic symptoms & $4(8 \%)$ & $10(34 \%)$ & $4(27 \%)$ & $18(19 \%)$ \\
\hline siles $(n>3)$ & $4(8 \%)$ & $9(31 \%)$ & $3(20 \%)$ & $16(17 \%)$ \\
\hline
\end{tabular}

Table 2. Treatment according to size of mediastinal mass in CS I-IIIA patients with Hodgkin's disease.

\begin{tabular}{|l|c|c|c|c|}
\hline \multirow{2}{*}{} & \multicolumn{4}{|c|}{ mediastinal mass } \\
\cline { 2 - 5 } & \multicolumn{1}{|c|}{ absent } & \multicolumn{1}{|c|}{ small } & \multicolumn{1}{c|}{ large* } & all \\
\hline patients $(n)$ & 52 & 29 & 15 & 96 \\
RTX & $30(58 \%)$ & $14(48 \%)$ & $6(40 \%)$ & $50(52 \%)$ \\
CTX & $7(13 \%)$ & $4(14 \%)$ & $3(20 \%)$ & $14(15 \%)$ \\
RTX + CTX & $15(29 \%)$ & $11(38 \%)$ & $6(40 \%)$ & $32(33 \%)$ \\
\hline RTX: radiation therapy, CTX: chemotherapy : *arge mass is M1 20.35. \\
\hline
\end{tabular}

IIB were treated with more extensive field irradiation with or without chemotherapy. Patients with CS IIIA received either total nodal radiation therapy, chemotherapy, chiefly mechlorethamine, vincristine, procarbazine, prednisolone (MOPP) or combined modality.

The statistical analyses were performed with the BMDP package. The survival curves for all causes of death were plotted according to the Kaplan-Meier method. Survival curves were compared with the generalized Wilcoxon (Breslow) and generalized Savage (Mantel-Cox) methods. The Chi-Square test was used to compare tables $(14,15)$. 


\section{Results}

In 44 of 96 patients there was an abnormal mediastinum by chest radiograph $(46 \%)$. Large mediastinal mass, which was defined as $\mathrm{M} 1 \geq 0.35$ and $\mathrm{M} 2 \geq 0.33$, was noted in 15 patients $(16 \%)$ and 11 patients $(11 \%)$, respectively. Analyzing the two calculated ratio's (M1 and M2) separately no differences in relapse or survival rates were found. Therefore, patients with a mediastinal ratio (M1) $\geq 0.35$ ( $n=15$ ) were grouped together to study further their clinical course compared to patients having smaller or no mediastinal mass. Patients with mediastinal enlargement had significantly more often systemic symptoms $(\mathrm{P}=0.009)$ and a higher number of involved sites $(\mathrm{P}=0.03)$ compared to patients with no mediastinal disease (table 1). Complete remission was achieved in 91 patients $(95 \%)$. The complete remission rate for patients without mediastinal disease was $94 \%$ (49/52) compared to $95 \%(42 / 44)$ for patients with small or large mediastinal mass: in this latter group both failures were patients having a large mediastinal mass. Relapses as shown in table 3 occurred more frequently in patients with than without mediastinal enlargement, although this difference was not statistically significant, $31 \%$ and $18 \%$, respectively $(\mathrm{P}=0.3$ ). This difference was more pronounced in the group of patients treated with radiation therapy only, but was not significant $(\mathrm{P}=0.15)$. The relapse rate for the subgroup of patients with a large mediastinal mass was only $15 \%(2 / 13)$. Of the 11 patients with mediastinal involvement relapsing after radiotherapy only 4 had infield relapses, while 2 of these 4 patients also recurred outside the radiotherapy field: only one of these four patients had large mediastinal mass.

Table 3. Number of relapses of patients with complete remission in CS I-IIIA patients with Hodgkin's disease; relation with mediastinal enlargement and treatment.

\begin{tabular}{|c|c|c|c|c|}
\hline & \multicolumn{4}{|c|}{ relapses (\%) } \\
\hline & \multirow[b]{2}{*}{ absent } & \multicolumn{3}{|c|}{ medlastinal mass } \\
\hline & & small & large* & all \\
\hline RTX only & $4 / 29(14 \%)$ & $6 / 14(43 \%)$ & $1 / 6(17 \%)$ & $11 / 49(22 \%)$ \\
\hline other & $5 / 20(25 \%)$ & $5 / 15(33 \%)$ & $1 / 7(14 \%)$ & $11 / 42(26 \%)$ \\
\hline all & $9 / 49(18 \%)$ & $11 / 29(38 \%)$ & $2 / 13(15 \%)$ & $22 / 91(24 \%)$ \\
\hline
\end{tabular}




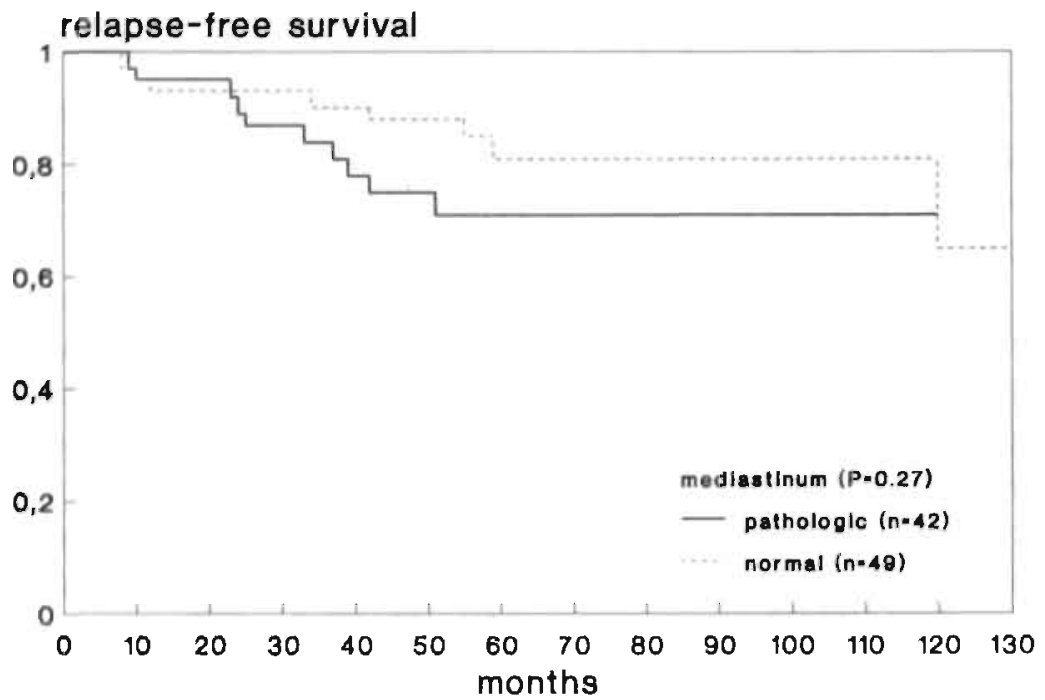

Flgure 1. Relapse-free survival according to the presence of mediastinal disease in patients with clinical stage I-IIIA Hodgkin's disease.

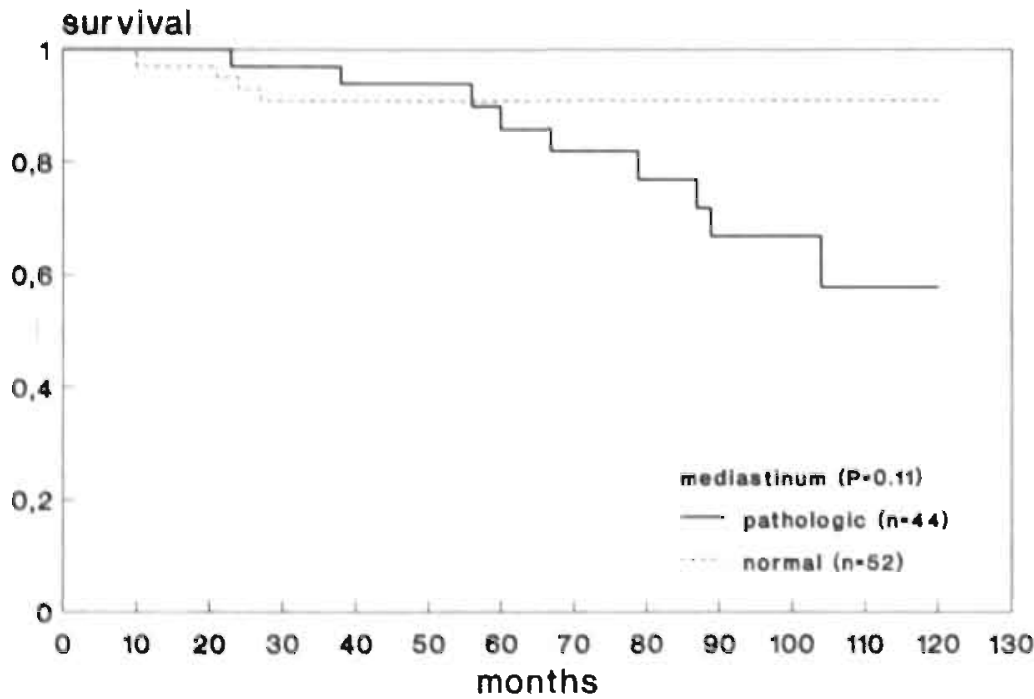

Figure 2. Survival according to the presence of mediastinal disease in patients with clinical stage I-IIIA Hodgkin's disease. 


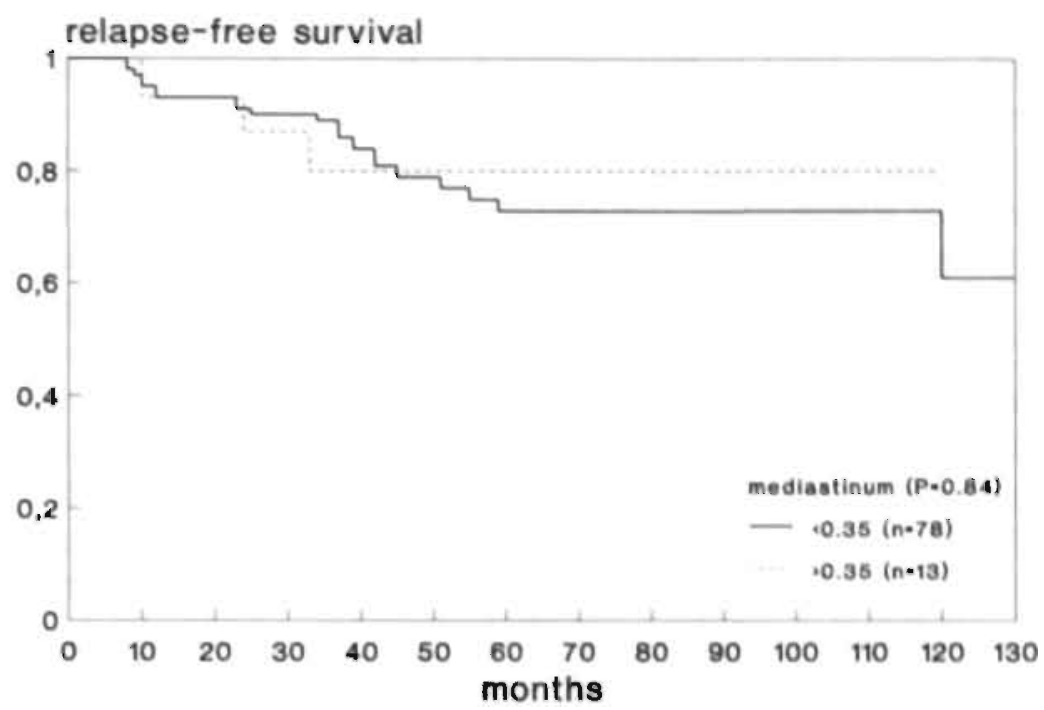

Figure 3. Relapse-free survival according to the size of mediastinal mass in patients with clinical stage I-IIIA Hodgkin's disease.

An analysis of relapse-free survival and overall survival did not show significant differences for patients with or without mediastinal involvement nor for patients with a large mediastinal mass compared to patients with small or no mediastinal enlargement (figure 1 to 4 ). However, comparing the survival data of patients with and without mediastinal involvement there was a tendency for a poorer survival for patients with mediastinal mass, that became apparent after 5 year (figure 4). After relapse effective salvage was possible in $7 / 9(78 \%)$ of patients with initially a normal mediastinum and in only $6 / 11(54 \%)$ of patients with mediastinal involvement. Although this is not significant $(\mathrm{P}=0.5)$ it might explain the difference in survival after a follow up of 5 to 10 years. Overall the ultimate failure rate in this study was $16 \%$ (15/96 died): 10 patients died from Hodgkin's disease, two from complications of treatment and three from intercurrent disease. 


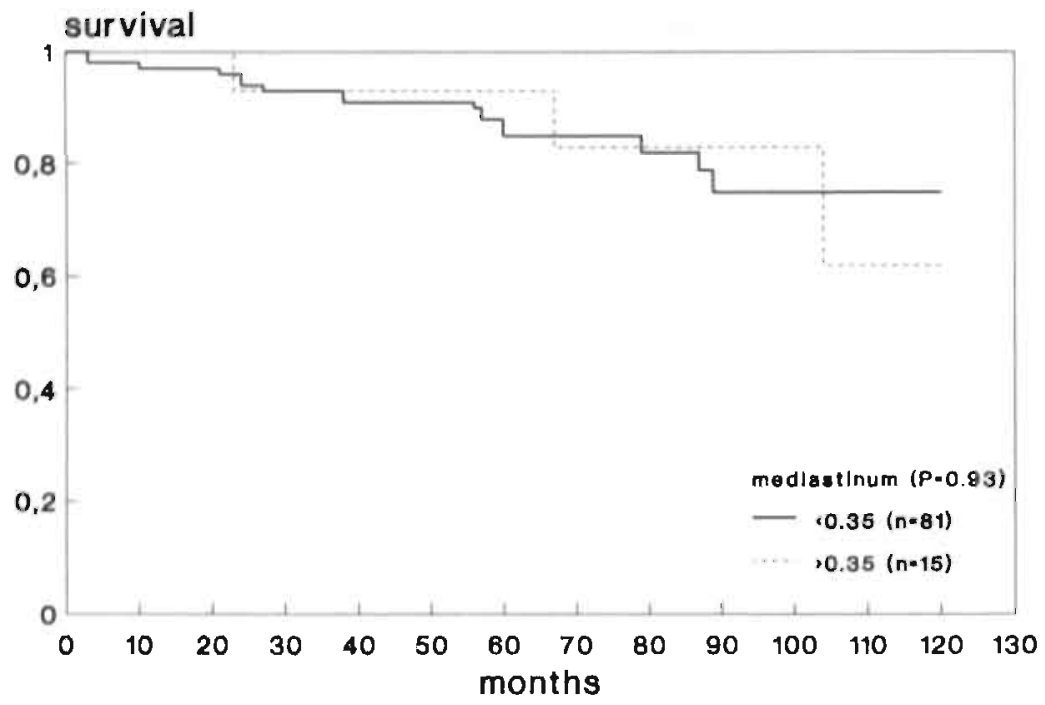

Flgure 4. Survival according to the size of mediastinal mass in patients with clinical stage I-IIIA Hodgkin's disease.

\section{Discussion}

The mediastinum is one of the most common sites of involvement in Hodgkin's disease (1). However, the prognostic importance of the presence of a small or large mediastinal mass independent from other prognostic factors remains controversial.

In this retrospective analysis in a population-based sample of 96 patients with early stage Hodgkin's disease we could not establish a significant correlation between the presence and size of mediastinal involvement and remission rate, relapse rate and survival. This overall conclusion did not change by applying alternative methods to measure the degree of mediastinal enlargement. Our results are in line with earlier reports $(11,16,17,18,19)$, in particular with results from a similar analysis performed by Ryoo et al (20) in patients with clinical stage I-IIIA Hodgkin's disease and large mediastinal masses. In contrast, in the late seventies and early eighties investigators from several centers were able to demonstrate an inverse correlation between relapse free survival and the presence of bulky mediastinal disease in early stage Hodgkin's disease (3-10); in two studies also the survival was affected $(8,9)$. 
The discrepancy between our results and earlier reports, who did find a relation between the degree of mediastinal enlargement and prognosis, can not be explained by differences in patient characteristics since these appear to be comparable between our study and those of major treatment centers in the USA and Europe (3-7). Treatment characteristics may affect results from retrospective analyses such as ours. Treatment schedules of our patient population were not uniform and treatment decisions could have been influenced by the presence of bulky mediastinal disease. In our series, only small treatment differences were observed for patients with or without mediastinal disease. It is true, however, that differences in relapse rate were observed in the group treated with radiation therapy only, although not significantly $(\mathrm{P}=0.15)$. A few centers have reported results from treatment with primary radiation therapy alone $(8,11,17)$; only the Minneapolis group reported in a small number of patients an effect on both relapse free and overall survival (8). It can not be excluded, therefore that mediastinal enlargement is a negative prognostic factor for relapse free survival in patients treated with radiation therapy alone. Since a retrospective study such as described here and in the literature may suffer from inconsistencies across the various groups particularly with regard to patient characteristics and treatment, only a prospective randomized trial of sufficient magnitude can resolve this issue in a definitive way. However, we believe that our study and data from the literature justify the conclusion that the majority of the patients with large mediastinal masses at presentation will be overtreated when combined modality therapy is given upfront as has been recommended recently for patients with bulky mediastinal disease (21).

Apart from treatment modality also the radiotherapeutical treatment technique may to a certain extent influence chance and site of relapse. Rostock and co-workers suggested that their high intrathoracic failure rate was caused by inadequate portals of irradiation (18). Lee et al reported that seven of ten extralymphatic relapses were in the lung, six of which at the margin of the mediastinal bulk (8). In this study and the work of Ryoo et al (20) in patients with mediastinal disease, treated initially by radiation therapy, only one lung recurrence was observed in seven and twenty relapses, respectively. Improved radiation therapy may obscure earlier described negative relations between mediastinal involvement and prognosis.

The survival curve of patients with mediastinal disease showed a drop after 5 years. This drop can only to a limited extent be explained by a slightly higher relapse rate. Obviously, post-relapse events were responsible and indeed the salvage rate was lower in patients with an initially enlarged mediastinum who 
relapsed. From our analysis it is apparent, that patients with mediastinal enlargement have significantly more often systemic symptoms and a higher number of involved sites. In a multivariate analysis performed by the EORTC in a population of more than 1000 patients treated between 1964 and 1982 these two factors appeared to be the only prognostic indicators for relapse (19), as was the case for total tumor burden in a recent report from the Danish Hodgkin study group (22). In our study patients with mediastinal enlargement were also slightly more often initially treated with chemotherapy (with or without radiation therapy), which may have compromised the possibility for salvage treatment. Therefore, although the drop in the survival curve after 5 years may be a real and interesting phenomena, it may well be dependent on other factors than the initially enlargement of the mediastinum.

In conclusion, our data support the view that also in the setting of community hospitals with standard levels of care mediastinal enlargement, whether small or large has no impact on overall survival. The decision whether to treat patients with Hodgkin's disease stage I to IIIA with radiation therapy or other (combined) modalities should depend on the absence or presence of other well-described factors $(19,21)$ rather than on the presence of a mediastinal mass alone. This is important to spare these patients unnecessary toxic treatments. 


\section{References}

1. Kaplan HS. Hodgkin's disease. 2nd ed. Cambridge, MA: Harvard University Press, 1980.

2. Somers R, Henry-Amar M, Meerwaldt JH, Carde P. Treatment strategy on Hodgkin's disease. Proceedings of the Paris international workshop and symposium held on june 28-30, 1989. London-Paris: John Libbey Eurotext, 1990.

3. Hoppe RT, Coleman NC, Cox RS, Rosenberg SA, Kaplan HS. The management of stage I-II Hodgkin's disease with irradiation alone or combined modality therapy: The Stanford experience. Blood 1982; 59:455-465.

4. Mauch P, Goodman R, Hellman S. The significance of mediastinal involvement in early stage Hodgkin's disease. Cancer 1978; 42:1039-1045.

5. Mauch P, Gorshein D, Cunningham J, Hellman S. Influence of mediastinal adenopathy on site and frequency of relapse in patients with Hodgkin's disease. Cancer Treat Rep 1982; 66:809-817.

6. Liew KH, Easton D, Horwich A, Barrett A, Peckham J. Bulky mediastinal Hodgkin's disease management and prognosis. Hematol Oncol 1984;2:45-59.

7. Gomez GA, Panahon AM, Stuzman L, Moayeri H, Park JJ, Barcos M et al. Large mediastinal mass in Hodgkin's disease. Results of two treatment modalities. Am J Oncol 1984; 6:65-73.

8. Lee CKK, Bloomfield CD, Goldman AI, Levitt SH. Prognostic significance of mediastinal involvement in Hodgkin's disease treated with curative radiotherapy. Cancer $1980 ; 46: 2403-2409$.

9. Anderson H, Jenkins JPR, Brigg DJ, Deakin DP, Palmer MK, Todd IDH et al. The prognostic significance of mediastinal bulk in patients with stage I-IVB Hodgkin's discase: A report from the Manchester lymphoma group. Clin Radiol 1985; 36:449.454.

10. Thar TL, Million RR, Hausner RJ, McKetty MH. Hodgkin's disease, stages I and II, relationship of recurrence to size of disease, radiation dose and number of sites involved. Cancer 1979; 43:1101-1105.

11. Fuller LM, Madoc-Jones H, Hagemeister FB, Rodgers RW, North LB, Butler JJ et al. Further follow-up of results of treatment in 90 laparotomy-negative stage I and II Hodgkin's disease patients: significance of mediastinal and non-mediastinal presentations. Int J Radiat Oncol Biol Phys 1980; 6:799-808.

12. Lukes RJ, Gompel LF, Hall TC, Rappaport H, Rubin P. Report of the nomenclature committee. Rye classification. Cancer Res 1966; 26:1311.

13. Carbone PP, Kaplan HS, Masshoff K, Smithers DW, Tubiana M. Report of the committee of Hodgkin's disease staging. Ann Arbor classification. Cancer 1971; 31:18601861 .

14. Bishop YMM, Fienberg SE, Holland PW. Discrete multivariate analysis: Theory and practice. Cambridge, MA: MIT press, 1975.

15. Gross AJ, Clark VA. Survival distribution reliability application in the biomedical sciences. New York: Wiley and Sons, 1975.

16. North LB, Fuller LM, Hagemeister FB, Rodgers RW, Butler JJ, Shullenberger CC. Importance of initial mediastinal adenopathy in Hodgkin's disease. Am J Roentg 1982; 138:229-235. 
17. Cosset JM, Henry-Amar M, Carde P, Clarke D, Le Bourgeois P, Tubiana M. The prognostic significance of large mediastinal masses in the treatment of Hodgkin's disease. The experience of the institute Gustave-Roussy. Hematol Oncol 1984; 2:33-43.

18. Rostock RA, Siegelman SS, Lenhard RE, Wharam MD, Order SE. Thoracic CT scanning for mediastinal Hodgkin's disease: Results and therapeutic implications. Int J Radiat Oncol Biol Phys. 1983; 9:1451-1457.

19. Tubiana M, Henry-Amar M, van der Werf-Messing B, Henry J, Abbatucci J, Burgers $M$ et al. A multivariate analysis of prognostic factors in early stage Hodgkin's disease. Int J Radiat Oncol Biol Phys 1985; 11:23-30.

20. Ryoo MC, Kagan AR, Wollin M, Nussbaum H, Chan PYM, Hintz BL el al. Observations on the treatment of mediastinal masses in Hodgkin's disease emphasizing site of failure. Am J Clin Oncoll 1987; 10:185-193i.

21. Longo DL. The use of chemotherapy in the treatment of Hodgkin's disease. Semin Oncol 1990; 17:716-735.

22. Specht L, Nordentoft AM, Cold S, Toffner Claussen N, Nissen NI. Tumor burden as the most important prognostic factor in early stage Hodgkin's disease. Relations to other prognostic factors and implications for choice of treatment. Cancer 1988; 61:17191727. 


\section{CHAPTER 5}

\section{The reliability and value of determining mediastinal involvement and width in Hodgkin's disease}

Frans L. Erdkamp, Martin J. Houben, Wim P. Breed, Harry C. Schouten, Frank H. Wesseling, Flip J. Jurgens, Geert H. Blijham

Eur J Radiol: In Press 


\section{Abstract}

Over the years several methods for evaluating mediastinal involvement in Hodgkin's disease have been applied to chest radiographs and conflicting results have been reported. In a retrospective study of 104 patients we evaluated interobserver variability in assessing mediastinal involvement and investigated various cut-off points for mediastinal size as to their ability to identify patients with high-and low-risk for recurrence. For mediastinal involvement the concordance rate for two reviewing radiologists was $94 \%(98 / 104)$ and compared with prior assessment by outside radiologists the concordance rates were $90 \%$ (94/104) and 88\% (92/104), respeciively. A good correlation between the reviewing radiologists was found for the quantitative evaluation of mediastinal diameter and thoracic ratios. ROC curves and relative risk figures were used to investigate the various cut-off points for mediastinal width and for the ratios of the maximal mediastinal diameter to the chest diameter at Th5-6 (M1) and to the chest diameter at the widest thoracic level (M2). Neither the $R O C$ curve analysis nor the use of relative risk figures was clearly more accurate in predicting recurrence. In conclusion, our results do not suggest that interobserver variability in mediastinal assessment, differences in the method of mediastinal measurement, or the cut-off points applied to mediastinal width can explain the discrepancies in the reported data on the prognostic value of mediastinal width in Hodgkin's disease, but rather factors such as patient selection and differences in treatment given may be responsible.

\section{Introduction}

The mediastinum is a common site of involvement in Hodgkin's disease [1]. In some studies a bulky mediastinal mass has been found to be an unfavourable prognostic factor [2-10], particularly in patients treated with radiotherapy as a single modality $[4,7,9,10]$. However, these results could not be confirmed by other investigators, even when presumably similar methods of determining mediastinal disease were applied [11-15]. Apart from other factors such as differences in treatment, the relatively small number of patients in many studies, and bias in patient selection due to differing referral protocols, these discrepancies might result from interobserver variability or other inconsistencies in assessing mediastinal enlargement. 
We therefore undertook a study to evaluate interobserver variability in evaluating mediastinal involvement. We also compared the results of several methods of determining mediastinal width and investigated the ability of various cut-off points of mediastinal size, to identify patients with a high- and low-risk of recurrence.

\section{Patients and Methods}

Between 1972 and 1983, 182 patients with Hodgkin's disease were diagnosed in 10 community hospitals in the southeastern part of The Netherlands. From these patients a central registration system was maintained by a Comprehensive Cancer Center (SOOZ/IKZ). Chest radiographs and reports on mediastinal disease from the participating centers were available for 104 patients with Hodgkin's disease. The clinical data were studied from the date of histologic diagnosis until last follow-up or death. Median observation time was 5 years (range 3 to 14 years). In all cases the histology was reviewed and classified according to the Rye classification [16]. All patients were clinically staged according to the Ann Arbor classification [17]. Patients with stages IA and IIA disease usually received mantle or inverted Y-field radiation to a total dose of $40 \mathrm{~Gy}$, whereas patients with stages IB, IIB, and IIIA disease usually received subtotal or total lymphoid exposure to radiation with or without chemotherapy. Most patients with stage IIIB and IV disease received combined modality treatment.

Standard postero-anterior chest radiographs taken at the time of diagnosis were independently reviewed by two radiologists (A and $\mathrm{B}$ ). The radiologists assessed films for the presence of mediastinal disease and measured the maximum mediastinal diameter (hilar structures excluded), chest diameter at TH5-6, and maximal chest diameter. A ratio of the maximal mediastinal diameter to chest diameter at TH5-6 (M1) was calculated as described by Lee et al [7]; the ratio of the maximal mediastinal mass to the chest diameter at the widest thoracic level (M2) was also determinied [3].

Concordance rates were calculated between the two centrally reviewing radiologists as well as between the reviewing radiologists and the external radiologists who initially read the films. Correlation coefficients were determined to compare the quantitative measurements of the mediastinal and thoracic diameters of both reviewing radiologists [18]. Finally, we investigated whether one specific cut-off point for mediastinal width and M1 or M2 ratio predicted 
relapse. To this end $2 \times 2$ tables were constructed for various cut-off points with the test result (positive or negative) displayed in relation to the outcome (yes (recurrent disease) or no (no recurrent disease). From these tables ROC curves [19] were drawn indicating the relation between sensitivity and specificity for mediastinal widths between 5 and $14 \mathrm{~cm}$, an M1 ratio from 0.2 to 0.4 , and an $\mathrm{M} 2$ ratio from 0.18 to 0.36 . Also the relative risk [20] of recurrence, defined as the ratio of the risk of recurrence in patients with mediastinal enlargement to the risk of recurrence in test negative patients, was calculated in relation to various cut-off points.

\section{Results}

As shown in table 1 , in $46 / 104(44 \%)$ of the patients the mediastinum was judged pathologic by both reviewing radiologists for a concordance rate of $94 \%$ $(98 / 104)$. The outside radiologists found an abnormal mediastinum in 44 out of 104 cases $(42 \%)$ and a suspicious mediastinum in 2 . The concordance rate for the outside radiologists with radiologist A was $94 / 104$ (90\%) and with radiologist B 92/104 (88\%). These differences occurred chiefly because the reviewing radiologists more frequently found a pathologic mediastinum.

Table 1. The relation between, two reviewing radiologists in judging the appearance of the mediastinum in patients with Hodgkin's disease.

\begin{tabular}{|l|l|c|c|c|c|}
\hline & & \multicolumn{4}{|c|}{ radiologist B } \\
\cline { 3 - 6 } & mediastinum & normal & pathologic & doubtful & total \\
\hline radiologist A A & normal & 52 & 3 & 0 & 55 \\
& pathologic & 1 & 46 & 0 & 47 \\
& doubtful & 2 & 0 & 0 & 2 \\
& total & 55 & 49 & 0 & 104 \\
\hline
\end{tabular}

Mediastinal and thoracic diameters were measured by both reviewing radiologists. There was a good correlation between the two radiologists for each diameter: a correlation coefficient of 0.94 for the mediastinal width as well as for the M1 and M2 ratios (figures not shown). Therefore, the interobserver variability for quantitative evaluation of mediastinal disease also appears to be low. The concordance between the two calculated ratios was determined using 


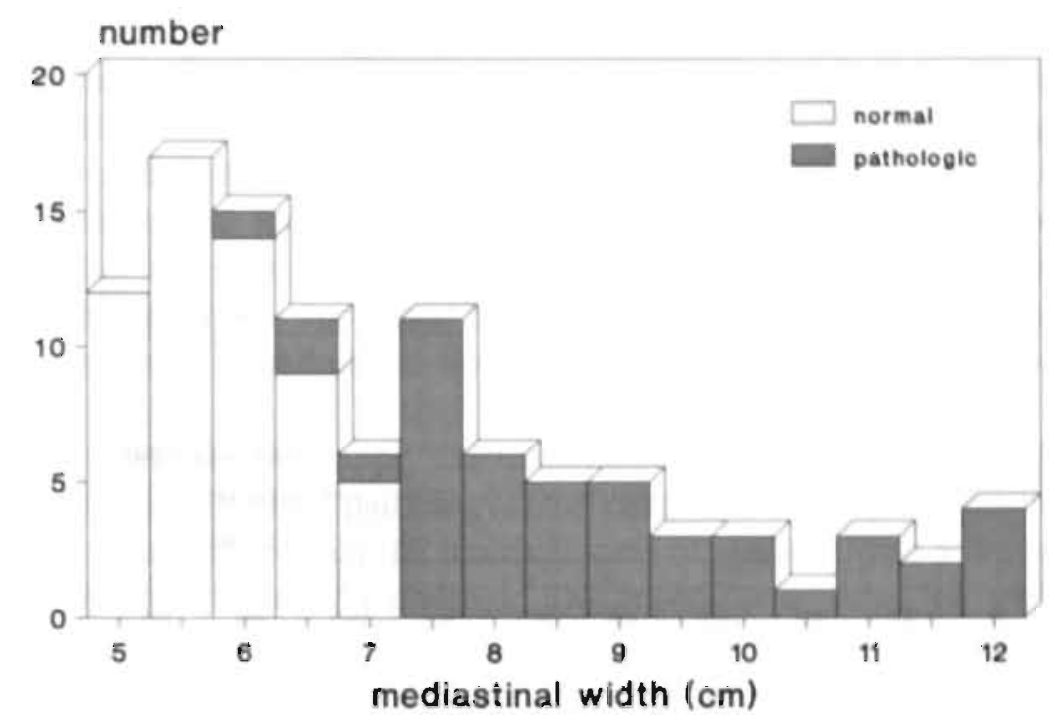

Figure 1. Radiologic assessment of the mediastinum at various mediastinal widths.

cut-off points to define bulk disease: for $\mathrm{M} 1 \geq 0.35$ and for $\mathrm{M} 2 \geq 0.33$. In eight of the 104 patients $(8 \%)$ the mediastinal mass was classified as bulky $(\geq 0.35$ or $\geq 0.33$ ) according to only one of both ratios.

To establish whether there was a difference between the qualitative and quantitative evaluations of mediastinal involvement we analyzed the relation between the radiological evaluation of the mediastinum (pathologic or not) and the measurement of the mediastinal width or the calculated ratios M1 and M2. A width of $7.5 \mathrm{~cm}$ or greater was always judged as pathologic; measurements of 6 $\mathrm{cm}$ or less were judged benign (figure 1). Radiographically mediastinal pathology is apparently most often associated with an increased mediastinal width and no additional information from the ratios $\mathrm{M} 1$ or $\mathrm{M} 2$ was obtained using a cut-off point of $7.5 \mathrm{~cm}$ for the mediastinal width.

The predictive values of the presence of mediastinal pathology, the M1 ratio, $(\geq 0.35)$ or the M2 ratio ( $\geq 0.33)$ for recurrence of Hodgkin's disease were $31 \%$, $23 \%$ and $27 \%$, respectively: this was not clearly different from the incidence of recurrence in the population as a whole $(28 \%)$. We therefore investigated various cut-off points in mediastinal width, M1, or M2 ratio for a better prediction of recurrence. This was done by constructing ROC-curves compar- 


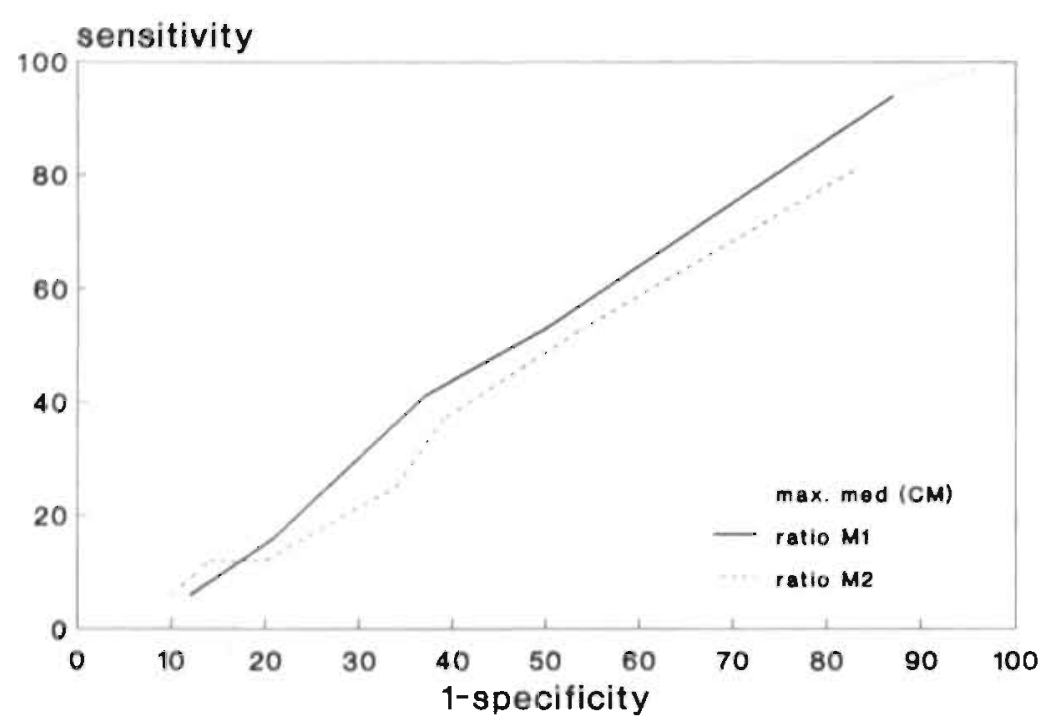

Figure 2. ROC curves indicating the relation between the probability for relapse and the mediastinal width, the ratio $\mathrm{M} 1$ and the ratio $\mathrm{M} 2$.

ing sensitivity and specificity for the different cut-off points and by calculating relative risks for those cut-off points. The ROC-curves for all three estimations of mediastinal involvement did not show a cut-off point clearly deviating from the diagonal line, indicating a lack of diagnostic value at all cut-off points (figure 2). This finding was substantiated by the calculation of relative risks ranging from 0.48 to 1.4 without any specific cut-off point standing out as defining a population with a clearly different risk of recurrence.

Since these data might be influenced by the stage of the disease and/or treatment with chemotherapy these analyses were repeated for the group of patients with clinical stage 1-IIIA treated initially with radiotherapy alone. Again the ROCcurve showed no clearly superior method of measurement or any specific cut-off point for determining mediastinal width. As a whole the relative risk for relapse was higher ( $R R$ varied from 1.5 to 3 ) for patients with a larger mediastinum, but the cut-off points did not appear crucial in obtaining this result. 


\section{Discussion}

In the present study re-examination of the chest radiographs of patients with Hodgkin's disease revealed only slight differences between the reviewing radiologists in judging the appearance of the mediastinum. The discordance rate with the institutional radiologists was about $11 \%$. A reasonable explanation would be that the new radiologists were examining the chest films more critically. This view was supported by the fact that disagreement generally led to a greater number of pathologic mediastinums.

Current clinical trials often apply calculated mediastinal diameters as a method of quantitating mediastinal pathology. Our comparison of the qualitative and quantitative data showed that the mediastinums of patients with a diameter of $\geq 7.5 \mathrm{~cm}$ were always judged pathologic. Discrepancies between the qualitative and quantitative judgments only occurred in the few patients with mediastinal widths of 6 to $7.5 \mathrm{~cm}$. We conclude that the absolute width of the mediastinum may be used as a practical measure of mediastinal disease. In current practice the clinical staging of patients with Hodgkin's disease often includes computed tomography scanning of the chest. Compared to conventional chest radiographs, this technique is more sensitive for the detection of mediastinal involvement and for measuring tumor volume at this site. However, the prognostic impact of the information acquired has not yet been established.

Investigators have suggested that the problem of mass size versus patient size can be resolved by using a ratio of the mediastinal mass to an intrathoracic diameter. We investigated the usefulness of this approach in two ways. First, it appeared that the $\mathrm{M} 1$ and $\mathrm{M} 2$ ratio did not appreciably change the information already obtained from qualitative judgments or measurement of the mediastinal width. If the cut-off points investigated in the Manchester group [8] for the M2 ratio and by Lee et al. [7] for the M1 ratio were applied, no patients with a mediastinal width below $7.5 \mathrm{~cm}$ and/or a qualitatively normal mediastinum had bulk mediastinal disease by one of these ratios ( $\mathrm{M} 1 \geq 0.35$ or $\mathrm{M} 2 \geq 0.33$ ). Second, the ratios were no better than mediastinal width in predicting recurrence. These results are in contrast to those described by the Manchester study group, although the data by which they identified the M2 ratio as the best predictor of remission duration were not given in their report [8]. Lee and coworkers, though reporting the Ml ratio of 0.35 to be the best cut-off point for prognostic discrimination, did not perform a comparison with other methods [7]. In addition, in our analysis using predefined cut-off points (M1 $\geq 0.35$ or M2 $\geq 0.33$ ), in $8 \%$ of the patients bulky mediastinal disease was determined by one 
ratio but only non-bulky mediastinal disease by the other ratio. From our data, therefore, neither the M1 nor the M2 ratio provides important information not already available from the measurement of mediastinal width.

In conclusion, our results do not suggest that interobserver variability or differences in cut-off points can explain the discrepancies between the various studies on the prognostic impact of mediastinal enlargement in Hodgkin's disease, but rather factors such as patient selection and differences in treatment given may be responsible. 


\section{References}

1. Kaplan HS. In: Hodgkin's disease. Cambridge MA: Harvard University Press, 1980.

2. Hoppe RT, Coleman NC, Cox RS, Rosenberg SA, Kaplan HS. The management of stage I-II Hodgkin's disease with irradiation alone or combined modality therapy: The Stanford experience. Blood 1982; 59:455-465.

3. Mauch P, Goodman R, Hellman S. The significance of mediastinal involvement in early stage Hodgkin's disease. Cancer 1978; 42:1039-1045.

4. Mauch P, Gorshein D, Cunningham J, Hellman S. Influence of mediastinal adenopathy on site and frequency of relapse in patients with Hodgkin's disease. Cancer Treat Rep 1982; 66:809-817.

5. Liew KH, Easton D, Horwich A, Barrett A, Peckham MJ. Bulky mediastinal Hodgkin's disease management and prognosis. Hematol Oncol 1984; 2:45-59.

6. Gomez GA, Panahon AM, Stuzman L, Moayeri H, Park JJ, Barcos M, Kim U, Han T, Henderson ES. Large mediastinal mass in Hodgkin's disease. Results of two treatment modalities. Am J Oncol 1984; 6:65-73.

7. Lee CKK, Bloomfield CD, Goldman AI, Levitt SH. Prognostic significance of mediastinal involvement in Hodgkin's disease treated with curative radiotherapy. Cancer 1980; 46:2403-2409.

8. Anderson H, Jenkins JPR, Brigg DJ, Deakin DP, Palmer MK, Todd IDH, Crowther D. The prognostic significance of mediastinal bulk in patients with stage I-IVB Hodgkin's disease: A report from the Manchester lymphoma group. Clin Radiol 1985; 36:449-454.

9. Thar TL, Million RR, Hausner RJ, McKetty MH. Hodgkin's disease, stages I and II, relationship of recurrence to size of disease, radiation dose and number of sites involved. Cancer 1979; 43:1101-1105.

10. Fuller LM, Madoc-Jones H, Hagemeister FB, Rodgers RW, North LB, Butler JJ, Martin RG, Gamble JF, Schullenberger CC. Further follow-up of results of treatment in 90 laparotomy-negative stage I and II Hodgkin's disease patients: significance of mediastinal and non-mediastinal presentations. Int J Radiat Oncol Biol Phys 1980; 6:799-808.

11. North LB, Fuller LM, Hagemeister FB, Rodgers RW, Butler JJ, Shullenberger CC. Importance of initial mediastinal adenopathy in Hodgkin's disease. AJR 1982; I 38:229-235.

12. Cosset JM, Henry-Amar M, Carde P, Clarke D, Le Bourgeois P. Tubiana M. The prognostic significance of large mediastinal masses in the treatment of Hodgkin's disease. The experience of the institute Gustave-Roussy. Hematol Oncol 1984; 2:33-43.

13. Rostock RA, Siegelman SS, Lenhard RE, Wharam MD, Order SE. Thoracic CT scanning for mediastinal Hodgkin's disease: Results and therapeutic impiications. Int J Radiat Oncol Biol Phys 1983; 9:1451-1457.

14. Tubiana M, Henry-Amar M, van der Werf-Messing B, Henry J, Abbatucci J, Burgers M, Hayat M, Somers R, Laugier A, Carde P. A multivariate analysis of prognostic factors in early stage Hodgkin's disease. Int J Radiat Oncol Biol Phys 1985; 11:23-30.

15. Ryoo MC, Kagan AR, Wollin M, Nussbaum H, Chan PYM, Hintz BL, Rao AR, McMahon J. Observations on the treatment of mediastinal masses in Hodgkin's disease emphasizing site of failure. Am J Clin Oncol 1987; 10:185-193.

16. Lukes RJ, Gompel LF, Hall TC, Rappaport H, Rubin P. Report of the nomenclature committee. Rye classification. Cancer Res 1966; 26:1311. 
17. Carbone PP, Kaplan HS, Masshoff K, Smithers DW, Tubiana M. Report of the committee of Hodgkin's disease staging. Ann Arbor classification. Cancer 1971; 31:18601861.

18. Colton T. Regression and correlation. In: Statistics in medicine. Boston: Little, Brown and company, 1974; 189-217.

19. Metz CE. Basic principles of ROC analysis. Semin Nucl Med 1978; 8:283-298.

20. Levine MN, Browman GP, Gent M, Roberts R, Goodyear M. When is a prognostic factor useful?: a guide for the perplexed. J Clin Oncol 1991; 9:348-356. 


\section{CHAPTER 6}

\section{DNA aneuploidy in Hodgkin's disease}

A multiparameter flow cytometric analysis

Frans L. Erdkamp, Harry C. Schouten, Wim P. Breed, Willy C. Janssen, Johannes J. Hoffmann, Bert Schutte, Geert H. Blijham

Submitted 


\section{Abstract}

Paraffin-embedded lymph nodes from patients with Hodgkin's disease were examined for flow cytometric DNA content. In order to increase the sensitivity of the assay we tried to enrich for the neoplastic cells by bivariate analysis using a polyclonal anti-nucleolar antibody $(A N-A B)$ and the forward scatter (FSC). DNA aneuploidy was found to be present in 67 of all 137 cases (49\%), in 24 cases only demonstrable by dual-parameter analysis. The DNA index varied from 0.69 to 1.89 with a total of 22 hypo-diploid cases. The number of aneuploid nuclei exceeded the expected frequency of Reed-Sternberg (RS) and Hodgkin $(H)$ cells in most of the analyzed specimens. In conclusion, flow cytometry in Hodgkin's disease appears to give useful information regarding the ploidy status and evidence has been provided that the malignant cell population in Hodgkin's disease is not limited to the classical RSiH cells.

\section{Introduction}

The introduction of flow cytometry in cancer research and the development of new methods to extract nuclei from paraffin-embedded tissue $(1,2)$ have enabled a large number of studies in this field. DNA aneuploidy has been found a common feature in solid tumors and to a lesser extent in non-Hodgkin's lymphoma (3-8). So far, limited data have become available in Hodgkin's disease (9-14) and from these data it appears that the number of aneuploid cases is low $(<20 \%)$ compared with the frequency found in other malignancies $(40-80 \%)(3-$ 6,15 ). A considerable problem with studies of this nature in Hodgkin's disease is the paucity of the presumed malignant Reed-Sternberg (RS) cell or its mononuclear variant the Hodgkin $(\mathrm{H})$ cell within tissues of patients with Hodgkin's disease. The majority of cells in these lymph nodes are considered to be reactive lymphocytes, histiocytes, eosinophils and plasma cells, whereas the RS/H cells generally account for less than $3 \%$ of the total cell population $(9,16)$. The use of methods to select more specific for malignant cells of the RS/H type would possibly increase the number of cases with an altered DNA content. In other tumors antibodies against phenotypic properties or cell size have proven to be useful in this respect $(3,7,8,17-19)$.

In the present study we investigated the frequency of DNA aneuploidy in Hodgkin's disease. In order to increase the sensitivity of the assay we tried to enrich for RS/H nuclei by applying a polyclonal goat anti-nucleolar antibody $(\mathrm{AN}-\mathrm{AB})$ and by selecting on nuclear size. Multiparameter flow cytometric 
analysis was applied to a large series of lymph node material from Hodgkin's disease patients with the full spectrum of stages, histologies and clinical characteristics that can be encountered in this heterogeneous disease.

\section{Materials and Methods}

Paraffin-embedded lymph node tissues from 142 previously untreated patients with Hodgkin's disease were obtained from the pathology departments of 10 community hospitals in the south-eastern part of The Netherlands. In all cases the histologic slides were centrally reviewed and classified according to the Rye classification (20). Specimens from 15 histologically reviewed "benign" lymph nodes served as controls.

Paraffin-embedded tissue was deparaffinized using a modification of the method described by Hedley et al and Schutte et al $(1,2)$. Sections of $50 \mu \mathrm{m}$ were cut from paraffin-embedded blocks using a standard microtome. Adjacent $5 \mu \mathrm{m}$ slides were used for histologic review. The thick sections were placed in glass tubes and dewaxed with xylene and rehydrated in a stepwise fashion with decreasing concentrations of aqueous ethanol (100\%-96\%-70\%-50\%). Finally, the tissue was washed twice in distilled water and transferred to a plastic tube. The tissue specimen was digested with pepsin $0.5 \%(\mathrm{pH} 1.5)$ in a water bath at $37^{\circ} \mathrm{C}$ for 1 hour with intermittent vortex mixing every 10 minutes. The nuclear suspension obtained was filtered through a $50 \mu \mathrm{m}$ nylon mesh, and was washed twice and finally resuspended in $2 \mathrm{ml}$ phosphate-buffered saline (PBS), containing $0.1 \%$ triton $\mathrm{X}-100$. Nuclei counts were made using a Bürker counting chamber and expressed as nuclei per gram of wet tissue. The resulting nuclei were stained with a polyclonal goat AN-AB, kindly supplied by Dr Robert S Greenfield (Bristol-Myers, Wallingford, CT, USA), using a modification of the method previously described (9). This anti-nucleolar antiserum has been raised against human tumor cell lines and reacted strongly with 100,94 and $38 \mathrm{kDa}$ nucleolar proteins (21). A $50 \mu \mathrm{l}$ nuclear suspension was incubated for 45 minutes at $0^{\circ} \mathrm{C}$ using a 1:50 dilution of the $\mathrm{AN}-\mathrm{AB}$. Afterwards the mixture was washed twice in Triton X-100 (0.1\% in PBS) and the solution was resuspended in $50 \mu \mathrm{l}$ 1:50 diluted fluorescein isothiocyanate conjugated swine anti-goat antibody (Caltag, San Francisco, CA, USA). After incubation for 30 minutes in melting ice, the solution was washed two times and incubated for 15 minutes at room temperature with $500 \mu \mathrm{l}$ of $0.1 \%$ RNase and then stained with $500 \mu \mathrm{l}$ ice-cold solution of Propidium Iodide $(415 \mu \mathrm{g} / \mathrm{ml}$ in PBS) for 15 minutes. Then the suspension was filtered again and flow cytometric analysis was performed 
within 3 hours. Two parameter fluorescence and volume analysis was done on the isolated nuclei using a FACScan analyzer (Becton-Dickinson, Sunnyville, CA, USA), equipped with an Argon-ion laser (excitation wavelength 488nm). In each sample 65000 nuclei were counted. DNA histograms were made using the CellFit software package (Becton-Dickinson).

In all samples the coefficient of variation (CV) of the G0/G1 peak was estimated by determining the peak width at the inflection point $(60 \%$ of peak height). Samples were considered to be aneuploid if more than one G0/G1 peak was identified. Samples with shouldering in the G0/G1 peak without two separate peaks were classified as diploid (22). Multiploidy was defined as more than two separate G0/G1 peaks. The first peak is considered by definition to be the diploid one (22). However, if a left-sided notch in the first peak of the DNA histogram was upgraded into a separately identifiable peak, using the $\mathrm{AN}-\mathrm{AB}$ or the forward scatter (FSC), the upgraded peak was considered to reflect the aneuploid population and the down graded peak the diploid population. The DNA index (DI) was calculated by dividing the modal channel number of the aneuploid peak by that of the diploid peak in the DNA histogram. An aneuploid fraction (AF) was estimated by the percentage of nuclei from the aneuploid peak in relation to those from both $\mathrm{G} 0 / \mathrm{G} 1$ peaks. In order not to overestimate the number of nuclei from the aneuploid GO/GI peak the calculation was made after subtracting an estimate of the overlap with the diploid G0/G1 peak. Correlation coefficients were determined to compare the relationships between variables (23).

\section{Results}

In 137 cases sufficient nuclei for fiow cytometric analysis were obtained with an average of $5.4 \times 10^{8}$ nuclei per gram of wet tissue (range $0.1-30.1$ ). The recovery of the remaining five specimens was less than $0.1 \times 10^{8}$ nuclei and no appropriate histograms could be obtained. The inadequate deparaffinisation and dissociation of these five cases could not be attributed to a specific histologic subtype or grade of sclerosis. The presence of diploidy or aneuploidy appeared not to be correlated with the number of nuclei obtained nor with one of the histologic subtypes. Fifteen samples from aneuploid and diploid cases each, were restained and analyzed again and in all specimens the results from the prior analysis were confirmed. The $\mathrm{CV}$ of the diploid $\mathrm{G} 0 / \mathrm{Gl}$ peaks varied from 2.0 to $9.4 \%$ (median $4.8 \%$ ). In seven samples with a CV exceeding $8 \%$, reanalysis again revealed one single peak with a $\mathrm{CV}>8 \%$. In none of the $\mathrm{G} 0 / \mathrm{Gl}$ 
peaks with a $\mathrm{CV}<4 \%$ ( 23 cases) we were able to detect a distinct, separate other peak applying selection on size or the $\mathrm{AN}-\mathrm{AB}$. Therefore only the samples with a $\mathrm{CV}>4 \%$ or a shouldering i.e. an asymmetric G0/G1 peak were re-analyzed by simultaneously measuring nucleolar fluorescence intensity or FSC and DNA content. In deparaffinized specimens from 15 control cases no aneuploid population could be detected, even not after selecting on the more bright fluorescent or larger nuclei.

In the single parameter analysis DNA aneuploidy was clearly present in $31 \%$ (43/137) of the samples; examples are given in figures 1 and 2 . In addition, with multiparameter analysis another 21 cases with an altered DNA content could be detected: 16 cases (12\%) due to selection of brightly fluorescent nuclei ( $\mathrm{AN}-\mathrm{AB}$ staining) and 5 (4\%) after selecting large nuclei (FSC); for examples see figures 3 and 4 . In three specimens DNA aneuploidy was found using the $\mathrm{AN}-\mathrm{AB}$ as well as the FSC. Nine samples were multiploid: four were already evident in the single parameter analysis and an additional five became apparent after addition of the AN-AB (table 1). Taken together, in the samples of 67 patients 76 DNA stemlines were observed with a DNA index varying from 0.69 to 1.89 and a distribution as shown in figure 5. The majority of cases had a DNA index

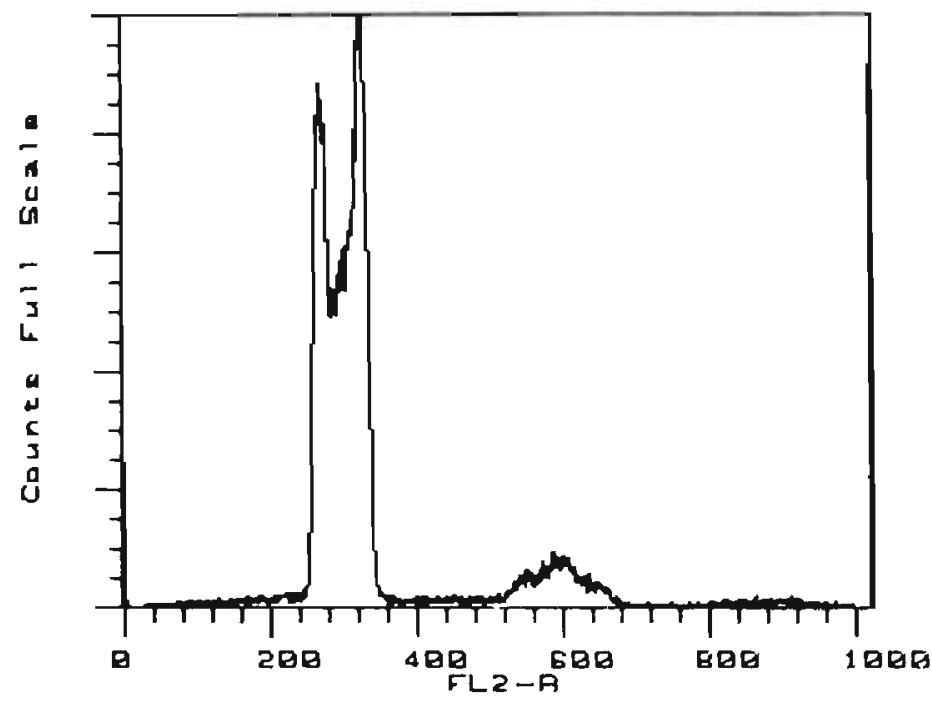

Figure 1. Single parameter DNA histogram showing two GO/G1 peaks (diploid and aneuploid) with a DNA index of 1.21. (FL2: DNA staining). 

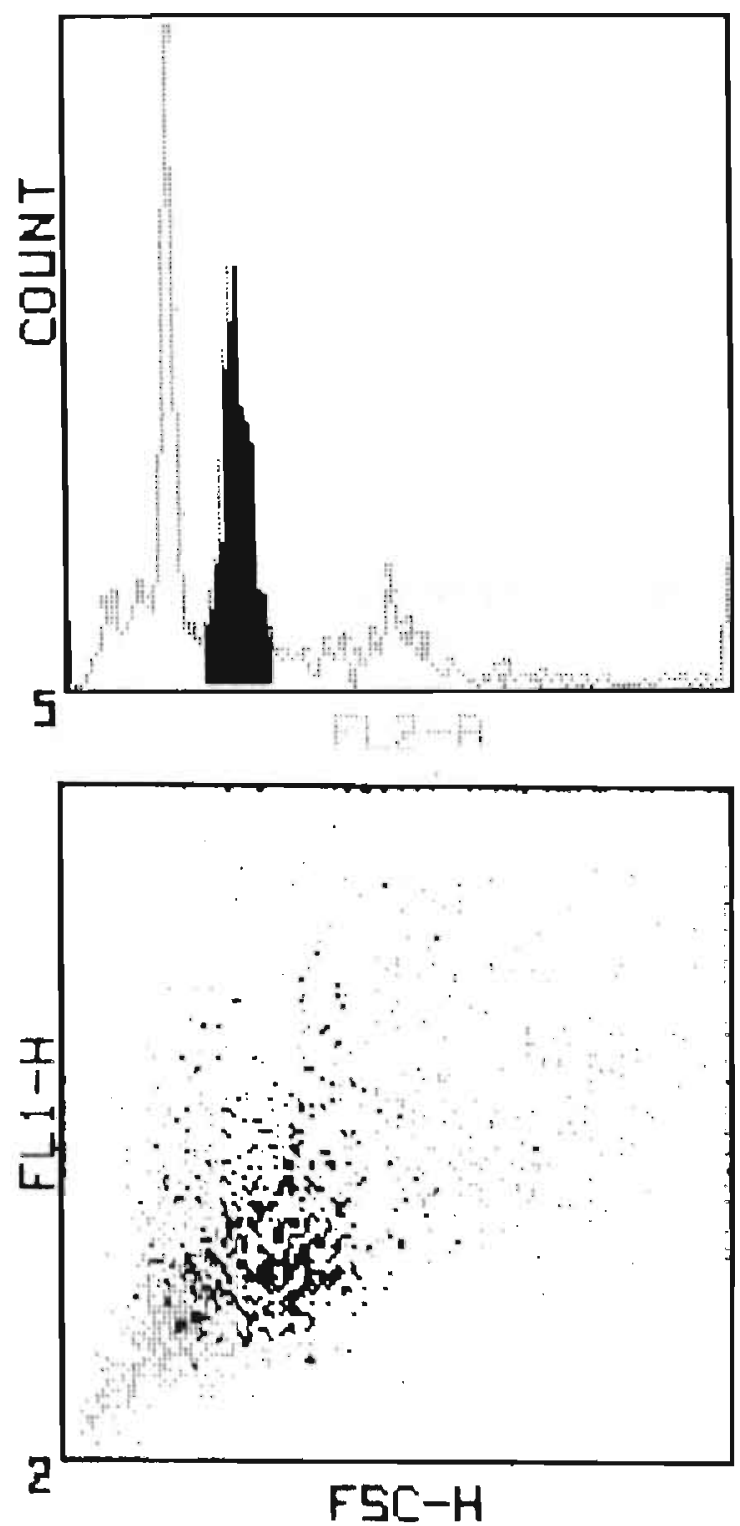

Figure 2. A: Single parameter DNA histogram showing two $\mathrm{GO} / \mathrm{G} 1$ peaks with a DNA index of 1.63. (FL2: DNA. staining).

B: The corresponding dot plot shows that mainly the larger and bright fluorescent nuclei (black dots) are represented in the second (aneuploid) Go/G1 peak (black peak figure 2A). ( $F L 1$ : $A N-A B$ staining, $F S C$ : nuclear size). 

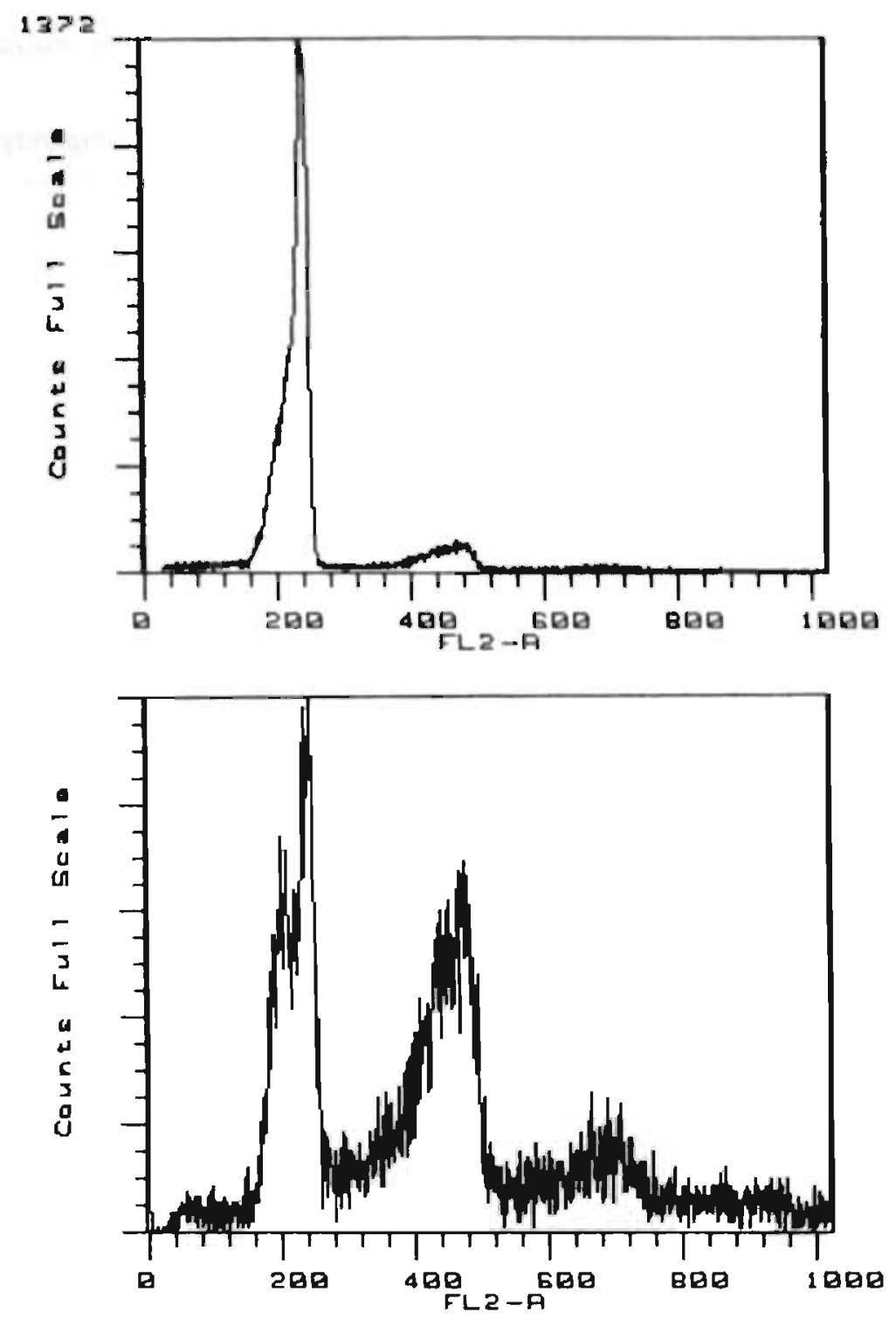

Figure 3. A: Single parameter DNA histogram with a left-sided notch in the Go/G1 peak and the G2/M peak. (FL2: DNA staining).

B: DNA histogram selecting on the bright fluorescent nuclei demonstrating two separately identifiable Go/G1 and G2/M peaks. (FL2: DNA staining). 
Table 1. The number of aneuploid cases by single and dual parameter analysis in 137 patients with Hodgkin's disease.

\begin{tabular}{|l|c|c|}
\hline & aneuploidy & multiploidy \\
\hline $\begin{array}{l}\text { single parameter DNA FCM } \\
\text { dual parameter DNA FCM }\end{array}$ & $43 / 137(31 \%)$ & $4 / 137(3 \%)$ \\
with the AN-AB only & $16 / 137(12 \%)$ & $5 / 137(4 \%)$ \\
with the FSC only & $5 / 137(4 \%)$ & \\
with AN-AB and FSC & $3 / 137(2 \%)$ & $9 / 137(7 \%)$ \\
total & $67 / 137(49 \%)$ & \\
\hline FCM; flowcytometry, AN-AB; antinucleolar antibody, FSC; forward scatter. \\
\hline
\end{tabular}
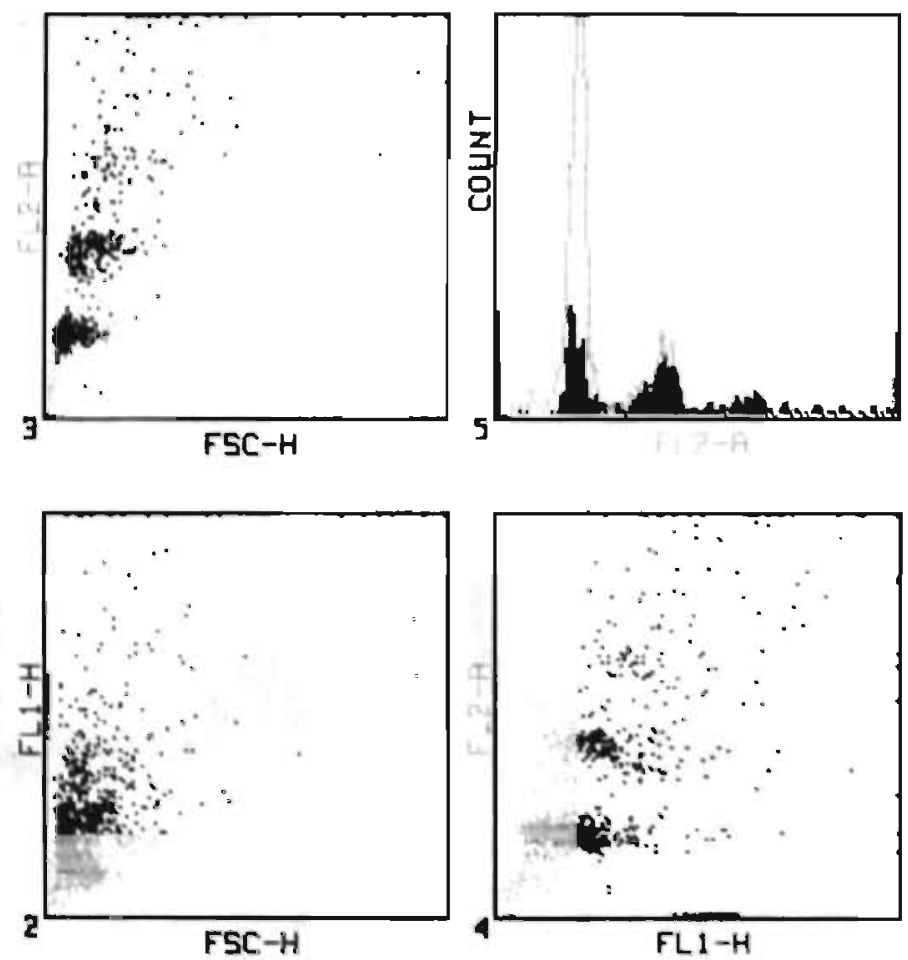

Figure 4. DNA histograms with corresponding dot plots. The suggestion of a near-tetraploid population is raised by the single parameter (grey and black dots) analysis (grey DNA histogram), but after selecting on the bright fluorescent nuclei (black dots) two separate $\mathrm{GO} / \mathrm{G} 1$ peaks and corresponding $\mathrm{G} 2 / \mathrm{M}$ peaks are found (black DNA histogram). The dot plots indicate that the bright fluorescent nuclei (black dots) show only slight differences in size. (FL1: AN-AB staining, FL2: DNA staining, FSC: nuclear size). 


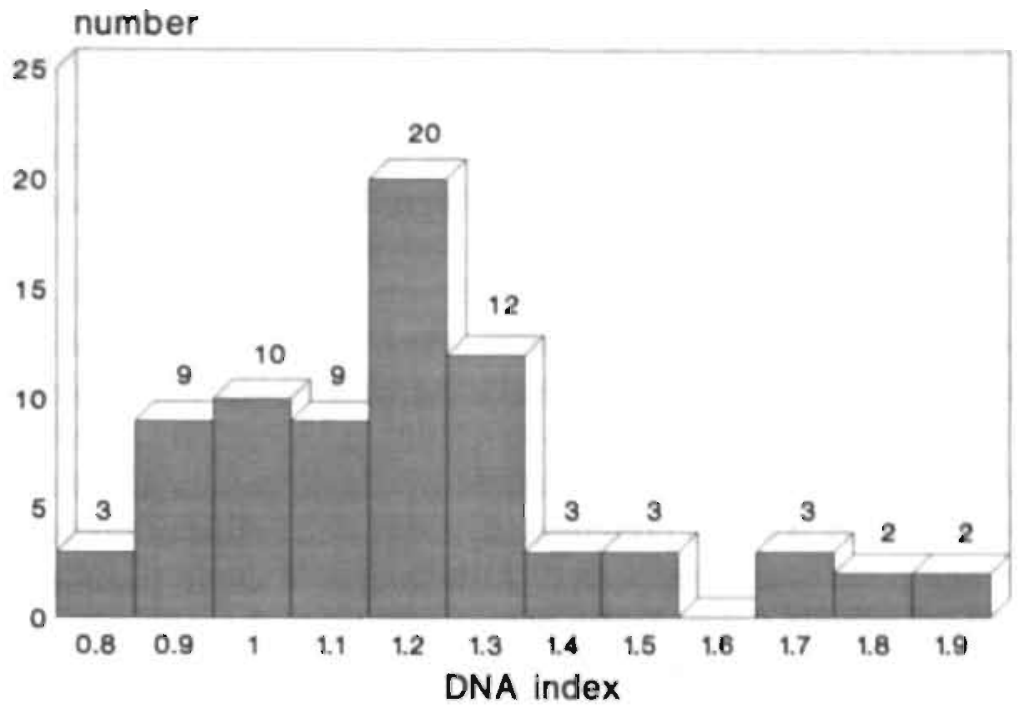

Figure 5. The distribution of the DNA index representing 76 stemlines from 67 aneuploid cases with Hodgkin's disease.

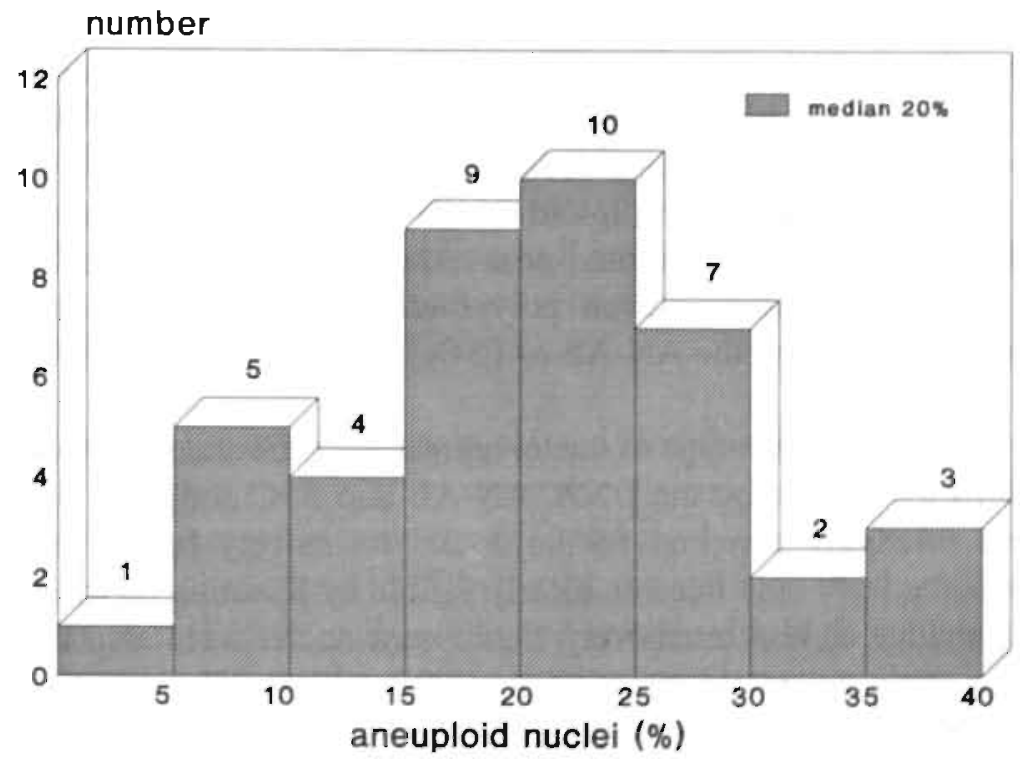

Figure 6. The distribution of the aneuploid fraction in $\mathbf{4 1}$ aneuploid cases with Hodgkin's disease. 
between 0.8 and 1.2 and 22 of 67 patients with aneuploidy had hypo-diploid stemlines. A reliable estimation of the aneuploid fraction was possible in 41 of 67 cases $(61 \%)$. In $85 \%$ of these cases the frequency of aneuploid nuclei exceeded $10 \%$ (figure 6 ). There existed no significant correlation between the aneuploid fraction and the DNA index.

By analyzing in more detail the DNA histograms and the corresponding DNA, $\mathrm{AN}-\mathrm{AB}$ and $\mathrm{FSC}$ scatter dot plots several interesting issues were encountered.

First, in 36 of 43 samples found aneuploid by single parameter analysis, the staining with the $\mathrm{AN}-\mathrm{AB}$ was preferentially expressed in one of the two peaks: in 9 cases one peak even disappeared. Also in case a single parameter DNA histogram (for example figure 3 ) showed one (diploid) population with a small left- or right-sided notch in the G0/G1 peak this G(0/G1 peak was split in two separate ones with a relative increase in the frequency of nuclei in the originally notch area, after the application of the $\mathrm{AN}-\mathrm{AB}$. Therefore, the $\mathrm{AN}-\mathrm{AB}$ seems almost always to stain preferentially one, often smaller population of nuclei. In view of the morphologic characteristics of the presumed neoplastic RS/H cells we assume that the $\mathrm{AN}-\mathrm{AB}$ enriches for the aneuploid (malignant) nuclei.

Second, in some cases the suggestion of a near-tetraploid population was raised by single parameter analysis (figure 4). After the application of the $\mathrm{AN}-\mathrm{AB}$ or the use of the FSC this peak appeared to be at twice the distance from the upgraded aneuploid, often hypo-diploid G0/G1 peak that had become apparent (figure 4). Therefore, this presumed near-tetraploid G0/G1 peak most likely reflected the $\mathrm{G} 2 / \mathrm{M}$ phase or even polyploidization peak of the aneuploid population detected using the $\mathrm{AN}-\mathrm{AB}$ or FSC.

Third, an impression of the type of nuclei representing the aneuploid population was obtained by comparing the DNA, AN-AB and FSC dot plots. Aneuploid peaks were relatively enriched for large and intensively bright fluorescent nuclei and sometimes only became clearly visible by selecting on these nuclei. However, smaller or less intensively fluorescent nuclei were also frequently observed in these aneuploid peaks (figures 2B and 4). This implicates that aneuploid populations are heterogeneous and that an altered DNA content is not limited to the larger $\mathrm{RS} / \mathrm{H}$ cells containing one or more bright fluorescent nucleoli. 


\section{Discussion}

In this study we demonstrate that aneuploidy can be detected in about half of the cases using DNA flow cytometry on deparaffinized material from lymph nodes of patients with Hodgkin's disease. Previous single parameter flow cytometric studies on Hodgkin's disease revealed an altered DNA content ranging from 6 to $12 \%$ of the cases $(9-13)$ and one group showed near-diploid populations in $19 \%$ of their patients (14). Using single parameter DNA analysis we were able to detect distinct aneuploid stemlines in $31 \%$ of the cases. This higher number of DNA aneuploidy may be related to the method of digestion or the number of nuclei analyzed: in our flow cytometric analysis 65.000 in contrast to 10.000 to 20.000 nuclei in most other studies (10-14). In addition, the flow cytometers nowadays available are more sensitive to detect small, but distinct differences in DNA content. By virtue of this sensitivity we were able to detect several cases of near-diploidy (0.9-1.1), while others did not report DNA indices below $1.1(9,10,11,13)$. This is particularly important in studies on Hodgkin's disease since the DNA index often appears to be in the near-diploid range rather than between 1.5 and 2.0, as usually seen in solid tumors (6). The DNA indices shown in figure 5 reflect the distribution of the gains and losses of chromosomes. Flow cytometers are sensitive enough to detect numerical abnormalities of three or more chromosomes (24-26), although this might also depend on the particular chromosome involved and the quality of the material used. In flow cytometric DNA studies of non-Hodgkin's lymphoma and Hodgkin's disease, including our own study, DNA indices were found in the range varying from 0.8 to 1.2 , indicating a loss or gain of up to 8 or 10 chromosomes $(3,7,10,11,13)$. This is consistent with the results of conventional karyotypic analysis in (Hodgkin's) lymphoma patients (27-31).

The nuclei of the putative malignant cells in Hodgkin's disease are larger than most of the nuclei of the so-called reactive cells and they often contain prominent nucleoli. We therefore used the FSC and a polyclonal AN-AB to select on nuclei with these characteristics. Obviously, the antibody used was not specific for nucleoli of malignant cells alone and nuclei with high nucleolar fluorescence intensity were indeed present in the 15 control cases analyzed. In none of these cases, however, DNA aneuploidy was detected, demonstrating that selection on nuclei with highly fluorescent nucleoli per se does not spuriously reflect the measurement of nuclei with an abnormal DNA content. In 19 of the 137 malignant lymph nodes (14\%) DNA aneuploidy could only be detected by dual parameter analysis using the $\mathrm{AN}-\mathrm{AB}$. Our multiparameter results are at variance with those reported by Anastasi et al (9). Whereas only one case was 
detected by their single parameter analysis they found DNA aneuploidy to be present in all of their 15 cases with the application of the same $A N-A B$ as used in our experiments. This discrepancy may be explained by differences in the operational definition of aneuploidy. In agreement with international conventions (22) we required a clear peak separation for the histograms to be considered aneuploid. Anastasi et al did not define DNA aneuploidy, but as can be seen from their examples (e.g. figure $2 \mathrm{E}$ and $2 \mathrm{H}$ in their paper), cases were called aneuploid on the basis of notches or slight displacements of peaks. This less strict application of peak separation as criterium for aneuploidy is also reflected in differences in the aneuploid fraction. In our series the median number of aneuploid nuclei was $20 \%$, whereas this was $3 \%$ in the study by Anastasi and co-workers (9). Although it may be possible to identify very small aneuploid populations by using less strict criteria, this also increases the risk of false-positive results and should be avoided unless the validity can be demonstrated by the application of other measurements of malignancy.

In contrast to previous reports we identified a considerable number of hypo-diploid cases. The majority of these represent cases with left-sided notches on the single parameter analysis which, without the $\mathrm{AN}-\mathrm{AB}$ and $\mathrm{FSC}$, would have been classified as diploid or even tetraploid. With the multiparameter method the left-sided peak was enhanced or the near-tetraploid peak could be shown to be the $4 \mathrm{~N}$ peak of a hypo-diploid $2 \mathrm{~N}$ peak. This result in fact represents another advantage of the multiparameter approach. Except for one near-tetraploid case (DNA index 1.89) no stemlines exceeding 4N DNA content were seen without the presence of a corresponding near-diploid stemline. This finding is substantiated by numerical karyotypic analysis of banded metaphase cells showing only hypo- or hyper-diploid stemlines but no hyper-tetraploid stemlines (2729). The relative size of the $4 \mathrm{~N}$ peaks and the presence of small $6 \mathrm{~N}$ or even $8 \mathrm{~N}$ peaks suggested that these peaks contain a number of doublets, triplets and quadruplets. Whether these multiplets were technical artifacts (clumping of two or more nuclei) or represented highly fluorescent, polyploidized RS "cells" could not be unequivocally assessed.

Hodgkin's disease is a disease with a heterogeneous cellular composition and the tumor cells may have a B, T or monocytic phenotype (32). The Reed-Sternberg cell and its mononuclear variant the Hodgkin cell are widely accepted to be part of the malignant cell population. From our data several interesting observations regarding the malignant cell population in patients with Hodgkin's disease can be made. We found the aneuploid fraction in the majority of cases to be much higher than the frequency of $\mathrm{RS} / \mathrm{H}$ cells, which generally form less 
than $3 \%$ of the total cell population $(9,16)$. This suggests that aneuploidy is not restricted to the population of $\mathrm{RS} / \mathrm{H}$ cells. These results have been obtained from single nuclei and because the classical RS or giant cells have more than one nucleus the percentage of aneuploid nuclei has to be divided by a factor two or three in order to reflect the actual number of aneuploid cells. Nevertheless, the frequency of aneuploid nuclei appears to exceed the expected frequency of nuclei from RS/H cells. Furthermore, from scatter plots it is obvious that other than large and intensively bright fluorescent nuclei are included in the aneuploid population, again indicating that aneuploidy occurs also in other than the classical neoplastic cells in Hodgkin's disease. This may suggest that these $\mathrm{RS} / \mathrm{H}$ cells probably arise from smaller lymphoid progenitor cells. This view that malignancy is not limited to the RS/H cells is corroborated by the detection of the $\mathrm{Ki}-1$ antigen in reactive and neoplastic lymphoid tissue and the indication from DNA gene rearrangement studies that beside RS/H cells other (lymphoid) cells must belong to the tumor cell population $(33,34,35)$.

In conclusion, multiparameter flow cytometry on nuclei from paraffin-embedded archival material of patients with Hodgkin's disease appears to give information regarding the ploidy status that may be useful for further classification of this heterogeneous disease. Also evidence has been provided supporting the concept that the neoplastic cell population in Hodgkin's disease exists of a spectrum of cells that is not limited to the classical RS/H cell population. 


\section{References}

1. Hedley DW, Friedlander ML, Taylor IW, Rugg CA, Musgrove EA. Method for analysis of cellular DNA content of paraffin-embedded pathological material using flow cytometry. J Histochem Cytochem 1983; 31:1333-1335.

2. Schutte B, Reynders MMJ, Bosman FT, Blijham GH. Flow cytometric determination of DNA ploidy level in nuclei isolated from paraffin-embedded tissue. Cytometry 1985; 6:26-30.

3. Braylan RC, Benson NA, Nourse VA. Cellular DNA of human neoplastic B-cells measured by flow cytometry. Cancer Res $1984 ; 44: 5010-5016$.

4. Merkel DE, Dressler LG, McGuire WL. Flow cytometry, cellular DNA content, and prognosis in human malignancy. J Clin Oncol 1987; 5:1690-1703.

5. Barlogie B, Latreille J, Freireich EJ, Fu CT, Mellard D, Meistrich M, Andreeff M. Characterization of hematologic malignancies by flow cytometry. Blood Cells 1980; 6:719-744.

6. Friedlander ML, Hedley DW, Taylor IW. Clinical and biological significance of aneuploidy in human tumours. J Clin Pathol 1984; 37:961-974.

7. Shackney SE, Levine AM, Fisher RI, Nichols P, Jaffe E, Schuette WH, Simon R, Smith CA, Occhipinti SJ, Parker JW, Cossman J, Young RC, Lukes RJ. The biology of tumor growth in the non-Hodgkin's lymphomas. A dual parameter flow cytometry study of 220 cases. J Clin Invest 1984 73:1201-1214.

8. Shackney SE, Skramstad KS, Cunningham RE, Dugas DJ, Lincoln TL, Lukes RJ. Dual parameter flow cytometric studies in human lymphomas. J Clin Invest 1980; 66:1281-1294.

9. Anastasi J, Bauer KD, Variakojis D. DNA aneuploidy in Hodgkin's disease. Am J Pathol 1987; 128:573-582.

10. Diamond LW, Nathwani BN, Rappaport H. Flow cytometry in the diagnosis and classification of malignant lymphoma and leukemia. Cancer 1982; 50:1122-1135.

11. Joensuu H, Kiemi PJ, Korekeila E. Prognostic value of DNA ploidy and proliferative activity in Hodgkin's disease. Am J Clin Pathol 1988; 90:670-673.

12. Joensuu H, Klemi PJ, Eerola E. Diagnostic value of DNA flow cytometry combined with fine needle aspiration biopsy in lymphomas. J Pathol 1988; 154:237-245.

13. Morgan KG, Quirke P, O'Brien CJ, Bird CC. Hodgkin's disease: a flow cytometric study. J Clin Pathol 1988; 41:365-369.

14. Lehtinen T, Lehtinen M, Aine R. Dammert K, Kulomaa P, Alavaikko M, Leinikki P. Quantity of nuclear DNA in malignancies and benign lymphadenopathies associated with Epste in-Barr virus. J Clin Pathol 1989; 42:699-704.

15. Hiddemann W, Wörmann B, Göhde W, Büchner T. DNA aneuploidies in adult patients with acute myeloid leukemia. Cancer 1986; 57:2146-2152.

16. Cossman J, Sundeen J, Uppenkamp M, Sussman E, Wahl L, Coupland R, Lipford E, Raffeld M. Rearranging antigen-receptor genes in enriched Reed-Stemberg cell fractions of Hodgkin's disease. Hematol Oncol 1988; 6:205-211.

17. Bauer KD, Clevenger CV, Endow RK, Murad T, Epstein AL, Scarpelli DG. Simultaneous nuclear antigen and DNA content quantitation using paraffin-embedded colonic tissue and multiparameter flow cytometry. Cancer Res 1986; 46:2428-2434. 
18. Kruth HS, Braylan RC, Benson NA, Nourse VA. Simultaneous analysis of DNA and cell surface immunoglobulin in human B-cell lymphomas by flow cytometry. Cancer Res 1981; 41:4895-4899.

19. Stonesifer KJ, Benson NA, Ryden SE, Pawliger DF, Braylan RC. The malignant cells in a Lennert's lymphoma are T-lymphocytes with a mature helper surface phenotype. A multiparameter flow cytometric analysis. Blood 1986; 68:426-429.

20. Lukes RJ, Gompel LF, Hall TC, Rappaport H, Rubin P. Report of the Nomenclature Committee. Rye classification. Cancer Res 1966; 26:1311.

21. Greenfield RS, Lamon MO, Olech LJ, Grattan JA. Immunohistochemical and biochemical characterization of antisera raised to human tumor nucleoli. J Cancer Res Clin Oncol 1989; 115:351-360.

22. Hiddeman W, Schumann J, Andreeff M, Barlogie B, Herman CJ, Leif RC, Mayall BH, Murphy RF, Sandberg AA. Convention of nomenclature for DNA cytometry. Cytometry $1984 ; 5: 445-446$.

23. Colton T. Regression and correlation. In Statistics in Medicine, edited by T Colton, pp 189-217. Boston: Little, Brown and company, 1974.

24. Vindelov LL, Christensen IJ, Jensen G. Limits of detection of nuclear DNA abnormalities flow cytometric DNA analysis. Cytometry 1983; 3:332-339.

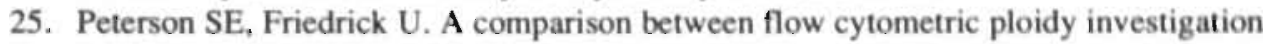
and chromosome analysis of 32 human colorectal tumors. Cytometry 1986; 7:307-312.

26. Barlogie B, Hittelman W, Spitzer G, Trujillo JM, Hart JS, Smallwood L, Drewinko B. Correlation of DNA distribution abnormalities with cytogenetic findings in human adult leukemia and lymphoma. Cancer Res 1977; 37:4400-4407.

27. Schouten HC, Sanger WG, Duggan M, Weisenburger DD, MacLennan KA, Armitage JO. Chromosomal abnormalities in Hodgkin's disease. Blood 1989; 73:2149-2154.

28. Thangavelu M, Le Beau MM. Chromosomal abnormalities in Hodgkin's disease. Hematol/Oncol Clin North America 1989; 3:221-236.

29. Tilly H, Bastard C, Delastre T, Duval C, Bizet M, Lenormand B, Dauce JP, Monconduit M, Piguet H. Cytogenetic studies in untreated patients with Hodgkin's disease. Blood $1991 ; 77: 1298-1304$.

30. Lakkala T, Laasonen A, Franssila KO, Teerenhovi L, Knuutila S. Comparison of DNA and karyotype aneuploidy in malignant lymphomas. Am J Clin Pathol 1990; 94:600-605.

31. Sanger WG, Armitage JO, Bridge J, Weisenburger DD, Fordyce R, Purtilo DT. Initial and subsequent cytogenetic studies in malignant lymphomas. Cancer 1987; 60:3014-3019.

32. Diehl V, von Kalle C, Fonatsch C, Tesch H, Jujecker M, Schaadt M. The cell of origin in Hodgkin's disease. Semin Oncol 1990; 17:660-672.

33. Stein H, Mason DY, Gerdes J, O'Connor N, Wainscoat J, Pallesen G, Gatter K, Falini B, Delsol G, Lemke H, Schwarting R, Lenner K. The expression of the Hodgkin's disease associated antigen $\mathrm{Ki}-1$ in reactive and neoplastic lymphoid tissue: evidence that Reed-Stemberg cells and histiocytic malignancies are derived from activated lymphoid cells. Blood 1985; 66:848-858.

34. Feller AC, Griesser H. DNA gene rearrangement studies in Hodgkin's disease and related lymphomas: a contribution to their cellular origin. Recent Results in Cancer Res Research 1989; 117: 27-34. Berlin-Heidelberg: Springer-Verlag.

35. Griesser H, Mak TW. Imunnotyping in Hodgkin's disease. Hematol Oncol 1988; 6:239-245. 



\section{CHAPTER 7}

\section{DNA aneuploidy and cell proliferation in relation to histology and prognosis in patients with Hodgkin's disease}

Frans L. Erdkamp, Wim P. Breed, Harry C. Schouten, Willy C. Janssen, Johannes J. Hoffmann, Jac Th. Wijnen, Geert H. Blijham

Ann Oncol: $1993 ; 4: 75-80$. 


\section{Abstract}

Aneuploidy and S-phase fraction are well recognized prognostic features of solid tumors and non-Hodgkin's lymphoma. However, only limited data on Hodgkin's disease are available. In this study flow cytometric data on ploidy status and S-phase fraction are analyzed in relation to clinical characteristics and prognosis in 137 patients with Hodgkin's disease. The presence of DNA aneuploidy was not associated with other clinical characteristics. When the histologic subtypes were clustered according to a higher number of Reed-Sternberg/Hodgkin cells into two classes (LP + NSI and the histologic NSII $+M C+$ $L D)$, it appeared that cases with an SPF $\geq 7.5 \%$ had the histologic subtypes NSII $+M C+L D$ significantly more frequently than those with a SPF $<7.5 \%$ $(P=0.001)$. There was no significant difference in complete remission rates, relapse-free or overall survivals between the patients with diploid and those with aneuploid lymph nodes. The complete remission rate for patients with an $S P F<7.5 \%$ was higher than for those with an SPF $\geq 7.5 \%: 95 \%$ (56/59) and $76 \%$ (50166), respectively $(P=0.006)$. The 10 -year survival rate was $78 \%$ for patients with an SPF $<7.5 \%$ and $48 \%$ for those with a SPF $\geq 7.5 \%(P=0.04)$. However, by multivariate analysis only the ESR, age and clinical stage proved to be of independent prognostic importance. In conclusion, DNA aneuploidy did not correlate with known prognostic factors or survival, but the SPF might turn out to be an indicator of patients who will have less favourable outcomes.

\section{Introduction}

In a number of malignancies ploidy abnormalities and proliferative activity as assessed by DNA flow cytometry appear to be of relevance for prognosis (1-8). There have been only a few studies in Hodgkin's disease on DNA content and cell cycle properties (9-14). In these few studies the frequency of DNA aneuploidy is low, and in only two of them have data from DNA flow cytometry been correlated with clinical outcome $(9,10)$. This paucity of data appears at least in part to be due to the inability of single pararneter DNA flow cytometry to select malignant cells from an abundant number of non-neoplastic cells. In a recent multiparameter flow cytometric study we have tried to overcome this problem by using selection on large nuclei or brightly fluorescent nucleoli. In this way we were able to demonstrate DNA aneuploidy in about half of the patients with Hodgkin's disease. 
In the present study we correlate these flow cytometric data on ploidy status and S-phase fraction with other clinical characteristics and analyse its influence on prognosis in 137 previously untreated patients with Hodgkin's disease.

\section{Patlents and Methods}

Between 1972 and 1983182 patients with Hodgkin's disease were diagnosed in 10 community hospitals in the southeastern part of The Netherlands. Data from these patients was maintained by a central registration system at the Comprehensive Cancer Centre South (SOOZ/IKZ). Paraffin-embedded tissues from 142 of these previously untreated patients were available for this study. All patients were studied from the date of histologic diagnosis until last follow-up or death. Median observation time was 5 years (range 3 to 14 years). In all cases the histologic slides, adjacent to the $50 \mu \mathrm{m}$ sections used for flow cytometric analysis, were centrally reviewed and classified according to the Rye classification (15). In addition the nodular sclerotic (NS) subtype was subdivided into grade NSI and NSII as described previously $(16,17)$. All patients were clinically staged according to the Ann Arbor classification (18). Staging procedures such as bone marrow examination, lymphangiography and laparotomy were performed as clinically indicated; in the later years of the entry period CT scanning was increasingly employed.

\section{Treatment}

Patients with stages IA and IIA were generally treated with either mantle or inverted Y-field irradiation to a dose of 40 gray, whereas patients with stages IB, IIB and IIIA generally were treated with subtotal or total lymphoid irradiation with or without chemotherapy. Patients with stages IIIB and IV mostly received combined modality treatment, usually MOPP (mechlorethamine, vincristine, procarbazine, prednisolone) followed by "iceberg" irradiation to a dose of 20 gray.

Preparation of paraffin-embedded tissues and flow cytometric analysis

Paraffin-embedded blocks were deparaffinized, dissociated and stained for DNA and with a polyclonal goat anti-nucleolar antibody (Drs Greenfield, Bristol-Myers, Wallingford, CT, USA). Briefly, $50 \mu \mathrm{m}$ sections were dewaxed 
with xylene and rehydrated in a stepwise fashion with decreasing concentrations of aqueous ethanol. Digestion was accomplished by pepsin $0.5 \%(\mathrm{pH} 1.5)$. The isolated nuclei were stained for DNA with propidium iodide and a polyclonal goat anti-nucleolar antibody ( $\mathrm{AN}-\mathrm{AB}$ ), followed by a fluoresein-isothiocyanate conjugated swine anti-goat antibody (Caltag, San Francisco, CA, USA). In 137 of the 142 cases sufficient nuclei were obtained to perform DNA flow cytometry using a FACScan analyzer (Becton-Dickinson, Sunnyville, CA, USA), equipped with an Argon-ion laser (excitation wavelength $488 \mathrm{~nm}$ ). In each sample 65000 nuclei were counted. DNA histograms were made using the CellFit software package (Becton-Dickinson). Dual parameter flow cytometry was performed by selecting on nuclear size by forward scatter (FSC) or on nucleolar fluorescence (AN-AB). Samples were considered to be aneuploid if more than one G0/G1 peak was identified. Samples with shouldering in the G0/Gl peak without two separate peaks were classified as diploid (19). Multiploidy was defined as more than two separate G0/G1 peaks. The first peak is considered by definition to be the diploid one (19). However, if a left-sided notch in the first peak of the DNA histogram changed into a separately identifiable peak, using the $\mathrm{AN}-\mathrm{AB}$ or FSC, this upgraded peak was considered to reflect the aneuploid population and the down graded the diploid population. The DNA index (DI) was calculated by dividing the modal channel number of the aneuploid peak by that of the diploid peak in the DNA histogram. For calculation of the S-phase fraction (SPF) we used a modified rectangle fit analysis model (20), applying the CellFit software package (Becton-Dickinson). In those cases where the diploid and aneuploid G0/Gl peaks were closely spaced the combined S-phase fraction for the total number of nuclei was calculated.

\section{Flow cytometric results}

DNA aneuploidy was present in $67 / 137$ (49\%) of the cases, in 24 of them demonstrable only by use of multiparameter flow cytometry. Nine samples showed multiploidy. The DNA index ranged from 0.69 to 1.89: 22 were classified as hypo-diploid and 25 had indices greater than 1.2 or lower than 0.8 . The distribution of the SPF is given in figure 1 and varied from 2.9 to $19.2 \%$ (median $7.5 \%$ ). Technically, the S-phase fraction could be reliably estimated in all diploid cases, but from 12 aneuploid DNA histograms no adequate rectangle model could be fitted. The clinical outcome in terms of complete remission, relapse free and overall survival for the excluded 12 patients in relation to the analyzed 125 patients was not significantly different. 


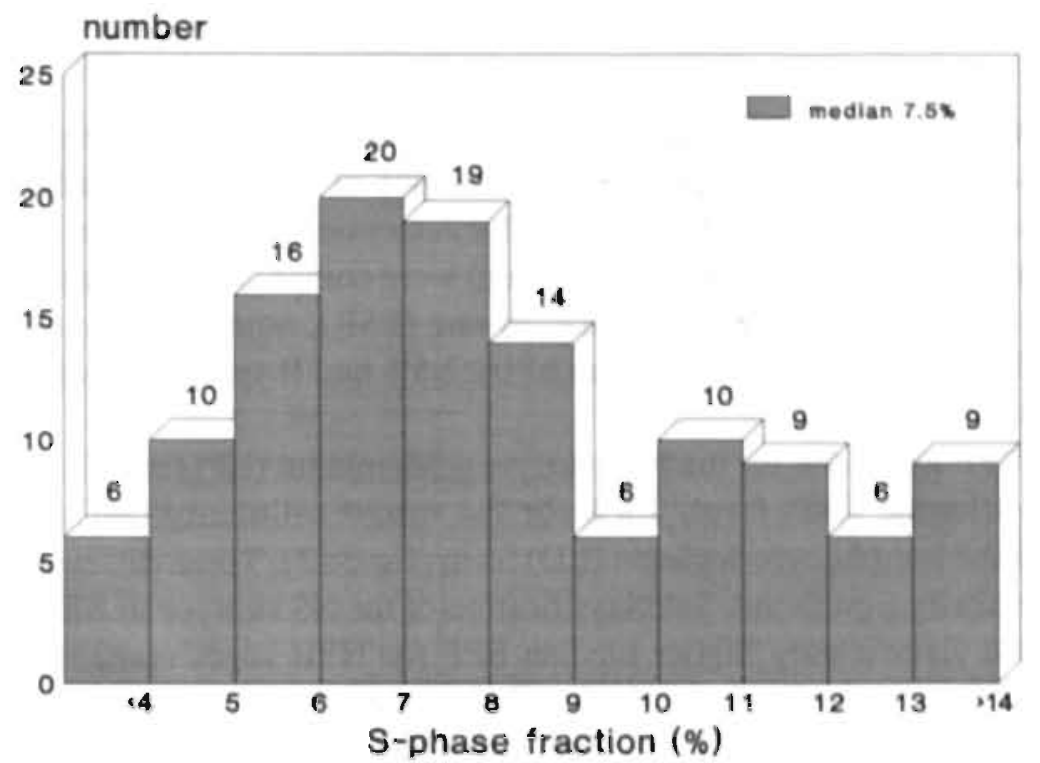

Figure 1. The distribution of the S-phase fraction estimated by flow cytometry in 125 patients with Hodgkin's disease.

\section{Statistics}

The statistical analyses were performed using the BMDP package. The survival curves for all causes of death were plotted according to the Kaplan-Meier method. Survival curves were compared with the generalized Wilcoxon (Breslow) and generalized Savage (Mantel-Cox) methods. The independent prognostic influence of the various elinical characteristics on survival was assessed by the Cox proportional hazard model, and the Chi-Square test was used to compare tables $(21,22)$. For comparison with other clinical characteristics the ploidy status (diploid or aneuploid) and the median (7.5\%) SPF were used. The influence of DNA aneuploidy on prognosis was analyzed using the categories diploidy vs aneuploidy, hypo- vs hyper-diploidy, DNA aneuploidy with a DNA index of $<0.8$ or $>1.2$ vs $\geq 0.8$ or $\leq 1.2$ and for SPF on prognosis the cut-off point was the median $(7.5 \%)$ SPF. 


\section{Results}

Patient characteristics in relation to the ploidy status and the S-phase fraction are shown in table 1. The presence or absence of DNA aneuploidy was not associated with other patient or disease characteristics. Cases with an SPF under and over the cut-off point of $7.5 \%$ (median) were comparable for mean age, sex, clinical stage, erythrocyte sedimentation rate (ESR), number of involved sites and mediastinal mass. Cases with an SPF $\geq 7.5 \%$ had B symptoms slighty more frequently $(\mathrm{P}=0.05)$.

Median SPF was $6.4 \%$ for the lymphocyte predominant (LP) form, $7.4 \%$ for the nodular sclerotic (NS) form, $7.8 \%$ for the mixed cellularity (MC) form and $7.9 \%$ for the lymphocyte depleted (LD) form (figure 2). These differences were not statistically significant. Subclassification of the NS subtype in NSI and NSII revealed a significantly higher median SPF for NSII cases compared to NSI cases: $9.5 \%$ and $6.9 \%$, respectively $(\mathrm{P}<0.01)$. Eight NS cases could not be histologically subtyped; all these eight cases had SPFs $\geq 7.5 \%$ (figure 2 ). Clustering the histology in the categories LP + NSI and NSII + MC + LD revealed a significantly lower median SPF for the LP + NSI compared to the NSII + MC $+\mathrm{LD}$ group: $6.8 \%$ and $8.5 \%$, respectively $(\mathrm{P}=0.001)$.

Table 1. Pattient characteristics of 137 patients with Hodgkin's disease in relation to the ploidy status and the S-phase fraction.

\begin{tabular}{|l|l|l|l|l|}
\hline & $\begin{array}{c}\text { diplold } \\
(\mathbf{n = 7 0 )}\end{array}$ & $\begin{array}{c}\text { aneuplold } \\
(\mathbf{n = 6 7 )}\end{array}$ & $\begin{array}{c}\text { SPF }<7.5 \% \\
(\mathbf{n = 5 9 )}\end{array}$ & $\begin{array}{c}\text { SPF } \geq 7.5 \% \\
(\mathbf{n = 6 6 )}\end{array}$ \\
\hline mean age & 34.5 years & 35 years & 35.5 years & 36 years \\
male & $41(59 \%)$ & $43(64 \%)$ & $35(59 \%)$ & $39(59 \%)$ \\
CS I-IIIA & $55(79 \%)$ & $58(87 \%)$ & $51(86 \%)$ & $55(83 \%)$ \\
B symptoms & $26(37 \%)$ & $14(21 \%)$ & $11(19 \%) \#$ & $24(36 \%) ;$ \\
sites $>3$ & $23(33 \%)$ & $14(21 \%)$ & $12(20 \%)$ & $21(32 \%)$ \\
histology LP+NSI & $46(65 \%)$ & $39(58 \%)$ & $46(78 \%)^{*}$ & $33(50 \%)^{*}$ \\
mediastinal mass & $28(40 \%)$ & $22(33 \%)$ & $21(36 \%)$ & $23(35 \%)$ \\
ESP $<30$ & $31(44 \%)$ & $29(43 \%)$ & $31(53 \%)$ & $22(33 \%)$ \\
\hline
\end{tabular}

SPF: S-phase fraction, CS: clinical stage, LP+NSI: lymphocyte predominant and nodular sclerotic type I histologic subtypes, ESR: erythrocyte sedimentation rate. \#: $p=0.05$, $n: p=0.001$. 


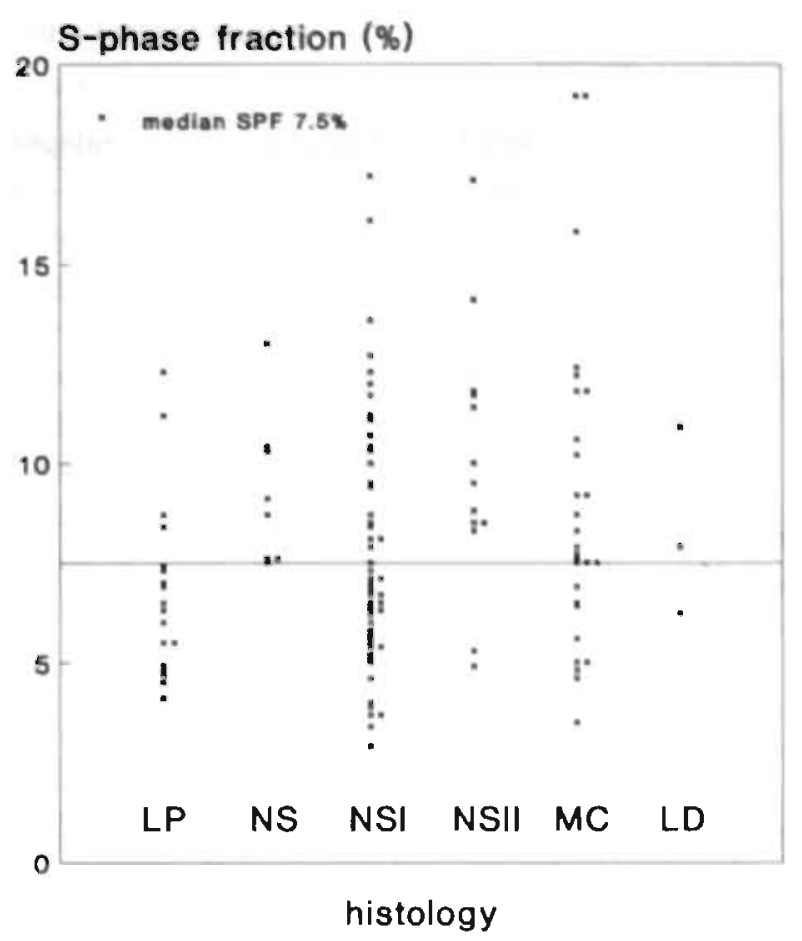

Flgure 2. Histologic subclassification in relation to the Sphase fraction in 123 patients with Hodgkin's disease.

DNA content in relation to prognosis

The relation between complete remission or relapse rates and ploidy status of 137 patients with Hodgkin's disease is illustrated in table 2. The complete remission rates for those presenting with diploid or aneuploid histograms were comparable: $86 \%$ vs $87 \%$. All 9 patients with multiploid specimens achieved complete remissions. The loss or gain of chromosomes, reflected by hypo- or hyper-diploid samples appeared to have no influence on the complete remission rate: $89 \%$ vs $85 \%$. Relapse rates were not statistically significantly different: diploid $30 \%$, hyper-diploid $34 \%$ and hypo-diploid $53 \%$. Samples with more than two aneuploid stemlines had relatively high relapse rates of $56 \%$.

There was no diffence in relapse-free and overall survival curves between diploid and aneuploid cases (figure 3 and 4). Subgroup analysis according to the degree of aneuploidy revealed no significant survival differences. Because total tumor burden, reflected by clinical stage, could have influenced our results the 
Table 2. The relation between DNA content and the complete remission and relapse rates in 137 patients with Hodgkin's disease.

\begin{tabular}{|c|c|c|}
\hline & complete remission (\%) & relapses (\%) \\
\hline overall & $118 / 137(86 \%)$ & $41 / 118(35 \%)$ \\
\hline diploid cases & $60 / 70 \quad(86 \%)$ & $18 / 60 \quad(30 \%)$ \\
\hline aneuploid cases & $58 / 67 \quad(87 \%)$ & $23 / 58 \quad(40 \%)$ \\
\hline hypo-diploidy & $17 / 19(89 \%)$ & $9 / 17 \quad(53 \%)$ \\
\hline hyper-diploidy & $41 / 48 \quad(85 \%)$ & $14 / 41 \quad(34 \%)$ \\
\hline $\mathrm{DI}<0.8$ or $>1.2$ & $20 / 25 \quad(80 \%)$ & $6 / 20 \quad(30 \%)$ \\
\hline $\mathrm{DI} \geq 0.8$ and $\leq 1.2$ & $38 / 42(90 \%)$ & $17 / 38 \quad(45 \%)$ \\
\hline multiploid cases & $9 / 9 \quad(100 \%)$ & $5 / 9 \quad(56 \%)$ \\
\hline
\end{tabular}

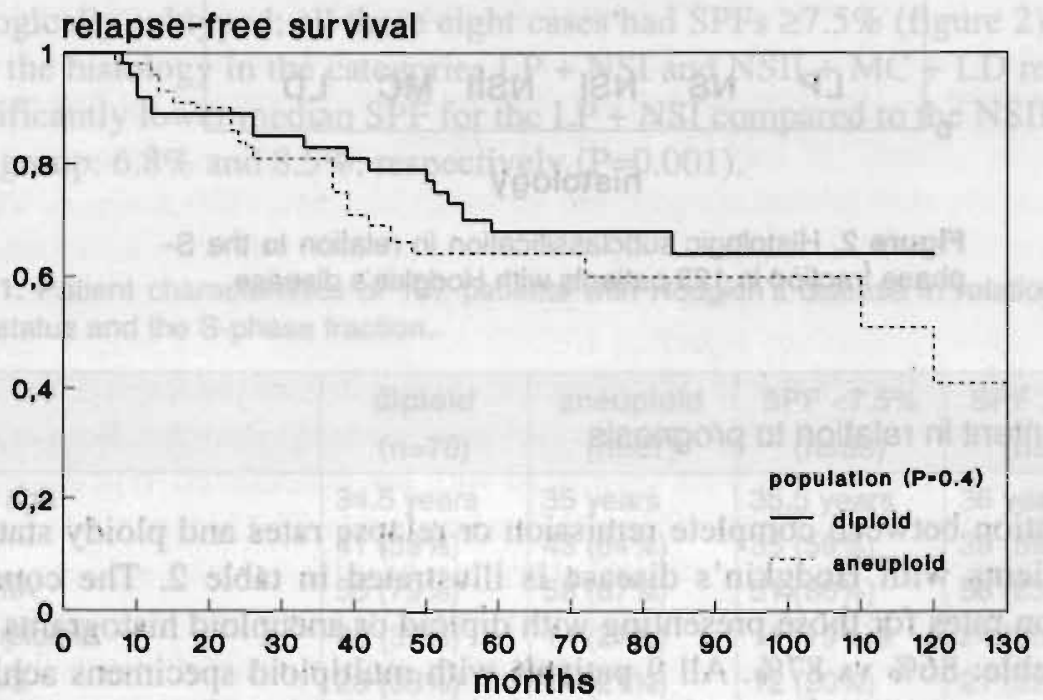

Figure 3. The relapse-free survival according to the ploidy status in 137 patients with Hodgkin's disease.

same analysis was performed for patients with clinical stage I-IIIA. Again no apparent differences were observed for relapse-free and overall survivals (data not shown). Taken together, it appears that ploidy status as assessed by DNA flow cytometry had no influence on the prognosis of patients with Hodgkin's disease. 


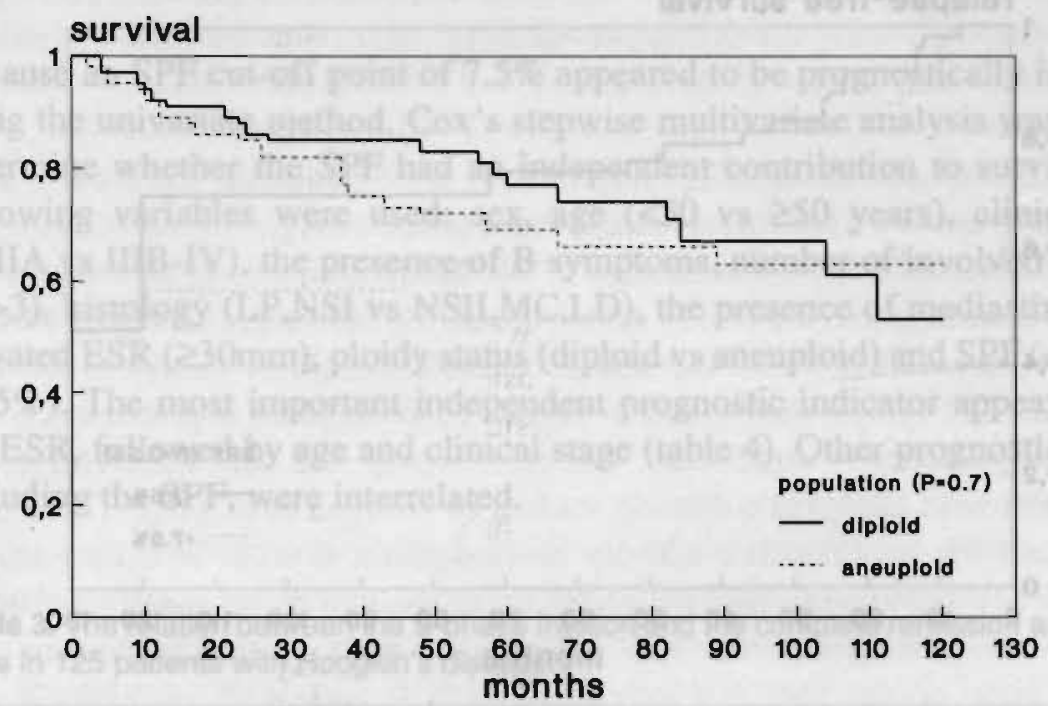

Figure 4. Survival according to the ploidy status in 137 patients with Hodgkin's disease.

S-phase fraction in relation to prognosis

Table 3 reflects the complete remission and relapse rate data correlated with the SPF. Cases with an SPF $<7.5 \%$ had a higher remission rate than those with an SPF $\geq 7.5 \%(P=0.006)$. For patients achieving remission the relapse rate was lower for those with an SPF $<7.5 \%$ vs an SPF $\geq 7.5 \%: 27 \%$ and $44 \%$, respectively $(\mathrm{P}=0.09)$. This tendency towards a lower relapse rate for patients with an SPF $<7.5 \%$ did not result in an improved relapse-free survival (figure 5). A statistically significant improvement in overall survival, however, was observed for patients with an SPF $<7.5 \%$ (figure 6), reflecting the combined effects of improved complete remission and relapse rates. Subgroup analysis for patients in clinical stage I-IIIA also revealed significantly better complete remission rates for those with an SPF $<7.5 \%$ vs $\geq 7.5 \%$ : $96 \%$ and $80 \%$, respectively $(\mathrm{P}=0.03)$. In addition, an increased number of deaths in this subgroup of patients with SPFs $\geq 7.5 \%$ vs. $<7.5 \%$ was found: $35 \%$ vs $16 \%$, $(P=0.05)$. 


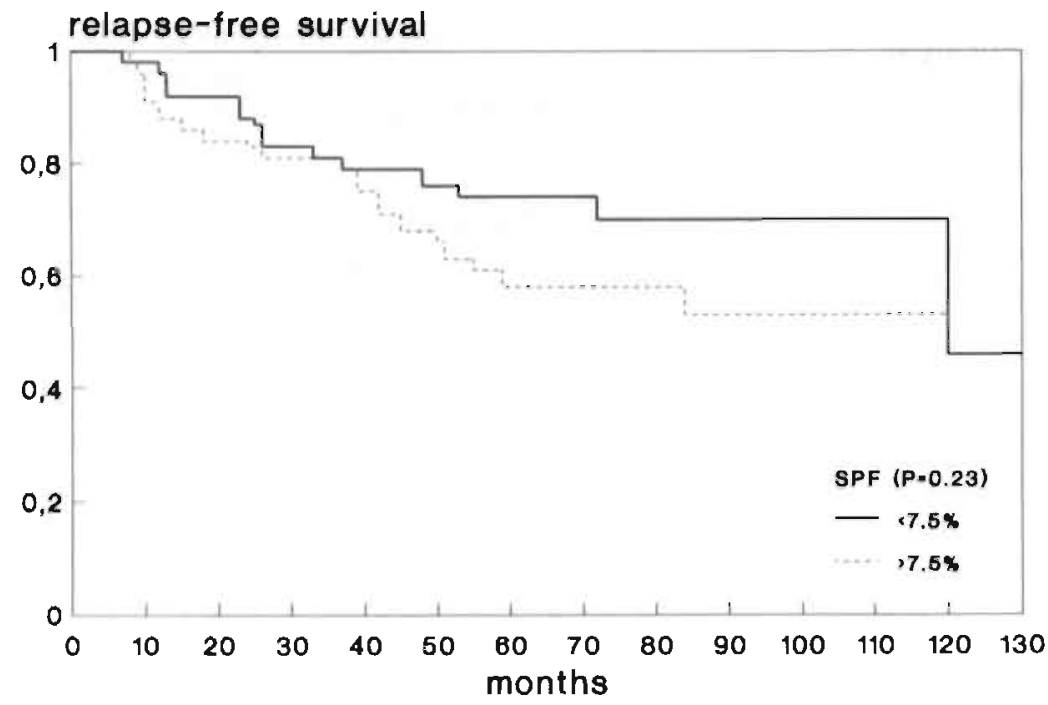

Flgure 5. The relapse-free survival according to the S-phase fraction in 125 patients with Hodgkin's disease

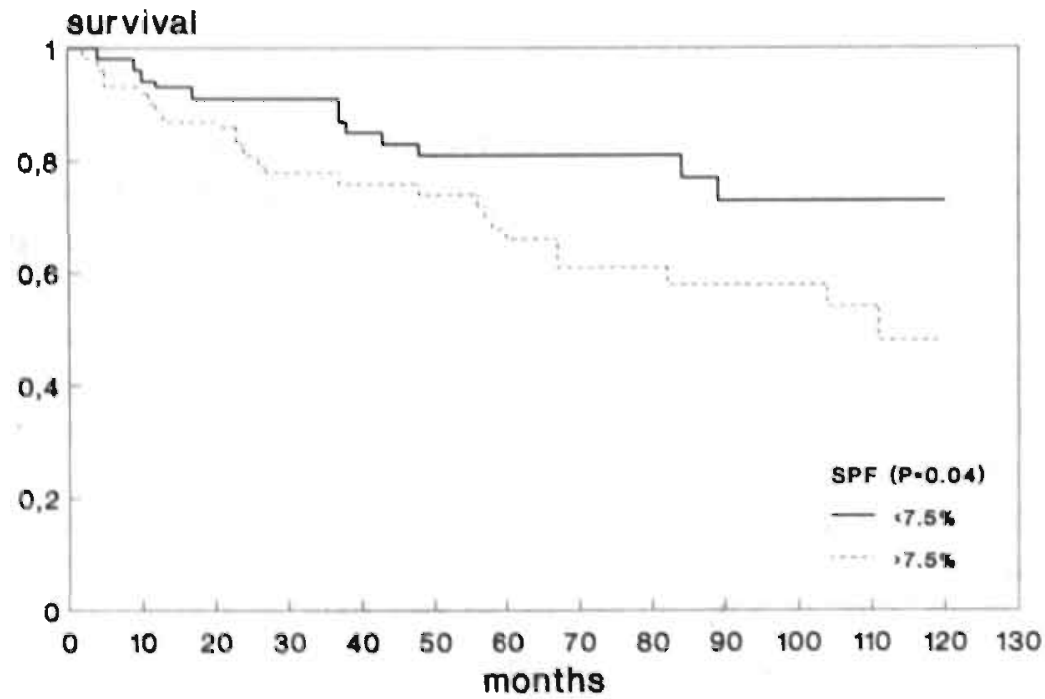

Flgure 6. Survival according 10 the S-phase fraction in 125 patients with Hodgkin's disease. 


\section{Multivariate analysis}

Because an SPF cut-off point of $7.5 \%$ appeared to be prognostically important using the univariate method, Cox.'s stepwise multivariate analysis was done to determine whether the SPF had an independent contribution to survival. The following variables were used: sex, age ( $<50$ vs $\geq 50$ years), clinical stage (I-IIIA vs IIIB-IV), the presence of B symptoms, number of involved sites ( $\leq 3$ vs $>3$ ), histology (LP,NSI vs NSII,MC,LD), the presence of mediastinal mass, elevated ESR. $(\geq 30 \mathrm{~mm})$, ploidy status (diploid vs aneuploid) and $\mathrm{SPF}$ ( $<7.5 \%$ vs $27.5 \%$ ). The most important independent prognostic indicator appeared to be the ESR, followed by age and clinical stage (table 4). Other prognostic factors, including the SPF, were interrelated.

Table 3. The relation between the S-phase fraction and the complete remission and relapse rates in: 125 patients with Hodgkin's disease.

\begin{tabular}{|l|c|l|}
\hline & complete reimission (\%) & relapsea (\%) \\
\hline overall & $106 / 125(85 \%)$ & $37 / 106(35 \%)$ \\
SPF $<7.5 \%$ & $56 / 59(95 \%) \#$ & $15 / 56(27 \%)^{*}$ \\
SPF $\geq 7.5 \%$ & $50 / 66(76 \%) \#$ & $22 / 50(44 \%)^{*}$ \\
\hline SPF: S-phase fraction. \#: $\mathrm{p}=0.006,: \mathrm{p}=0.09$. \\
\hline
\end{tabular}

Table 4. Cox multivariate analysis of variables important for predicting survival in Hodgkin's disease.

\begin{tabular}{|l|c|c|c|}
\hline \multicolumn{1}{|c|}{ characteristic } & $\beta$ value & z value & P value \\
\hline ESR & 0.67 & 2.46 & 0.001 \\
age & 1.13 & 2.45 & 0.04 \\
CS & 0.95 & 1.96 & 0.06 \\
\hline
\end{tabular}

ESR: erythrocyte sedimentation rate, CS: clinical stage. $\beta$ : coefficient, $z$ : the ratio of the $\beta$ to its standard error.

\section{Discussion}

The flow cytometric determination of DNA content is a rapid and reliable quantitative technique which obviates the need for fresh tumor specimens. It yields data on the presence of cells with numerical chromosomal aberrations as well as on the frequency of cells in the S-phase of the cell cycle. Although the results on the SPF in particular need to be interpreted with caution it is impor- 
tant to note that a good correlation has been demonstrated between cell cycle kinetics measured using the thymidine-labelings index and the flow-cytometrically-determined S-phase $(23,24,25)$.

From studies of non-Hodgkin's lymphoma it is obvious that the most highly proliferating tumors were found among those cases with the higher histological grades $(26,27,28,29,30,31)$. Although in our study no relation was found between the histology and the ploidy status, clustering histologic subtypes showed a strong correlation between the less favourable histologic subtypes (NSII + $\mathrm{MC}+\mathrm{LD})$ and lymph nodes with a higher percentage of S-phase cells. Although not statistically significant, this relationship was also observed in the 115 patients with Hodgkin's disease studied by Morgan et al. (10). These data suggest that the proliferative activity in Hodgkin's disease is linked to the histologic subtypes, with the SPF going up in relation to a higher number of Reed-Sternberg/Hodgkin cells. This finding may be of direct practical importance in view of the fact that subtyping in NSI and NSII is difficult and time-consuming for most general pathologists. The flow-cytometrically-obtained SPF, therefore, could be diagnostically additive in distinguishing NSI and NSII. This corroborates results from Osborne et al. suggesting that the SPF provided additional information in distinguishing peripheral $\mathrm{T}$-cell lymphoma from Hodgkin's disease in histologically similar cases (32). Joensuu and coworkers also recently reported that histologic transformation in non-Hodgkin's lymphoma was positively correlated with a rise in $S$-phase cells and that the SPF appeared to provide information not obtainable by histologic classification alone (33). Taken together, the histologically favourable subtypes (LP + NSI) were not more often diploid but appeared to contain fewer cells in S-phase. Whether this simply reflects the relative frequency of neoplastic vs non-neoplastic cells or is in fact indicative of biological differences remains to be investigated.

In this study of 137 patients with Hodgkin's disease DNA aneuploidy was not associated with prognosis, not even after the analysis was focused on patients with clinical stage I-IIIA. Two previous studies on flow- cytometrically-analyzed DNA content in Hodgkin's disease reached the same conclusion $(9,10)$. In non-Hodgkin's lymphoma, however, conflicting results about the influence of DNA aneuploidy in relation to clinical outcome have been reported. Some investigators observed improved complete remission rates and/or survival for patients with diploid tumors $(26,34,35)$, but others were unable to confirm these results $(27-30,36-38)$. This was particularly true of studies with a higher percentage of abnormal DNA stemlines $(28,29,36,38)$. In contrast, in solid tumors, 
where the frequency of DNA aneuploidy is relatively high, this feature was found to be associated with a poorer prognosis. It should be noted, however, that the pattern of DNA aneuploidy, that is, the distribution of DNA indices, is clearly different in lymphoma (DI mostly near-diploid) and, for instance, breast cancer patients (usually $\mathrm{Dl}>1.5$ ). Therefore, the prognostic impact of DNA aneuploidy in solid tumors may be a function of the presence of gross chromosomal abnormalities leading to high DNA indices. In contrast, in acute lymphoblastic lymphoma it was noted that patients with DNA indices $<1.16$ more frequently had late treatment failure $(6,7)$. This could correspond to our findings that the relapse rate was high in the group of patients with near-diploid (DNA index between 0.8 and 1.2 ) tumors.

The present study provides clear evidence of the prognostic value of SPF measurements for predicting overall survival in patients with Hodgkin's disease. These findings are accord with most of the (Hodgkin's) Jymphoma and solid tumor reports (1-5,27-30,34-36,38). A high number of S-phase cells suggests a more aggressive clinical behaviour. This hypothesis is supported by the reduced response rates and the increased relapse risk. for cases with higher SPFs compared to those with lower SPFs in our study. In contrast, theoretically the higher proliferative activity might give a better response to chemotherapy as was found in one study of non-Hodgkin's lymphoma patients (39). Other studies in patients with non-Hodgkin's lymphoma have not confirmed these latter results $(28,29,35,36,38)$. The lower initial response rates in lymphoma patients with high numbers of proliferating cells suggest the need for more intensive induction therapy in order to overcome tumor growth between two cycles of chemotherapy.

The SPF which qualified as a prognostic factor in the univariate analysis lost its significance when Cox's stepwise proportional hazard analysis, was used. It must be realized, however, that determination of the SPF by DNA flow cytometry on formalin-fixed, paraffin-embedded tissue is by no means the most accurate way to measure proliferative activity. Although the SPF has been shown to correlate with thymidine-labeling characteristics $(23,24,25)$, it is subject to problems related to the digestive steps in tissue processing and may not accurately measure actual DNA synthesis. It is quite possible, therefore, that with the application of a more reliable DNA synthesis methodology, e.g., incorporation of in vivo-administered $\mathrm{BrdU}$, proliferation activity will turn out to be a major prognostic determinant in Hodgkin's disease. 
In conclusion, we did not find DNA ploidy as determined by DNA flow cytometry useful in predicting the prognosis of patients with Hodgkin's disease. In contrast, the proliferative activity may be a reliable and easily applicable tool for differentiating subclasses of patients presenting with a more aggressive clinical behaviour. More sensitive assessment of SPF by application of antibodies against DNA precursors or markers of S-phase, and selecting the neoplastic cell population may be useful to further improve the correlation between proliferation and prognosis. 


\section{References}

1. Friedlander ML, Hedley DW, Taylor IW et al. Influence of cellular DNA content on survival in advanced ovarian cancer. Cancer Res 1984; 44:397-400.

2. Frankfurt OS, Chin JL, Englander LS et al. Relationship between DNA ploidy, glandular differentiation, and tumor spread in human prostate cancer. Cancer Res 1985; 45:1418-23.

3. Dressler LG, Seamer LC, Owens MA et al. DNA flow cytometry and prognostic factors in 1331 frozen breast cancer specimens. Cancer 1988; 61:420-7.

4. Hedley DW, Rugg CA, Gelber RD. Association of DNA index and S-phase fraction with prognosis of nodes positive early breast cancer. Cancer Res 1987; 47:4729-35.

5. Clark GM, Dressler LG, Owens MA et al. Prediction of relapse or survival in patients with node-negative breast cancer by DNA flow cytometry. N Eng J Med 1989; 320:627-33.

6. Look AT, Roberson PK, Williams DL et al. Prognostic importance of blast cell DNA content in childhood acute lymphoblastic leukemia. Blood 1985; 65:1079-86.

7. Pui CH, Dodge RK, Look AT et al. Risk of adverse events in children completing treatment for acute lymphoblastic leukemia: St.Jude total therapy studies VIII, IX and X. J Clin Oncol 1991: 9:1341-7.

8. Merkel DE, Dressler LG, McGuire WL. Flow cytometry, cellular DNA content, and prognosis in human malignancy. J Clin Oncol 1987; 5:1690-1703.

9. Joensuu H, Klemi PJ, Korekeila E. Prognostic value of DNA ploidy and proliferative activity in Hodgkin's disease. Am J Clin Pathol 1988; 90:670-3.

10. Morgan KG, Quirke P, O'Brien CJ et al, Hodgkin's disease: a flow cytometric study. J Clin Pathol 1988; 41:365-9.

11. Anastasi J, Bauer KD, Variakojis D. DNA aneuploidy in Hodgkin's disease. Am J Pathol 1987; 128:573-82.

12. Diamond LW, Nathwani BN, Rappaport H. Flow cytometry in the diagnosis and classification of malignant lymphoma and leukemia. Cancer 1982; 50:1122-35.

13. Joensuu H, Klemi PJ, Eerola E. Diagnostic value of DNA flow cytometry combined with fine needle aspiration biopsy in lymphomas. J Pathol 1988; i 54:237-45.

14. Lehtinen $T$, Lehtinen $M$, Aine $R$ et al. Quantity of nuclear DNA in malignancies and benign lymphadenopathies associated with Epstein-Barr virus. J Clin Pathol 1989; 42:699-704.

15. Lukes RJ, Gompel LF, Hall TC et al. Report of the Nomenclature Committee. Rye classification. Cancer Res 1966; 26:1311.

16. Bennett MH, Tu A, Vaughan Hudson G. Analysis of grade I Hodgkin's disease. Report no.2, part.2. Clin Radiol 1981; 32:491-8.

17. Jairam R, Vrints LW, Breed WPM et al. Histological subclassification of the nodular sclerotic type of Hodgkin's disease. Neth J Med 1988; 33:160-7.

18. Carbone PP, Kaplan HS, Masshoff $\mathrm{K}$ et al. Report of the committee of Hodgkin's disease staging. Ann Arbor classification. Cancer 1971; 31:1860-1.

19. Hiddeman W, Schumann J, Andreeff $\mathbf{M}$ et al. Convention of nomenclature for DNA cytometry. Cytometry 1984; 5:445-6.

20. Baisch H, Göhde W, Linden WA. Analysis of PCP-data to determine the fraction of cells in the various phases of cell cycle. Rad and Environm Biophys 1975; 12:31-9. 
21. Bishop YMM, Fienberg SE, Holland PW. Discrete multivariate analysis: Theory and practice. Carnbridge, MA: MIT press, 1975.

22. Gross AJ, Clark VA. Survival distribution reliability application in the biomedical sciences. New York: Wiley and Sons, 1975.

23. Braylan $\mathrm{RC}$, Diamond $\mathrm{LW}$, Powell ML et al. Percentage of cells in the S-phase of the cell cycle in human lymphoma determined by flow cytometry. Cytometry 1980; 1:1714.

24. Beauregard P, Witzig TE, Kurtin PJ et al. Models of S-phase determination in lymphomas from flow cytometric DNA content histograms. Proc ASCO 1991; 32:155 p.26.

25. Hedley WH. Flow cytometry using paraffin-embedded tissue: five years on. Cytometry 1989; 10:229-41.

26. Morgan DR, Williamson JMS, Quirke $P$ et al. DNA content and prognosis of nonHodgkin's lymphoma. Br J Cancer 1986; 54:643-9.

27. Jaikanen S, Joensuu H, Klemi P. Prognostic value of lymphocyte homing receptor and S-phase fraction in non-Hodgkin's lymphoma. Blood 1990; 75:1549-56.

28. Cowan RA, Harris $M$, Jones $M$ et al. DNA content in high and intermediate grade non-Hodgkin's lymphoma - prognostic significance and clinicopathological correlations. Br J Cancer 1989; 60:904-10.

29. Rehn S, Glimelius B, Strang P et al. Prognostic significance of flow cytometry studies in B-cell non-Hodgkin's lymphoma. Hematol Oncol 1990; 8:1-12.

30. Young GAR, Hedley DW, Rugg CA et al. The prognostic significance of proliferative activity in poor histology non-Hodgkin's lymphoma: a flow cytometry study using archival material. Eur J Cancer Clin Oncol 1987; 23:1497-1504.

31. Juneja SK, Cooper IA, Hodgson GS et al. DNA ploidy pattems and cytokinetics of non-Hodgkin's lymphoma. J CLin Pathol 1986; 39:987-92.

32. Osborne BM, Uthman MO, Butler JJ et al. Differentiation of T-cell lymphoma from Hodgk in's disease. Am J Clin Pathol 1990; 93:227-32.

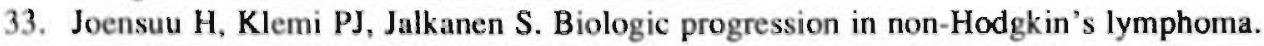
Cancer 1990; 65:2564-71.

34. Christensson B. Tribukait B, Linder I et al. Cell proliferation and DNA content in non-Hodgkin's lymphoma. Cancer 1986; 58:1295-1304.

35. Wooldridge TN, Grierson HL., Weisenburger DD et al. Association of DNA content and proliferative activity with clinical outcome in patients with diffuse mixed cell and large cell non-Hodgkin's lymphoma. Cancer Res 1988; 48:6608-13.

36. Christensson B, Lindemalm C, Johansson B et al. Fiow cytometric DNA analysis: a prognostic tool in non-Hodgkin's lymphoma. Leukemia Res 1989; 13:307-14.

37. Aine R, Lehtinen T, Lehtinen M et al. Flow cytometric analysis of DNA ploidy in large cleaved cell lymphomas. Hematol Oncol 1990; 8:339-46.

38. Bauer KD, Merkel DE, Winter JN et al. Prognostic implications of ploidy and proliferative activity in diffuse large cell lymphomas. Cancer Res 1986; 46:3173-78.

39. Srigley J, Barlogie B, Butler JJ et al. Heterogeneity of non-Hodgkin's lymphoma probed by nucleic acid cytometry. Blood 1985; 65:1090-6. 


\section{CHAPTER 8}

\section{Comparison of image and flow cytometry determined DNA content of paraffin-embedded Hodgkin's disease tissue}

Frans L. Erdkamp, Harry C. Schouten, Wim P. Breed, Willy C. Janssen, Johannes

J. Hoffmann, Michelle Reynders, Bert Schutte, Geert H. Blijham 


\section{Abstract}

To assess the reliability of DNA estimation using image cytometry, deparaffinized lymph nodes from 70 patients with Hodgkin's disease were examined and the results obtained were compared with those from flow cytometry. Image analysis without discriminating between the various cell types, as found in Hodgkin's disease, revealed no separate aneuploid peak. Selecting on morphologically defined nuclear types DNA aneuploidy was detected in $20 \%$ of the cases (14/70). The aneuploid populations were limited to the population of nuclei defined as Reed-Sternberg (RS) like or medium sized lymphocytes. In none of the control benign lymph nodes DNA aneuploidy was found. Comparison of DNA histograms obtained by image and flow cytometry showed aneuploid peaks using image cytometry in 4 of 30 diploid and 10 of 40 aneuploid flow histograms. In conclusion, image analysis as compared to flow cytometry is more time consuming and less sensitive to assess ploidy status, although it may provide extra information in some selected cases. Evidence is obtained that DNA aneuploidy in Hodgkin's disease is preferentially expressed by cells with the $R S / H$ like and medium sized lymphocyte morphology.

\section{Introductlon}

Flow cytometry has emerged as a well established tool suitable for the rapid analysis of cellular ploidy status and proliferative activity $(5,8,16)$. One of the drawbacks of this technique, however, is the absence of morphologic information on the individually measured cells. Therefore it does not permit discrimination between morphologically non-malignant cells and tumor cells with a diploid. DNA content. Moreover, the presence of a small aneuploid population may be masked when there is a preponderance of non-neoplastic cells, as is assumed to be the case in Hodgkin's disease. This has led to an increasing interest for DNA image cytometry, that may be used to select cells according to the same morphologic criteria applied for histologic diagnosis. The number of studies on this subject in lymphoma, however, are scarce (7) and, so far, we were not able to find one single study related to Hodgkin's disease.

The aims of this study were to assess the feasibility of image cytometry to determine DNA content in morphologically selected nuclei from deparaffinized Hodgkin's disease tissues and to correlate these findings with those obtained by flow cytometric analysis. 


\section{Materials and Methods}

Paraffin-embedded lymph node tissues from previously untreated patients with Hodgkin's disease were obtained from the pathology departments of $10 \mathrm{com}-$ munity hospitals in the south-eastern part of The Netherlands. All histologic slides were centrally reviewed and classified according to the Rye classification (14). Seventy DNA flow cytometrically analyzed specimens (30 diploid and 40 aneuploid) were used for image cytometry. Samples from 10 histologically reviewed "benign" lymph nodes served as controls.

\section{Tissue preparation}

Paraffin-embedded biocks were deparaffinized and dissociated as previously described $(10,19)$. Briefly, 50 im sections were dewaxed with xylene and rehydrated in a stepwise fashion with decreasing concentrations of aqueous ethanol. Digestion was accomplished by pepsin $0.5 \%\left(\mathrm{pH} \mathrm{1.5)}\right.$ in a water bath at $37^{0} \mathrm{C}$ for 1 hour. The nuclear suspension obtained was filtered through a $50 \mu \mathrm{m}$ nyion mesh, was washed twice and finally resuspended in $2 \mathrm{ml}$ phosphate-buffered saline (PBS), containing $0.1 \%$ triton X-100.

\section{Image cytometry}

For image analysis the resulting nuclei were centrifuged on to slides and then fixed in formalin. All specimens were stained by the Feulgen method with the staining kit from Cell Analysis Systems (Becton-Dickinson, Erembodegem. Belgium). In brief, the slides were exposed to $5 \mathrm{~N} \mathrm{HCL}$ for 60 minutes, incubated in thionin containing staining solution for 1 hour, rinsed with the CAS rinse solution. After washing in deionized water for 5 minutes, dehydration in ethanol and xylene the slides were mounted with entellan. All handling were performed at room temperature. Cytospins were analyzed using the CAS 200/QDA system and software. Calibration was performed applying simultaneously stained rat hepatocyte control slides provided in the kit. Individual nuclei were identified by the image analyzer. Nuclei which appeared intact and did not overlap were studied under $\times 40$ power. Each nucleus in the field could be accepted or rejected by the operator who could also artificially separate adhering nuclei. Nuclei were recognized and selected by their size, shape and chromatin pattern. By this approach we were able to identify four classes of nuclei: 1. small lymphocytes with a round, uniform nuclear border, and a 
condensed chromatin pattern; 2 . medium sized lymphocytes that are somewhat larger with a more irregular border and a granular, non-uniform chromatin distribution; 3. large Reed-Stemberg (RS) and Hodgkin (H) like, often lobulated nuclei, about twice as large as the small lymphocytes and with clumping of the chromatin pattern; 4 . the histiocytic like nuclei with a variable size, a bean-shaped or oval border and a disperse chromatin pattern. Generally during the analysis enough small and medium sized lymphocytes were encountered; $\mathrm{RS} / \mathrm{H}$ like nuclei were much less frequently seen; they usually made up around 10 to 15 of the total nuclei count. Neutrophils were excluded from the analysis because it was frequently difficult to determine whether these nuclei were intact or damaged. At least 150 nuclei, but in most instances 200 nuclei of each sample were analyzed. DNA histograms for all nuclei analyzed and for each subclass of nuclei were generated by the Quantitative DNA Analysis (QDA) program. Because no extem diploid control is available when deparaffinized tissue is used, the mean peak of the small lymphocytes served as an internal control. A peak in the DNA histogram was defined as aneuploid if it was separate from the peak used as the intemal diploid control. Because the coefficient of variation (CV) of DNA measurements in fixed tissues is usually higher compared to unfixed tissues, the diploid range was defined as a DNA index between 0.85 and 1.15. The DNA index of each peak was calculated by the computer, whereby the mean peak value from the peak that was separable from the internal control was divided by the mean value of the control peak. All cytospins were analyzed without knowledge of the results obtained by flow cytometry.

\section{Flow cytometry}

The isolated nuclei were stained for DNA with propidium iodide and a polyclonal goat anti-nucleolar antibody (AN-AB), followed by a fluorescein-isothiocyanate conjugated swine anti-goat antibody (Caltag. San Francisco, CA, USA), as described elsewhere (chapter 6). DNA flow cytometry was performed using a FACScan analyzer (Becton-Dickinson, Sunnyville, CA, USA), equipped with an Argon-ion laser (excitation wavelength $488 \mathrm{~nm}$ ). In each sample 65000 nuclei were counted. DNA histograms were made using the CellFit software package (Becton-Dickinson). Dual parameter flow cytometry was performed by selecting on nuclear size by forward scatter (FSC) or on nucleolar fluorescence (AN-AB). Samples were considered to be aneuploid if more than one G0/Gl peak was identified. Samples with shouldering in the G0/GI peak without two separate peaks were classified as diploid (11). The first peak is by definition considered to be the diploid one (11). However, if a 
left-sided notch in the first peak of the DNA histogram was upgraded into a separately identifiable peak, using the AN-AB or the forward scatter (FSC), the upgraded peak was considered to reflect the aneuploid population and the down graded peak the diploid population. The DNA index (DI) was calculated by dividing the modal channel number of the aneuploid peak by that of the diploid peak in the DNA histogram.

\section{Results}

\section{Image cytometry}

DNA histograms from the 70 cases analyzed without discriminating between cell types revealed no DNA aneuploidy using image cytometry. Eight out of these 70 histograms had an asymmetric G0/Gil peak: five were skewed to the right and three to the left. None of the benign lymph nodes showed an aneuploid or skewed peak. With the analysis of DNA content in relation to the defined types of nuciei, DNA aneuploidy was detected in 14 of the 70 cases $(20 \%)$. Aneuploid nuclei were found in the population RS/H like only $(n=9)$, the medium-sized lymphocytes class of nuclei only $(n=3)$ and in both RS/H and medium-sized populations $(n=2)$. In all but one of the 70 cases the small lymphocytes and the presumably benign histiocytic like nuclei had comparable DNA contents. The DNA index of the aneuploid cases varied from 0.8 to 1.7 with two hypo-diploid cases. Small- and medium-sized lymphocytes and histiocyte like nuclei could also be easily recognized in the 10 control benign lymph node specimens and in none of these populations a second DNA peak was found.

\section{Image and flow cytometry}

Next we investigated the relation between DNA contents determined by flow or image cytometry (table 1). Thirty cases were diploid by flow cytometry; four were found to have a small aneuploid peak with image cytometric analysis by nuclear type. An example is given in figure 1. These aneuploid peaks were always limited to the population of RS/H like and medium sizedl lymphocytes nuclei. The DNA index of these four cases varied from 1.15 to 1.7. After re-analyzing the original flow cytometrically obtained DNA histogranis in one of the four cases the G0/G1 peak appeared to be skewed but even after the 
Table 1. Ploidy status as determined by image and flow cytometry in 70 Hodgkin's disease specimens.

\begin{tabular}{|l|c|c|}
\hline & \multicolumn{2}{|c|}{ image cytometry } \\
\hline \multicolumn{1}{|c|}{ flow cytometry } & diploid & aneuploid \\
\hline diploid & 26 & 4 \\
aneuploid & 30 & $10^{*}$ \\
\hline * one case with a discordant DNA index comparing image and flow cytometry. \\
\hline
\end{tabular}

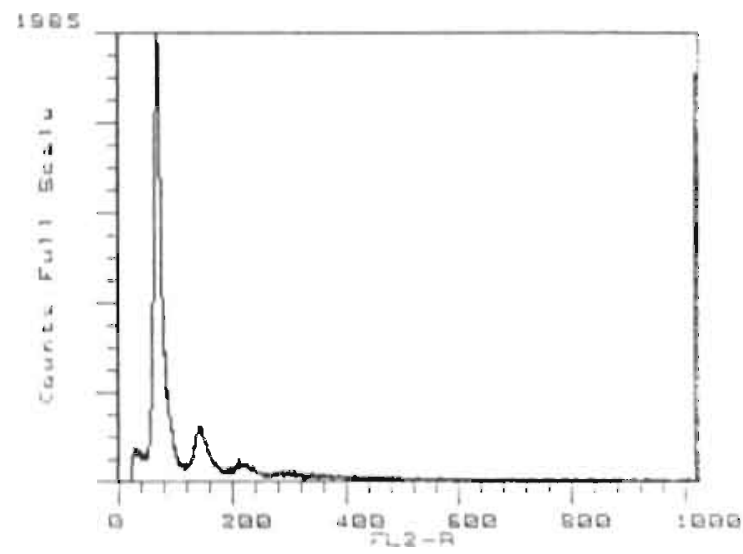

Flgure 1. A: diploid DNA histogram determined by flow cytometry. (FL2: DNA staining).

application of selection on size or anti-nucleolar fluorescence no separate peak was detected. In the other three cases flow cytometric DNA histograms displayed only one narrow $\mathrm{G} 0 / \mathrm{G} 1$ peak (CV $2.0,4.1$, and 4.6 , respectively). The occurrence of DNA aneuploidy, exclusively detected with image cytometry was not correlated with a specific histologic subtype; two samples had the nodular sclerotic and two the mixed cellularity subtype.

Forty cases were aneuploid by flow cytometry; 30 were diploid by image analysis even if nuclei were selected by nuclear type. Nine of the ten remaining cases showed congruent DNA indices including two cases that were hypo-diploid by both methods. An example is given in figure 2. Four of those nine samples showed aneuploid peaks by flow cytometry only after selecting nuclei by size or fluorescence intensity of the $\mathrm{AN}-\mathrm{AB}$. The remaining case was classified hypo-diploid (DNA index 0.7 ) by flow cytometry using the $\mathrm{AN}-\mathrm{AB}$ 


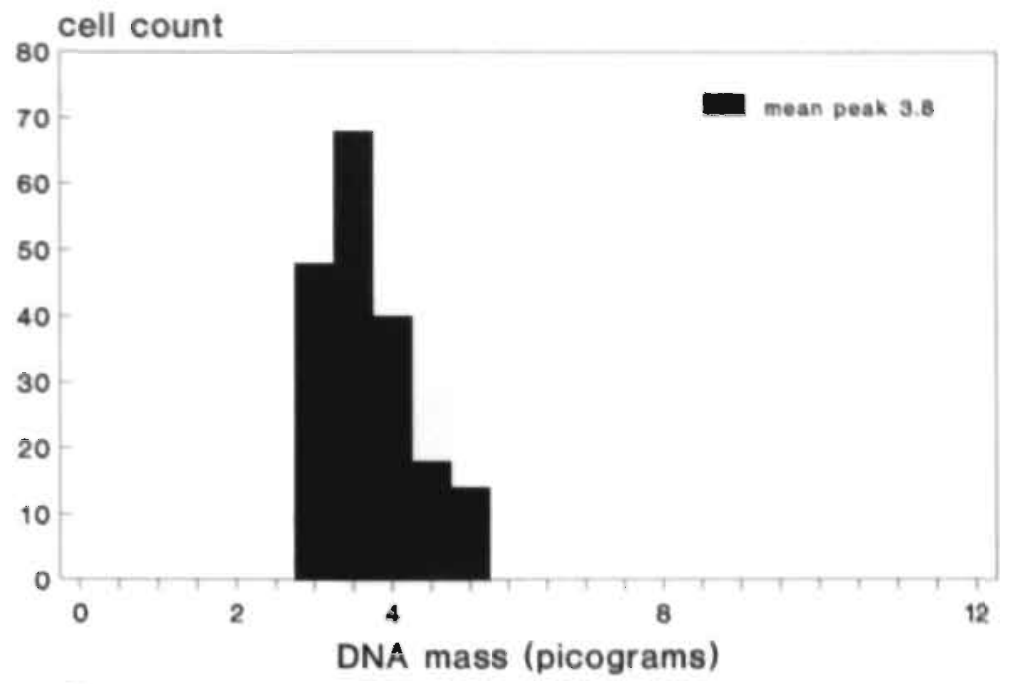

figure $1 \mathrm{~B}$

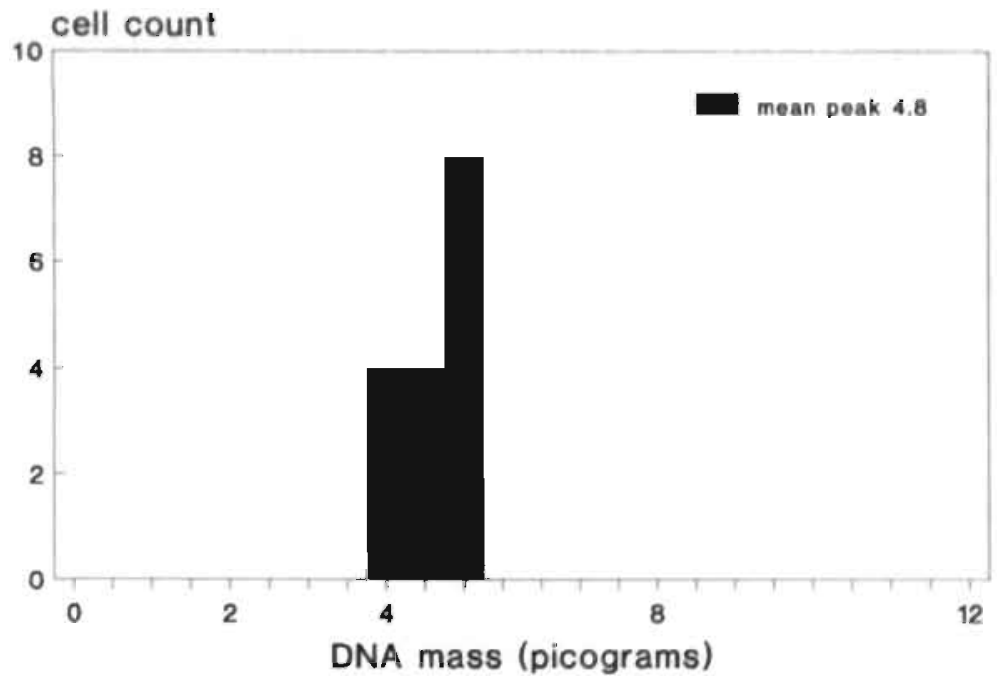

figure $1 \mathrm{C}$

Figure 1. B: image analysis of the same, total population of nuclei, showing a diploid DNA histogram skewed to the right.

C: image analysis of the Reed-Sternberg/Hodgkin like nuclei showing a mean peak of 4.8 picograms with a DNA index of 1.2 . 


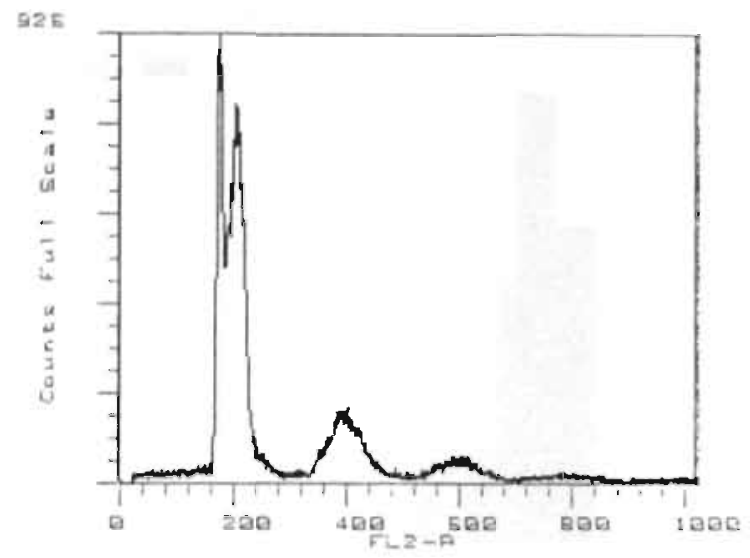

Figure 2. A: Aneuploid DNA histogram determined by flow cytometry. (FL2: DNA staining)

and hyper-diploid (DNA index 1.6) by image cytometry. Of the 30 cases with DNA aneuploidy that could only be detected by flow cytometry the DNA index varied from 1.05 to 1.78 . In 15 of these 30 cases (50\%), however, the DNA index was between 0.85 and 1.15 , which were the detection limits for image cytometry. Taken this into account, $40 \%$ of the cases (10/25) with flow cytometrical DNA aneuploidy were also classified as aneuploid by image cytometry. These results were not clearly different if the comparison was restricted to any of the histological subtypes.

\section{Discussion}

With image cytometry we were able to find DNA aneuploidy in 20\% (14/70) of lymph nodes from patients with Hodgkin's disease. In none of these cases the nuclear abnormality was observed in the morphologically unselected population but became only evident after selection on cells that were operationally defined as medium sized lymphocytes or RS/H like cells. Visible selection of nuclei apparently increases the sensitivity to detect abnormalities in DNA content, that appear to be preferentially present in the latter populations. It has to be kept in mind, however, that the use of single nuclei (rather than intact cells) suspensions reduces the power of morphological discrimination. This makes the distinction between medium sized lymphocytes and $\mathrm{RS} / \mathrm{H}$ like nuclei or small lymphocytes, respectively, not to be an absolute one. The class of 


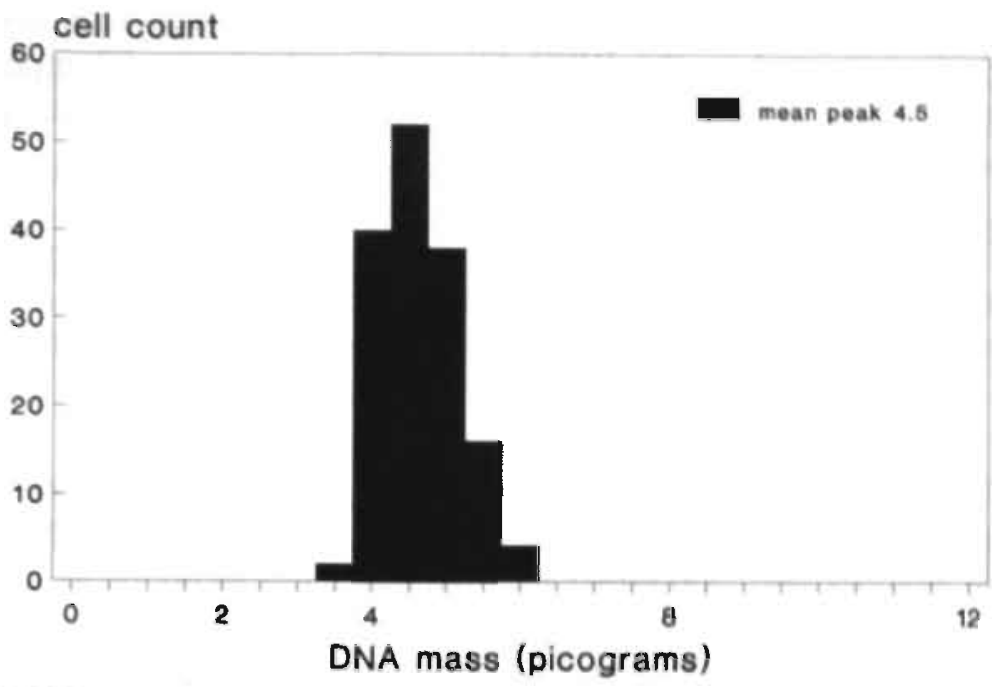

figure $2 B$

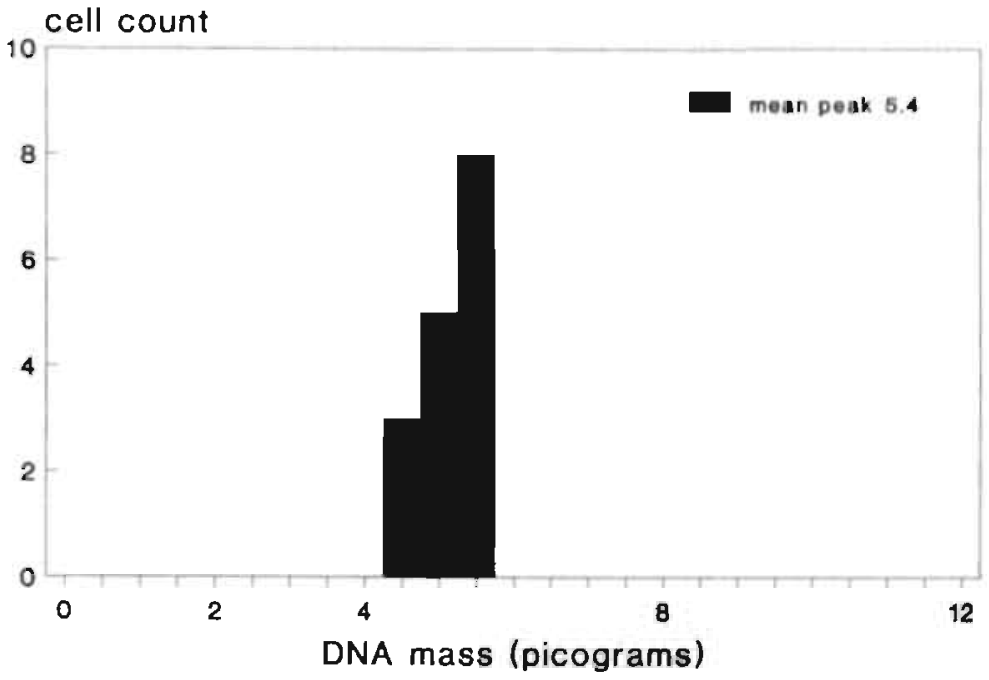

figure $2 \mathrm{C}$

Figure 2. B: image analysis of the same, total population of nuclei, showing a diploid DNA histogram. C: image analysis of the Reed-Sternberg/Hodgkin like nuclei showing a mean peak of 5.4 picograms with a DNA index of 1.17 . 
medium sized lymphocytes will show some overlap with smaller lymphocytes or RS/H like nuclei. As a consequence we may not safely conclude that DNA aneuploidy is restricted to the RS/H like and medium sized lymphocytes, although the frequency of aneuploid cells in the population of small lymphocytes, if not absent, is certainly much lower.

In only 10 of 40 flow cytometrically aneuploid cases this nuclear abnormality could also be detected by morphologically guided image analysis. For the interpretation of these data two aspects are particularly important. First, from studies in solid tumors it is obvious that the relative contribution of aneuploid nuclei in the cell population as a whole is generally much higher $(4,6,9,13$, $15,22)$. This may be related to the fact that in Hodgkin's disease reactive rather than neoplastic cells often predominate in the malignant tissue (1). Moreover, with image analysis only 200 rather than ten thousands of nuclei as with flow cytometry are subjected to the determination of DNA content, allowing greater resolution of aneuploid peaks (23). Taken together, this implicates that with cytometry the chance to detect aneuploid nuclei is much lower than using flow cytometry. Second, due the fact that the CV of the peaks using image cytometry is usually high as compared to flow cytometry $(3,6,18,21)$, small but distinct DNA aneuploid populations are less well detectable with image cytometry if their DNA content is in the near-diploid range. The latter is particularly important in Hodgkin's disease and non-Hodgkin's lymphoma with DNA indices more frequently in the near-diploid range compared to solid tumors (chapter 6 , $2,12,17,20$ ) with DNA indices usually between 1.4 and $1.8(8)$. In conclusion, although image cytometry provides visible selection of nuclei and reduces "background noise" we believe that underestimation of the actual frequency of DNA aneuploidy may be a real problem using image analysis on deparaffinized Hodgkin's disease tissues. This low sensitivity makes it difficult to reliably answer questions on the morphology of the aneuploid cells as stated above.

The presence of aneuploid peaks using image analysis in four cases with diploid flow histograms suggests, on the other hand, that visual discrimination afforded by the CAS system may provide additive information regarding the ploidy status in some selected cases. This is the more remarkable because DNA flow cytometry was made more than conventionally sensitive by adding an antinucleolar antibody with some selectivity for the presumabiy malignant cell types. One explanation might be that in these cases aneuploidy was a very rare event in the population as a whole but occurred with high frequency in the morphologically defined subpopulation that necessarily then should be a small one. In that case one would suspect these four cases to have a more than average 
content of diploid small lymphocytes; this was not substantiated, however, by their histology since they were equally divided over the subtypes nodular sclerosis and mixed cellularity. It remains, therefore, speculative why these aneuploid populations of nuclei were not detected with flow cytometry. These findings illustrate the power of nuclear selection to pick up rare events and encourage to look for combinations of DNA cytometry and more specific methods to identify neoplastic nuclei. 


\section{References}

1. Anastasi J, Bauer KD, Variakojis D. DNA aneuploidy in Hodgkin's disease. Am J Pathol 1987; 128:573-82.

2. Braylan RC, Benson NA, Nourse VA. Cellular DNA of human neoplastic B-cells measured by flow cytometry. Cancer Res 1984; 44:5010-5016.

3. Claudi RD, Weinstein RS, Howeedy A, Straus AK, Coon JS. Comparison of image analysis of imprints with flow cytometry for DNA analysis of solid tumors. Mod Pathol 1989; 2:463-467.

4. Cohen C, Tickman RJ, DeRose PB, Whitaker BP. DNA ploidy studies of benign and malignant tumours: Comparison of flow cytometry and image analysis techniques using two types of cytological specimen. Cytopathol 1991; 2:247-259.

5. Coon IS, Landay AL, Weinstein RS. Biology of disease. Lab Invest 1987; 57:453-479.

6. Cope C, Rowe D, Delbridge L, Philips J, Friedlander M. Comparison of image analysis and flow cylometric determination of cellular DNA content. J Clin Pathol 1991; 44:147-151.

7. Felman P, French M, Souchier C, Magaud J-P, Gentilhomme O, Bryon P-A. Comparison between image and flow DNA cytometry in non-Hodgkin's lymphomas. Path Res Pract 1989; 185:709-714.

8. Friedlander ML. Hedley DW, Taylor IW. Clinical and biological significance of aneuploidy in human tumours. J Clin Pathol 1984; 37:961-974.

9. Greene DR, Taylor SR, Wheeler TM, Scardino PT. DNA ploidy by image analysis of individual foci of prostate cancer: a preliminary report. Cancer Res 1991; 51:40844089.

10. Hedley DW, Friedlander ML, Taylor IW, Rugg CA, Musgrove EA. Method for analysis of cellular DNA content of paraffin-embedded pathological material using flow cytometry. J Histochem Cytochem 1983; 31:1333-1335.

11. Hiddeman W, Schumann J, Andreeff M, Barlogie B, Herman CJ, Leif RC, Mayall BH, Murphy RF, Sandberg AA. Convention of nomenclature for DNA cytometry. Cytometry 1984; 5:445-446.

12. Joensuu H. Klemi PJ. Korekeila E. Prognostic value of DNA ploidy and proliferative activity in Hodgkin's disease. Am J Clin Pathol 1988; 90:670-673.

13. Lee AKC, Dugan I. Hamilton WM. Cook L, Heatley G, Kamat B, Silverman ML. Quantitative DNA analysis in breast carcinomas: a comparison between image analysis and flow cytometry. Mod Pathol 1991; 4:178-182.

14. Lukes R.j, Gompel LF, Hall TC, Rappaport H, Rubin P: Report of the Nomenclature Committee. Rye classification. Cancer Res 1966;26:1311.

15. McFadden PW, Ciowry LJ, Daehnert K, Hause LL, Koethe SM. Image analysis confirmation of DNA aneuploidy in flow cytometric DNA distributions having a wide coefficient of variation of the G0/GI peak. Am J Clin Pathol 1990; 93:637-642.

16. Merkel DE, Dressler LG, McGuire WL. Flow cytometry, cellular DNA content, and prognosis in human malignancy. J Clin Oncol 1987; 5:1690-1703.

17. Morgan KG, Quirke P, O'Brien CJ. Bird CC. Hodgkin's disease: a flow cytometric study. J Clin Pathol 1988; 41:365-369. 
18. Peters JM, Miles BJ, Kubus JJ, Crissman JD. Prognostic significance of the nuclear DNA content in localized prostatic adenocarcinoma. Analyt Quant Cytol Histol 1990; 12:359-365.

19. Schutte B, Reynders MMJ, Bosman FT, Blijham GH. Flow cytometric determination of DNA ploidy level in nuclei isolated from paraffin-embedded tissue. Cytometry 1985; 6:26-30.

20. Shackney SE, Levine AM, Fisher RI, Nichols P, Jaffe E, Schuette WH, Simon R, Smith CA, Occhipinti SJ, Parker JW, Cossman J, Young RC, Lukes RJ. The biology of tumor growth in the non-Hodgkin's lymphomas. A dual parameter flow cytometry study of 220 cases. J Clin Invest 1984; 73:1201-1214.

21. Thunnissen FBJM, Perdaen. H, Forrest J. Influence of different cell extraction methods on cytometric features. Cytometry 1992; 13:484-489.

22. Uyterlinde AM, Smeulders AWM, Baak JPA. Reproducibility and comparison of quantitative DNA histogram features obtained with a scanning microdensitometer and a flow cytometer in breast cancers. Analyt Quant Cytol Histol 1989; 11:353-360.

23. Vindelov LL, Christensen IJ, Jensen G. Limits of detection of nuclear DNA abnormalities flow cytometric DNA analysis. Cytometry 1983; 3:332-339. 


\section{CHAPTER 9}

\section{Summary and future outlook}

Hodgkin's disease is one of the most curable malignancies, but in contrast to many other malignant diseases the origin of the clonogenic neoplastic cell is still unknown. Because of the curability there is a growing interest for side effects of treatment and methods to identify subgroups of patients who need less intensive therapy. Clinical investigators have focused their interest the last decade on the identification of indicators for prognosis enabling treatment to be tailored to individual needs. In addition, on the biologic level, much effort has been put into the exploration of the origin of the neoplastic cell in Hodgkin's disease. In this thesis we have evaluated treatment results, clinical features, and DNA ploidy and proliferation characteristics in patients with Hodgkin's disease, all diagnosed and treated in non-university hospitals.

Chapter 1 gives an overview of the historical, clinical and therapeutical aspects of Hodgkin's disease. It also reviews flow and image cytometry data on nuclear DNA content and cell proliferation with a special focus on Hodgkin's disease.

In chapter 2 a registry-based analysis of 182 patients with Hodgkin's disease is described. The observed incidence of 1.9 per 100.000 persons fits fairly well with data from other countries. Because clinical characteristics of our patient population are similar with those observed by others and the treatment results were comparable, we conclude that Hodgkin's disease can be adequately staged and treated in community hospitals. However, we believe that this has to be done by physicians with special interest in and knowledge of the field of hemato-oncology and only if consultation on a regular basis between the physicians involved can be provided. 
In chapter 3 special interest is given to the effect of age on the curability of patients with Hodgkin's disease. In the patient population studied the survival appears to decrease markedly if the diagnosis is made after the age of 50 years. Significantly fewer patients over 50 years of age received adequate treatment compared to younger ones and complete remission was achieved less often. However, if appropriate therapy had been given relapse free survival rates were not significantly different for patients under and over 50 years of age. Intercurrent disease appeared not to be responsible for the excess of death in the elderly. Therefore, the decreased overall survival for patients over 50 years of age is probably related to elderly patients dying from Hodgkin's disease who had not achieved complete disease remission. The inability to deliver full therapy may be resolved by the development of new treatment strategies with diminished side effects. Hematopoietic growth factors may be of importance for this goal.

Chapter 4 and 5 review the role of mediastinal enlargement in the management of patients with Hodgkin's disease. In a population-based study of 96 patients with early stage Hodgkin's disease no significant correlation between the presence and size of mediastinal involvement and outcome determined in various ways was observed. This overall conclusion did not change by using different methods to measure the degree of mediastinal disease. Interobserver variability and various cut-off points for determining the degree of mediastinal enlargement were investigated, but the data did not lead to an explanation for the discordant results found between the different studies on the prognostic impact of mediastinal enlargement in Hodgkin's disease. It appears that this controversy in the literature can only be resolved by prospective studies in which is controlled for the treatment schedules. Only by this approach the need for additional therapy for patients already in complete remission after initial treatment with radiotherapy or chemotherapy can be evaluated. Because two-dimensional measurement of mediastinal disease may not be accurately enough, three-dimensional or volume measurement has to be included in future clinical trials. For the time being, we believe that patients with bulky mediastinal disease, particularly those who have well known adverse risk features for prognosis, need systemic therapy upfront.

Chapter 6 provides the results of the fiow cytometric determination of the ploidy status. In order to increase the sensitivity of the assay we used a polyclonal goat antinucleolar antibody and forward scatter (size selection) to enrich for the neoplastic nuclei in a bivariate analysis. The deparaffinisation method applied yielded a sufficient number of nuclei from Hodgkin's disease lymph nodes. In about half of the cases DNA aneuploidy was found. The 
majority of cases had a DNA index between 0.8 and 1.2. With dual parameter analysis we were able to detect 22 hypo-diploid cases. All analyzed "benign" control lymph nodes appeared to be diploid. The frequency of aneuploid nuclei within one sample appeared to exceed the expected frequency of Reed-Sternberg/Hodgkin cells, suggesting that DNA aneuploidy is not limited to this cell population. Therefore, we hypothesize that the neoplastic cell population in Hodgkin's disease seems to consist of a spectrum of cells. The larger more diagnostic cells may arise from smaller progenitor cells, which may be more important biologically. On this basis it can be speculated, that part of the difficulties encountered in characterizing Hodgkin's disease is due to the heterogeneity of the non-RS/H cell population containing malignant and benign cells with partly overlapping properties. It therefore seems worthwhile to consider other approaches than morphology to select for the neoplastic cells.

In chapter 7 flow cytometrically obtained data are related to patient characteristics, histology, and prognosis. DNA aneuploidy did not correlate with clinical characteristics and survival curves were not different for patients with diploid or aneuploid tumors. S-phase analysis revealed a significantly lower S-phase fraction (SPF) for the histologic subtypes LP and NSI versus NSII, MC, and $\mathrm{LD}$, indicating that a higher rate of cell proliferation is linked with a relative higher frequency of neoplastic cells i.c. RS/H cells. Responses, relapse rates, and relapse-free survival rates showed a tendency to be higher for cases with a SPF $\geq 7.5 \%$ (the median SPF in our material). The SPF at a cut-off point of $7.5 \%$ was correlated with overall survival but lost its significance in a multivariate analysis. Further studies are needed to evaluate the impact of cell proliferation on prognosis.

Chapter 8 describes the results of the application of image cytometry in Hodgkin's disease. After selection on morphologically defined nuclear types, DNA aneuploidy could be detected in $20 \%$ of the cases $(14 / 70)$, which was preferentially observed in the population of nuclei of the RS/Hi like or medium sized lymphocytes. However, compared to flow cytometry image analysis seems a less sensitive method for investigating ploidy status on deparaffinized Hodgkin's disease tissues, although in selected cases additive information was obtained. Two "methodological" aspects seem particularly responsible for the observed discrepancy in detecting DNA aneuploidy between the two cytometry methods. First, the high degree of near-diploidy as is the case in Hodgkin's lymphoma, requires a higher resolution of the peaks in a DNA histogram, as is 
provided by flow cytometry. Second, with image cytometry only a limited number of nuclei can be analyzed making it more difficult to detect small aneuploid populations.

In conclusion, in current clinical practice there is a tendency towards tailoring treatment for patients with Hodgkin's disease. For this purpose a considerable number of prognostic factors have been identified, but they appear more or the less to be correlated with the total tumor volume. Therefore, a general consensus between investigators from different centers and groups, on how to use these prognostic factors is much more important than further studies with regard to single or combinations of factors, who all are an indication of tumor mass. In addition, biologic factors such as ploidy grade, cell kinetics and immunophenotyping are needed to characterize the aggressivity of the disease. At the same time they may provide further insight in the pathobiology of the disease and which cells belong to the neoplastic population. 


\section{CHAPTER 10}

\section{Samenvatting}

De ziekte van Hodgkin is één van de maligniteiten met een hoog genezingspercentage, echter in tegenstelling tot andere kwaadaardige ziekten is de origine van de maligne cel tot op heden onbekend. Door de hoge genezingskans is de belangstelling toegenomen voor de late gevolgen van de therapie en voor methoden om subgroepen van patiënten te identificeren die mogelijk minder intensief behandeld kunnen worden. Het identificeren van risico factoren moet hierbij een op de individuele patient toegespitste behandeling mogelijk maken. Op moleculair-biologisch gebied is veel aandacht besteed aan het zoeken naar de kwaadaardige cel bij de ziekte van Hodgkin. Kennis over de aard en eigenschappen van deze cel zou tot nieuwe vormen van therapie kunnen leiden. In dit proefschrift hebben wij de behandelingsresultaten en de klinische kenmerken van patiënten met de ziekte van Hodgkin, die alle gediagnostiseerd en behandeld zijn in niet-academische ziekenhuizen, onderzocht. Vervolgens is in het weefsel van deze patiënten gekeken naar afwijkingen in het DNA gehalte en naar de celdelings-activiteit. Het doel van deze onderzoekingen is te komen naar betere methoden om de prognose van patiënten met de ziekte van Hodgkin in te schatten.

Hoofdstuk 1 geeft een overzicht van de historische, klinische en therapeutische aspecten van de ziekte van Hodgkin. Voorts worden de flow en beeld cytometrie besproken met name toegespitst op metingen van het DNA gehaite en de S-fase fractie bij patiënten met de ziekte van Hodgkin.

In hoofdstuk 2 wordt een regionaal, retrospectief onderzoek naar 182 patiënten met de ziekte van Hodgkin beschreven. De gegevens over de incidentie, 1,9 per 100.000 inwoners, zijn vergelijkbaar met die uit andere landen. Aangezien de bestudeerde patiënten groep en de behandelings resultaten goed overeenkomen met die in andere studies zijn wij van mening dat de ziekte van Hodgkin 
adequaat gestageerd en behandeld kan worden in niet-universitaire ziekenhuizen. De behandeling dient echter te geschieden door internisten met speciale belangstelling voor en kemnis op het gebied van de haemato-oncologie, waarbij geregeld overleg met gespecialiseerde centra noodzakelijk is.

In hoofdstuk 3 wordt de samenhang tussen de leeftijd en de genezingskans van patiënten met de ziekte van Hodgkin beschreven. Na het vijftigste levensjaar werd een duidelijke afname van de overlevingskans waargenomen. Patiënten ouder dan 50 jaar kregen in vergelijking met jongere patiënten significant minder vaak een adequate behandeling en het percentage patiënten dat geheel ziekte-vrij werd, was duidelijk lager. Indien echter de juiste behandeling gegeven kon worden, bleek de ziekte-vrije overleving voor patiënten ouder en jonger dan 50 jaar niet te verschillen. De oversterfte bij oudere patiënten kon maar voor een klein deel toegeschreven worden aan een bijkomende ziekte. De slechtere overleving van de oudere patiënt met de ziekte van Hodgkin wordlt waarschijnjijk dan ook veroorzaakt door de groep die niet ziekte-vrij werd door de ingestelde therapie. Nieuwe behandelings methoden dienen ontwikkeld te worden die het mogelijk maken om ook bij ouderen de therapie adequaat te doseren. Haematopoëtische groeifactoren zouden hieraan in belangrijke mate kunnen bijdragen.

Hoofdstuk 4 en 5 geven een overzicht van de rol die de aanwezigheid van een verbreed mediastinum speelt bij het te volgen therapeutische beleid bij patiënten met de ziekte van Hodgkin. In studies van patiënten met een laag stadium (I-IIIA) van de ziekte bleek noch de aanwezigheid noch de mate van mediastinum vergroting gecorreleerd met de uiteindelijke prognose. Deze resultaten veranderden niet na het toepassen van verschillende methoden om de mate van mediastinale vergroting te analyseren. Verschillen tussen onderzoekers en de keuze van het afkappunt voor het bepalen van de mate van mediastinale vergroting werden bestudeerd. Hiermee konden echter de uiteenlopende resultaten met betrekking tot het prognostisch belang van een verbreed mediastinum bij de ziekte van Hodgkin, gevonden in andere studies, niet worden verklaard. Alleen prospectieve studies, waarbij voor de diverse vormen van behandeling gecontroleerd wordt, kunnen een oplossing brengen voor deze controverse in de literatuuir. Op deze wijze kan worden onderzocht of bij patiënten, die reeds ziekte-vrij zijn na initiële behandeling met radio- of chemotherapie, additionele therapie nodig is. Daar het twee-dimensionaal bepalen van de mediastinale massa niet accuraat genoeg lijkt te zijn, dient in toekomstige klinische trials drie-dimensionale of volume meting te worden opgenomen. Totdat deze resul- 
taten bekend zijn verdient het ons inziens de voorkeur om patiënten met een sterk verbreed mediastinum en met name de patiënt met prognostisch ongunstige factoren in eerste opzet met chemotherapie te behandelen.

In hoofdstuk 6 worden de resultaten van het onderzoek naar het DNA gehalte van celkernen (ploidie) met behulp van flow cytometrie beschreven. Om de gevoeligheid van de bepaling te vergroten hebben wij een polyclonaal antilichaam gericht tegen de nucleolus en selectie op kerngrootte gebruikt, waarbij dan middels bi-variate analyse een verrijking voor maligne kernen bewerkstelligd kan worden. Met de door ons toegepaste methode van deparaffiniseren werden voldoende kernen uit lymfeklieren van patiënten met de ziekte van Hodgkin verkregen. In ongeveer de helft van de gevallen werd DNA aneuploidie gevonden, waarbij het merendeel een DNA index had tussen de 0,8 en 1,2. Gebruik makend van de twee-parameter methode werd in 22 monsters hypo-diploidie aangetoond. Alle "goedaardige" controle lymfeklieren waren diploid. De frequentie van aneuploide kemen in een monster bleek hoger dan verwacht op basis van het aantal Reed-Sternberg/Hodgkin (RS/H) cellen, hetgeen suggereert dat DNA aneuploidie niet beperkt is tot deze populatie. Daarom postuleren wij dat de populatie van kwaadaardige cellen bij de ziekte van Hodgkin bestaat uit een spectrum van cellen, waarbij de grotere, diagnostische cellen wellicht voortkomen uit kleinere voorloper cellen. Op basis van deze gegevens lijkt het waarschijnlijk dat een deel van de moeilijkheden bij het karakteriseren van de ziekte van Hodgkin gelegen is in de heterogeniteit van de niet-RS/H celpopulatie, die benigne en maligne cellen bevat met gedeeltelijk overlappende eigenschappen. Het lijkt daarom de moeite waard om voor verder onderzoek bij het selecteren van kwaadaardige cellen een andere dan de morfologische benadering te kiezen.

In hoofdstuk 7 worden de flow cytometrie gegevens onderzocht in relatie tot de patiënt karakteristieken, de histologie en de prognose. Behalve ploidie werd ook het percentage cellen met een $\mathrm{S}$-fase DNA gehalte ( $\mathrm{S}$-fase fractie) in de analyse betrokken. DNA aneuploidie was niet gecorreleerd met de klinische karakteristieken van de patiënt en de overleving van patiënten met diploide en aneuploide tumoren bleek niet verschillend. S-fase analyse liet een significant lagere S-fase fractie zien voor de histologische subtypes lymfocyten-rijk en nodulair-scleroserend type I ten opzichte van nodulair-scleroserend type II, gemengd-cellig en lymfocyten-arm. Dit is een indicatie dat een hogere mate van proliferatie gerelateerd is aan de histologische subtypes met een relatief hoger aantal maligne c.q. RS/H cellen. Hogere respons, hogere kans op recidief en kortere ziekte-vrije overleving leken te correleren met een $\mathrm{S}$-fase fractie van meer dan 
$7,5 \%$ (de mediaan in dit onderzoek). Patiënten met een $\mathrm{S}$-fase fractie van kleiner dan 7,5\% hadden een significant betere overleving dan de patiënten met een $\mathrm{S}$-fase fractie groter dan de mediaan. Bij een multivariant analyse bleek dit prognostische belang echter niet onafhankelijk te zijn van andere factoren. Vervolg studies zijn dan ook noodzakelijk om het belang van proliferatieve eigenschappen voor de prognose nader te bepalen.

Hoofdstuk 8 beschrijft de resultaten van de toepassing van beeld cytometrie bij de ziekte van Hodgkin. DNA aneuploidie kon, selecterend op vooraf morfologisch gedefinieerde kern types, in $20 \%$ van de gevallen aangetoond worden. Hierbij werd de aneuploidie vrijwel uitsluitend gevonden in kernen van cellen van het $\mathrm{RS} / \mathrm{H}$ type en van middelgrote lymfocyten. Alhoewel in een aantal gevallen aanvullende informatie werd verkregen, lijkt beeld cytometrie in vergelijking met flow cytometrie een minder gevoelige methode om de ploidie status te bestuderen in gedeparaffiniseerd weefsel van patiënten met de ziekte van Hodgkin. Twee "methodologische" aspecten lijken met name verantwoordelijk voor de gevonden verschillen tussen de beide cytometrie methoden. Ten eerste vereist het grote aantal bijna-diploide gevallen bij de ziekte van Hodgkin een techniek met een hogere resolutie dan beeld cytometrie kan bieden. Ten tweede kan met beeld cytometrie maar een beperkt aantal kernen geanalyseerd worden, waardoor het moeilijk wordt om aneuploide populaties van beperkte omvang te detecteren.

In de dagelijkse praktijk bestaat een tendens om de behandeling van patiënten met de ziekte van Hodgkin te individualiseren en te richten op het risico profiel. Om dit mogelijk te maken zijn een groot aantal prognostische factoren geïdentificeerd, maar deze lijken alle in meer of mindere mate gecorreleerd met het totale volume van de tumor. Het is tijd dat onderzoekers uit verschillende centra en van verschillende studie groepen zich beraden over een consensus met betrekking tot het gebruik van deze factoren in de dagelijkse praktijk. Bovendien is het nu mogelijk om biologische indicatoren van prognose te bestuderen zoals de ploidie graad, cel proliferatie en immunofenotypering. Daarmee kan wellicht een verfijning van de prognostische classificatie worden bereikt. Tegelijkertijd kunnen resultaten van deze studies bijdragen aan het inzicht in de pathobiologie van de ziekte en daarmee hopelijk leiden tot mogelijkheden om nieuwe vormen van behandeling te vinden. 


\section{Dankwoord}

De bereidwilligheid van perifeer (niet-academisch) werkende onderzoekers gecombineerd met specifieke universitaire kennis vormde de basis voor dit proefschrift. Allen die op welke wijze dan ook hun bijdrage hebben geleverd wil ik hierbij bedanken.

Het initiatief voor een retrospectief onderzoek bij patiënten met de ziekte van Hodgkin werd genomen door de werkgroep haematologie-oncologie van de IKZ regio. Wim Breed, jij stimuleerde mij tot dit onderzoek. Jouw nimmer aflatende energie en consciëntieuze wijze van werken hebben grote indruk op mij gemaakt. Harry Schouten, jouw inzicht en opbouwende kritiek waren en zijn van wezenlijk belang voor dit en huidig wetenschappelijk onderzoek op dit gebied in Zuid-Nederland. Geert Blijham, de vele gesprekken gaven diepgang aan het onderzoek. Jij leerde mij om het werk van elke zijde te belichten en mede door jouw stimulerende begeleiding kwam dit proefschrift tot stand.

Luc Vrints wil ik bedanken voor de vakkundige begeleiding bij het beoordelen van de histologische preparaten. Jac Wijnen, jij maakte mij wegwijs in de wereld van de statistiek, waarbij vele analyses uitgevoerd werden. Bert Schutte ben ik erkentelijk voor de inspirerende wijze waarop hij mij de beginselen van de celkinetiek leerde en voor zijn hulp bij het opstarten van de flow cytometrie analyses. Hans Hoffmann en Willie Janssen zorgden op deskundige en accurate wijze voor de flow cytometrische bepalingen. Voor de introductie in en de begeleiding bij het CAS werk wil ik Michelle Reynders en Erik Thunnissen bedanken.

Last but not least: Carin, jij zorgde voor de broodnodige rust, ondersteuning en bovenal begrip. Yvette, Stephanie en Tom, nu zal er meer tijd voor jullie zijn. 



\section{Curriculum vitae}

De schrijver van dit proefschrift werd geboren op 10 november 1958 te Tegelen. Het diploma gymnasium $\beta$ werd behaald in 1977 aan het St Thomascollege te Venlo. Na uitloting voor de studie geneeskunde studeerde hij 1 jaar bedrijfskunde aan de Technische Hogeschool te Eindhoven. De medische opleiding werd gevolgd aan de Katholieke Universiteit te Nijmegen, welke in 1985 afgerond werd met het behalen van het arts examen. De eerste schreden in de interne geneeskunde werden gezet als assistent interne niet-in-opleiding in het St Jozef ziekenhuis te Kerkrade. In 1986 werd begonnen met de opleiding tot internist in het Catharina ziekenhuis te Eindhoven (opleider: Dr H.F.P. Hillen) en werd in 1991 voltooid in het Academisch Ziekenhuis Maastricht (opleider: Prof.dr J.A. Flendrig). Na zijn opleiding tot internist werkte hij als internist bij de vakgroep interne geneeskunde (hoofd: Prof.dr J.A. Flendrig), werkgroep haematologie-oncologie (hoofd Prof.dr G.H. Blijham). Sinds maart 1992 is hij werkzaam in het Maasland ziekenhuis te Sittard/Geleen als internist met als aandachtsgebied haematologie-oncologie. 

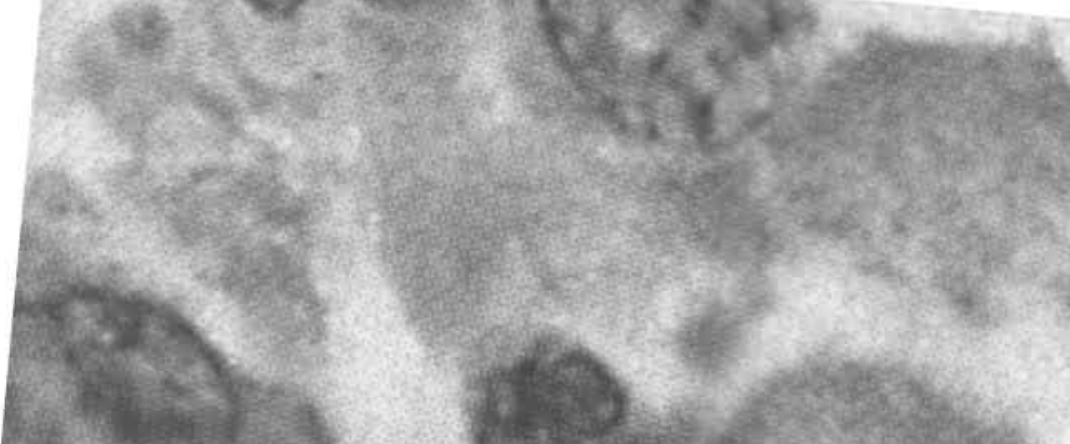